\title{
Fuzzy Classification for Eastern Ontario Land Cover Mapping
}

by

Jessica van den Berg

A thesis submitted to the Faculty of Graduate and Postdoctoral Affairs in partial fulfillment of the requirements for the degree of

Master of Science

in

M.Sc. Geography

Carleton University

Ottawa, Ontario

(C) 2012, Jessica van den Berg 
Library and Archives

Canada

Published Heritage

Branch

395 Wellington Street

Ottawa ON K1A ON4

Canada
Bibliothèque et

Archives Canada

Direction du

Patrimoine de l'édition

395 , rue Wellington

Ottawa ON K1A ON4

Canada
Your file Votre référence

ISBN: 978-0-494-93540-8

Our file Notre référence

ISBN: $978-0-494-93540-8$
NOTICE:

The author has granted a nonexclusive license allowing Library and Archives Canada to reproduce, publish, archive, preserve, conserve, communicate to the public by telecommunication or on the Internet, loan, distrbute and sell theses worldwide, for commercial or noncommercial purposes, in microform, paper, electronic and/or any other formats.

The author retains copyright ownership and moral rights in this thesis. Neither the thesis nor substantial extracts from it may be printed or otherwise reproduced without the author's permission.
AVIS:

L'auteur a accordé une licence non exclusive permettant à la Bibliothèque et Archives Canada de reproduire, publier, archiver, sauvegarder, conserver, transmettre au public par télécommunication ou par l'Internet, prêter, distribuer et vendre des thèses partout dans le monde, à des fins commerciales ou autres, sur support microforme, papier, électronique et/ou autres formats.

L'auteur conserve la propriété du droit d'auteur et des droits moraux qui protege cette thèse. $\mathrm{Ni}$ la thèse ni des extraits substantiels de celle-ci ne doivent être imprimés ou autrement reproduits sans son autorisation.
In compliance with the Canadian Privacy Act some supporting forms may have been removed from this thesis.

While these forms may be included in the document page count, their removal does not represent any loss of content from the thesis.
Conformément à la loi canadienne sur la protection de la vie privée, quelques formulaires secondaires ont été enlevés de cette thèse.

Bien que ces formulaires aient inclus dans la pagination, il n'y aura aucun contenu manquant. 


\title{
Abstract
}

As the presence of mixed pixels is particularly problematic when coarse resolution data is used, the ability to assess heterogeneity within a pixel becomes vital. The aim of this thesis is to compare fuzzy and discrete classification methods in order to determine which classifier better represents the heterogeneity of an agriculturally dominated landscape in eastern Ontario.

\begin{abstract}
Although the final fuzzy classification displayed some confusion between classes, the heterogeneous nature of the landscape was well represented. The results from the distribution of the normalized entropy, along with the combination of results from the highest and second highest membership values provided valuable sub-pixel information. This information could not have been obtained by using the standard deterministic maximum likelihood classifier. Overall, the fuzzy classifier allowed for the assessment of the sub-pixel information and was better able to depict the heterogeneity along field boundaries and in areas of transition.
\end{abstract}




\section{Acknowledgements}

Firstly, I would like to thank my supervisor, Dr. Scott Mitchell. It was his guidance and support that helped to make this thesis possible. I would also like to thank my committee member, Dr. Doug King, for his valuable input and advice.

A big thank you goes out to everyone who helped make my field work possible. Mainly, Jude Girard for showing me the ropes, Sampsa Hamalainen for developing an easy way to collect all the data and most of all, Glenda Smith for putting up with me day-in and day-out (especially when I didn't know my right from my left!).

I would also like to thank everyone in the Department of Geography at Carleton University for making this experience such a pleasant one. To my cohort, thank you for always being there for me if I had questions or just needed to rant. You guys helped me get through it all.

Finally, I would like to thank my incredible family for their unwavering support and confidence in me. I would not be where I am today if it wasn't for my mom and my sister. They are my rock, and my strength. And I know I can achieve anything with them at my side. 


\section{Table of Contents}

Abstract

Acknowledgements..............................................................................................................................ii

List of Tables ................................................................................................................................ vi

List of Figures...........................................................................................................................vii

List of Appendices...............................................................................................................................ix

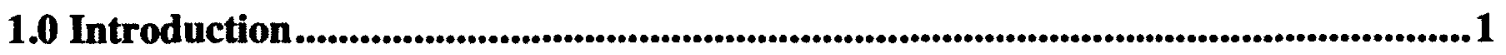

1.1 Research Context and Scope ………………………………….....................................................

1.2 Research Questions...................................................................................................................

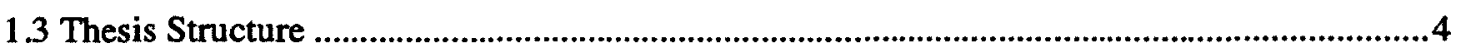

2.0 Background ....................................................................................................................................5

2.1 Landscape Heterogeneity ..............................................................................................

2.2 Remote Sensing Classification Techniques ........................................................................6

2.2.1 Unsupervised Classification .........................................................................................6

2.2.2 Supervised Classification ...................................................................................................

2.2.3 Maximum Likelihood Classification ................................................................................9

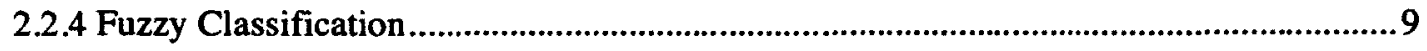

2.2.4.1 Fuzzy Membership Creation ........................................................................................11

2.2.4.2 Advantages of Fuzzy Classification .........................................................................14

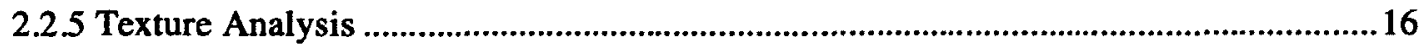

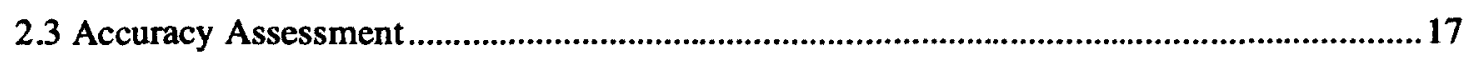

2.3.1 Accuracy Assessment for 'Hard' Classifiers ..................................................................18

2.3.2 Accuracy Assessment for Fuzzy Classifiers ................................................................2

3.0 Methodology 
3.1 Study Area

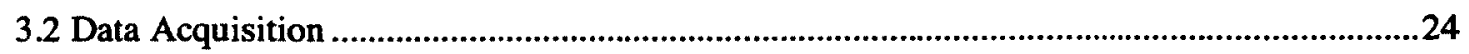

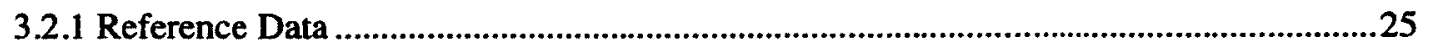

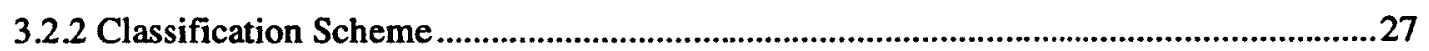

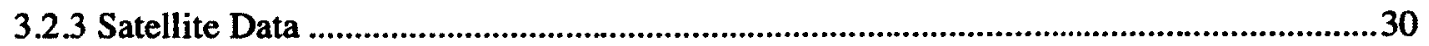

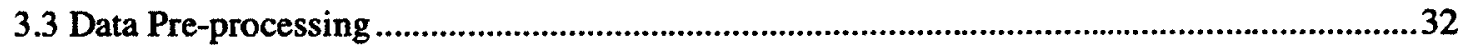

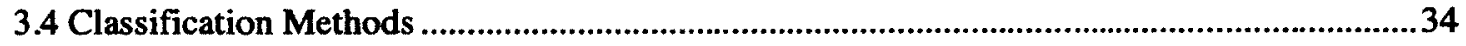

3.4.1 Quickbird Maximum Likelihood Classification ..................................................................34

3.4.2 Landsat Maximum Likelihood Classification .......................................................................36

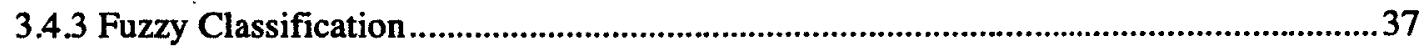

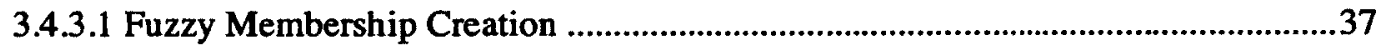

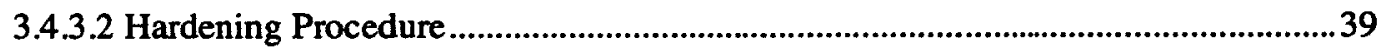

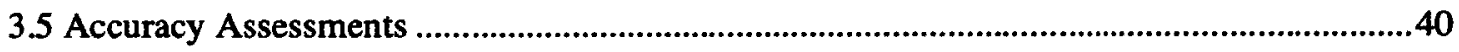

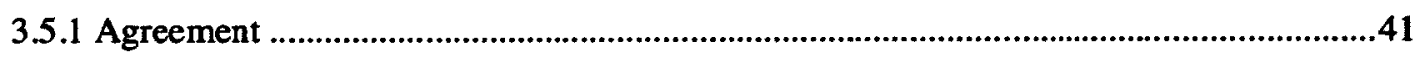

4.0 Results.............................................................................................................. 43

4.1 Overall Classified Map Analyses ........................................................................................43

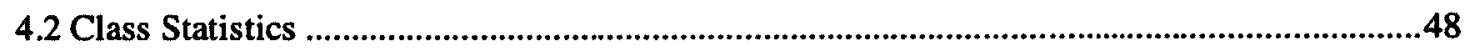

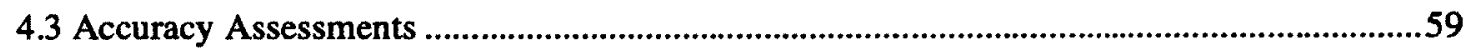

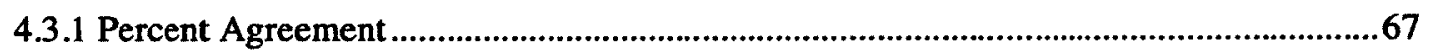

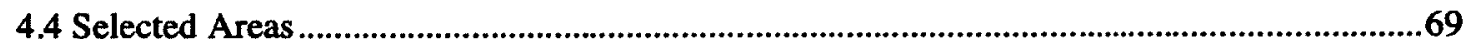

5.0 Discussion and Conclusion ...................................................................................................76

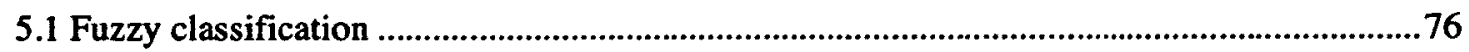

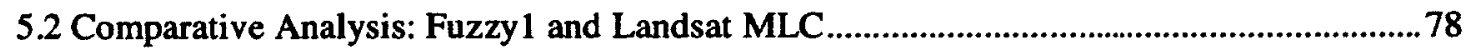

5.3 Comparative Analysis: Fuzzy1 and Quickbird MLC ............................................................80

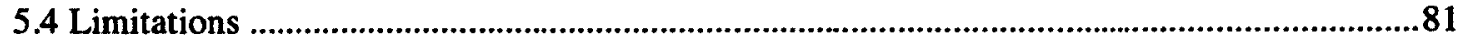




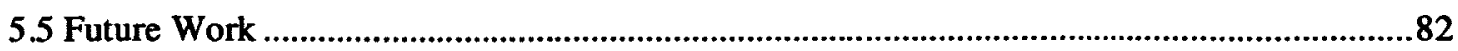

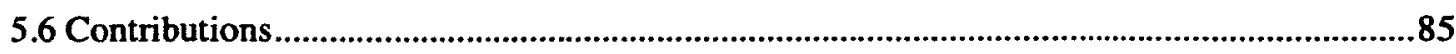

5.7 Conclusions

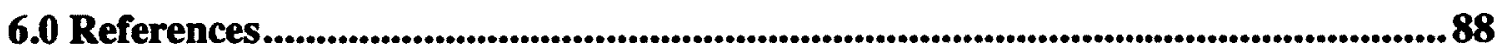

Appendix I - Training Data ...........................................................................................................94

Appendix II - Classified Images.................................................................................................96

Appendix III - Accuracy Assessments ..................................................................... 100 


\section{List of Tables}

Table 1. List and brief description of the 38 land cover classes observed in the field..... 28

Table 2. List and description of the 14 land cover classes after the original 38 were

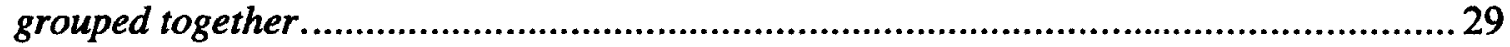

Table 3. List and description of the final 8 land cover classes.................................29

Table 4. Number of training pixels for each of the 14 classes.................................. 30

Table 5. Outline of the Quickbird bands used in this research.................................... 31

Table 6. Acquisition data and area for each of the 5 Quickbird scenes....................... 31

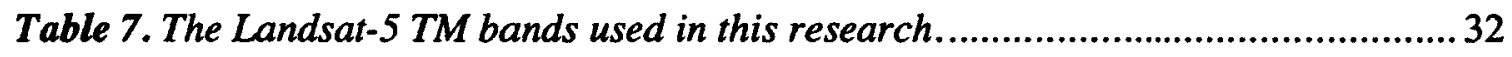

Table 8. Transformed divergence values using Quickbird data ................................ 35

Table 9. Mean digital number for each class per band analyzed for the Landsat MLC.. 49

Table 10. Location of cluster centre for each class per band analyzed for the fuzzy

classification

Table 11. Frequency of occurrence of fuzzy membership values in the 8 classes identified.

Table 12. Percentage of pure pixels, defined by frequency of membership values greater than 0.8 , for each class.

Table 13. Statistics for the normalized entropy values for the fuzzy membership values. 60

Table 14. Summary statistics for the classified maps. 


\section{List of Figures}

Figure 1. The relationship between the input layers and the output layers when a fuzzy classifier is used.

Figure 2. Study area of eastern Ontario, Canada.

Figure 3. Reduced study area due to satellite data acquisition restrictions. The five boundaries for the Quickbird scenes represent the new study areas. .25

Figure 4. Original unclassified Quickbird image and classified images for Scene 2.......44

Figure 5. Percentage of total area based on class frequencies for (a) the Quickbird MLC, (b) Landsat MLC, (c) Fuzzyl and (d) Fuzzy2.

Figure 6. Percentage of total area from Fuzzyl based on the No Value pixels from Fuzzy2.

Figure 7. Images of the fuzzy memberships in each of the 8 land cover classes identified: (a) Built-up, (b) Water, (c) Forest, (d) Grass, (e) Corn, (f) Soybean, (g) Cereal, (h) Mixed Vegetable. $.50-57$

Figure 8. The frequency of occurrence of each class for each classification method used, in comparison to the reference data. $61-62$

Figure 9. Distribution of the normalized entropy for the fuzzy membership values for Scene 2 . .64

Figure 10. Close up distribution of the normalized entropy for a Built-up area. .65

Figure 11. Close up distribution of the normalized entropy for a cropland area. .66

Figure 12. A subset of the study area showing the distribution of agreement between (a) Quickbird MLC and Landsat MLC, (b) Quickbird MLC and Fuzzyl and (c) Quickbird $M L C$ and the soft hardened fuzzy. .68

Figure 13. (a) Aerial photograph and distribution of agreement between (b) Quickbird MLC and Landsat MLC and (c) Quickbird MLC and the soft hardened fuzzy for a subset of the study area that highlights areas of transition and field edges.

Figure 14. Sub-set of a residential area showing the aerial photograph, the Quickbird and Landsat MLCs, and the Fuzzyl and Fuzzy2 images. . .71

Figure 15. Sub-set of a cropland area showing the aerial photograph, the Quickbird and Landsat MLCs, and the Fuzzyl and Fuzzy2 images. 
Figure 16. Sub-set of a cropland area showing the aerial photograph, the Quickbird and Landsat MLC's, and the Fuzzyl and Fuzzy2 images....................................75 


\section{List of Appendices}

Appendix I - Training Data......................................................... 94

Figure I-A. Examples of training polygons for a select number of classes......94

Table I-A. Transformed divergence for the Landsat data (no texture)...........95

Table I-B. Transformed divergence for the Landsat data (GLCM mean texture

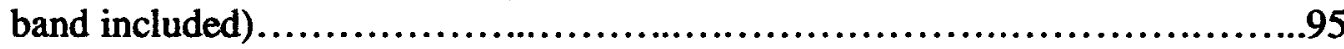

Appendix II - Classified images. ...........................................................96

Figure II-A. Original unclassified Quickbird image and classified images for

Scene 1 .......................................................................96

Figure II-B. Original unclassified Quickbird image and classified images for

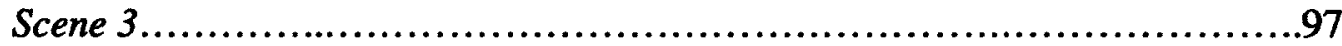

Figure II-C. Original unclassified Quickbird image and classified images for

Scene 4 ..........................................................................98

Figure II-D. Original unclassified Quickbird image and classified images for

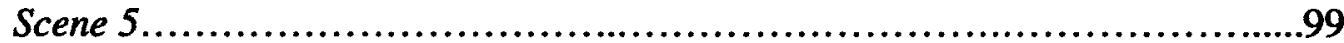

Appendix III - Accuracy Assessments. .................................................100

Table III-A. (a) Error matrix and (b) percent commission and omission errors

and kappa statistic, per class for Quickbird MLC............................100

Table III-B. (a) Error matrix and (b) percent commission and omission errors and kappa statistic, per class for Landsat MLC ...................................101 Table III-C. (a) Error matrix and (b) percent commission and omission errors and kappa statistic, per class for Fuzzyl .........................................102 Figure III. Distribution of the normalized entropy for the fuzzy membership values. 


\subsection{Introduction}

Land cover maps provide information on the types of features present on ground surfaces including the presence of urban infrastructures, types of vegetation, and presence of water bodies (Lillesand et al. 2008). By providing valuable data for the planning and monitoring of activities, the use of these types of maps is essential for modeling and understanding environmental systems (Lillesand et al., 2008). Derived predominantly from remotely sensed data, land cover maps are indispensable tools for understanding the implication of land cover change. Land cover change greatly influences many aspects of environmental systems including geomorphological, hydrological and ecological systems (Foody, 2010). In addition, land cover change is believed to be one of the most significant variables impacting biodiversity (Foody, 2002). The eastern Ontario region has seen significant land cover change of aquatic and terrestrial nature and the ability to accurately depict the ground surface in these types of landscapes is imperative (Zhang and Guidon, 2005; Dingle Robertson, 2007).

The process of classifying true land cover is not straightforward. There is no set method that works best for all situations (Fisher and Pathirana, 1990). Standard methods can include minimum distance classification, maximum likelihood classification (MLC), $k$ means clustering or object-based classification. These methods can potentially provide accurate results when high-resolution data are available. However, these methods can often be limited for many purposes due to their inability to characterize areas of transition or represent the sub-pixel information common in complex landscapes. In addition, factors such as sensor capabilities (including spatial resolution, revisit times, etc.), 
financial resources available to an organization or community, as well as assumptions made in the application of a classification scheme, all combine to limit the ability of an accurate depiction of the land cover. This can, and often does, result in confusion between land cover classes and an inability to properly depict the heterogeneity of a landscape. Therefore, there is a need to evaluate alternatives to the standard methods of classification.

This thesis examines one alternative to these standard methods, implementing fuzzy logic. As far back as half a century, the concept of fuzzy logic has been used to describe the imprecision that is common within human reasoning, particularly in the fields of pattern recognition and communication of information (Gopal and Woodcock, 1994; Zadeh, 1965). Fuzzy logic has evolved to define objects in the real world that do not have clearly defined boundaries. Fuzzy logic has consequently been used to enhance land cover mapping accuracies and to more realistically represent land cover types present within a landscape (Shakelford and Davies, 2003; Melgani et al., 2000). The aim of this thesis is to compare fuzzy and discrete classification methods in order to determine which classifier better represents the heterogeneity of an eastern Ontario landscape. This discrete classifier is the maximum likelihood classification (MLC). As one of the most popular image classifiers, MLC is known for its robustness and performance accuracy (Melgani, et. al., 2000). As such, this classifier is often used as a base comparison for other classification methods (Flanders, et al., 2003). It is for this reason that the MLC classifier was selected for analysis in this thesis. 


\subsection{Research Context and Scope}

The results of this study are to be used as part of a larger research initiative conducted by the Geomatics and Landscape Ecology Laboratory (GLEL) of Carleton University. Their goal is to determine the strength of the link between spatial heterogeneity and biodiversity in agricultural landscapes in eastern Ontario. Further, they wish to enhance biodiversity by recommending new approaches to cropping systems (crop diversity, field configuration, etc.) that can be implemented by farmers. This study was designed to provide the GLEL research initiative with a land cover map through which heterogeneity measures can be extracted. In this thesis, a comparative analysis between the standard maximum likelihood classification and fuzzy classification will be presented that help identify the optimal methodology for this type of landscape. In addition, methods developed for this project can potentially be used to assess the heterogeneity of landscapes in other environments across Canada. This is especially pertinent in environments where the presence of mixed pixels has been shown to negatively impact land cover classification and in areas where high-resolution data are not available or accessible.

\subsection{Research Questions}

There were three main research questions addressed by this study.

1) Can a fuzzy classifier be used to accurately depict the heterogeneity of agriculturally dominated areas in eastern Ontario?

2) How do the results of this fuzzy classification compare to those derived from a standard maximum likelihood classification (MLC)? 
3) How do the results of this fuzzy classification compare to discrete maximum likelihood classification using higher resolution data?

The purpose of addressing these research questions is to avoid the ever-present problems common when using the more standard classification methods - mainly the inability to represent sub-pixel information and the problems with availability and feasibility of obtaining costly high-resolution data.

\subsection{Thesis Structure}

This thesis is organized into five chapters. The first chapter introduces land cover classification and the importance of accurately depicting it. The research context, scope and objectives are also outlined. The second chapter provides more details regarding land cover classification, including different classification techniques and accuracy assessment. Chapter 3 outlines the methodology, including information regarding data acquisition, processing, and the classifications conducted. Chapter 4 presents the results of each classification as well as a comparison between each resulting land cover map. A discussion of the results and findings is presented in Chapter 5, along with an analysis of the limitations and strengths of this research. 


\subsection{Background}

This chapter provides background information on landscape heterogeneity and its implications for land cover classifications. As well, a summary of remote sensing techniques is provided - including information on unsupervised and supervised classification methods, maximum likelihood and fuzzy classification methods, texture analysis, and accuracy assessment.

\subsection{Landscape Heterogeneity}

A heterogeneous landscape can be described as having many different land cover types interspersed with each other and distributed in a complex pattern. This can include compositional and/or configurational diversity in cover types (Fahrig, 2011). In contrast, landscapes that contain only a few land cover types and are uniformly distributed over large areas are referred to as homogeneous landscapes. The degree to which a landscape is considered heterogeneous, or not, is often influenced by human practices or alterations to a landscape. For example, in agricultural regions, decisions made by farmers, land tenure patterns, and effects of cropping and grazing, can all influence the amount of heterogeneity (Fahrig, 2011). Essentially, landscape heterogeneity is a function of the size, form, configuration, and type of land cover present (Sklenicka and Lhota, 2002).

The amount of landscape heterogeneity also plays a role in ecological responses, ecosystem functions and species biodiversity (Wiens, 2002; Fahrig, 2011). For example, species diversity tends to be higher in landscapes where many different ecosystem types are present (Sklenicka and Lhota, 2002). As well, many studies have linked the presence 
of high landscape heterogeneity to the biotic wellbeing of the area (Odum, 1959; Hansson, 1977; Noss, 1983; Forman, 1995). It is therefore important that this land cover diversity measure be appropriately assessed. Commonly used statistical land cover methods do provide information regarding the landscape macrostructure, however they do not provide accurate information about the spatial composition or distribution of landscape elements (Sklenicka and Lhota, 2002). Remote sensing techniques can bridge this gap and have been widely used for land cover assessments.

\subsection{Remote Sensing Classification Techniques}

While land cover mapping dates back to the early 1800's, it was not until the 1960's that remote sensing became a routinely applied technique (Campbell, 2002). Since that time, one of the most common applications of remote sensing has been the production of land cover maps using image classification (Foody, 2002). The overall purpose of image classification is to categorize all pixels in an image into land cover classes or themes (Lillesand et al., 2008). The reflectance, or spectral data, for each pixel is obtained from the sensor and is used as the numerical basis for categorizing the data (Lillesand et al., 2008; Aronoff, 2005). There are two main approaches to classification: unsupervised and supervised.

\subsubsection{Unsupervised Classification}

In unsupervised classification, there is no prior knowledge of the data. Clusters of data that are distinct from each other based on a given inter-cluster distance metric are identified and then given informational significance; i.e., assigned class labels. There are 
many different approaches used for unsupervised classification. For example, algorithms are commonly used to find statistical groupings such that data in a given cluster would be close together in the feature space, whereas data in different clusters would be more separated (Eastman, 2001; Lillesand et al., 2008). One widely used algorithm is $k$-means clustering, which partitions the data into $k$ clusters with each pixel assigned to the cluster whose mean vector is closest in feature (normally spectral reflectance) space based on the Euclidean distance. This process continues iteratively, with the statistics describing the pixels that have been assigned to each cluster evaluated at each iteration, resulting in reassignment of some pixels to new clusters that have become closer. The process repeats itself until there are no significant changes in the cluster statistics (Lillesand et al., 2008).

Unsupervised classification using image brightness or reflectance data as inputs is based entirely on natural groupings of the image values and the resulting clusters solely represent spectral classes. Consequently, the identity of the spectral class is unknown. It is only after the pixels have been clustered into natural groupings that the groups can then be assigned to specific classes. This is achieved through a comparison to reference data obtained from ground data or from higher resolution maps (Lillesand et al., 2008).

\subsubsection{Supervised Classification}

Whereas unsupervised classification groups together pixels by their relative spectral similarity, supervised classification allocates pixels on the basis of their similarity to a set of predefined classes that have been sampled and characterized (Foody, 2002). With supervised classification, training areas that are representative samples of each class are 
delineated. The data obtained from the training areas are used as 'interpretation keys' that describe the attributes for each class of interest. Each pixel in the data set is then compared to each category in the training areas and labelled with the name of the class to which it is numerically closest (Lillesand et al., 2008).

In supervised classification, the selection of predefined classes is important, as these classes must be distinguishable based on the selected input variables. Measures such as the Bhattacharya distance and the transformed divergence are commonly used to assess separability of class pairs. In this thesis, the transformed divergence metric was used, which is a covariance-weighted distance between class means (Lillesand et al., 2008). It is often used in remote sensing to further understand class separability in feature space (Chandola and Vatsavai, 2010).

For classes $i$ and $j$, the transformed divergence is calculated as follows:

$$
\mathrm{T}_{i j}=2000\left(1-\exp \left(\frac{-\mathrm{D}_{i j}}{8}\right)\right)
$$

Where $\mathrm{D}_{i j}$ is the divergence between classes $i$ and $j$ :

$$
\mathrm{D}_{\mathrm{ij}}=1 / 2 \operatorname{tr}\left(\left(\sum_{i}-\sum_{j}\right)\left(\sum_{i}^{-1}-\sum_{j}^{-1}\right)\right)+1 / 2 \operatorname{tr}\left(\left(\sum_{i}^{-1}-\sum_{j}^{-1}\right)\left(\mu_{i}-\mu_{j}\right)\left(\mu_{i}-\mu_{j}\right)^{\mathrm{T}}\right)
$$

Where $\Sigma_{i}$ and $\Sigma_{j}$ are the covariance matrices, and $\mu_{i}$ and $\mu_{\mathrm{j}}$ are the means for class $i$ and $j$, respectively.

With a maximum possible value of 2000 , transformed divergence of less than 1500 suggests that there may be overlap between a given pair of classes, thereby potentially 
leading to misclassification between those classes (Lillesand et al., 2008; Chandola and Vatsavai, 2010).

\subsubsection{Maximum Likelihood Classification}

Traditionally, within the classification processes for remotely sensed data, each pixel is allocated a single, discrete value, regardless of whether a supervised or unsupervised method was used. The maximum-likelihood classification (MLC) method, for example, is one of the most commonly used hard classification methods. In this supervised method, training data is used as a means of estimating means, variances and covariances of the classes, which are then used to estimate the multi-dimensional probability density function for each class. This method assumes normality of the training data for each class, thereby allowing for the statistical probabilities of a given pixel belonging to a specific class to be computed. Essentially, each pixel is assigned to the class to which it most probably belongs (Zhang and Foody, 2001; Lillesand et al., 2008).

\subsubsection{Fuzzy Classification}

Lotfi A. Zadeh first introduced the concept of fuzzy logic in 1965 (Zadeh, 1965). The premise was that classes of objects in the real world were not always defined by discrete criteria of membership. A fuzzy set is defined as "a 'class' with a continuum of grades of membership" (Zadeh, 1965). Therefore, unlike typical hard classifiers that require pixels to be assigned to one discrete value, a fuzzy classifier allows for more than one value to be assigned to each pixel. These values, called membership values, indicate the degree to which each class is assigned to that pixel. The grades of membership range from 
complete membership (1.00) to non-membership (0.00) (Zadeh, 1965; McMahan et al., 2003). The fuzzy membership value of a pixel for a given class has been shown to be related to the proportion of that class occurring within that pixel (Fisher and Pathirana, 1990).

When a fuzzy classifier is used to create a land cover map from remotely sensed data, the result is a set of images, also known as data layers, for each land cover class present. The value for each pixel within each layer is the fuzzy membership value for that particular class. As seen in Figure 1, with $n$ bands of imagery as input, the fuzzy classifier outputs $c$ land cover data layers, each of which record the fuzzy membership of the $c$-th land cover type occurring within any pixel (Fisher and Pathirana, 1990).
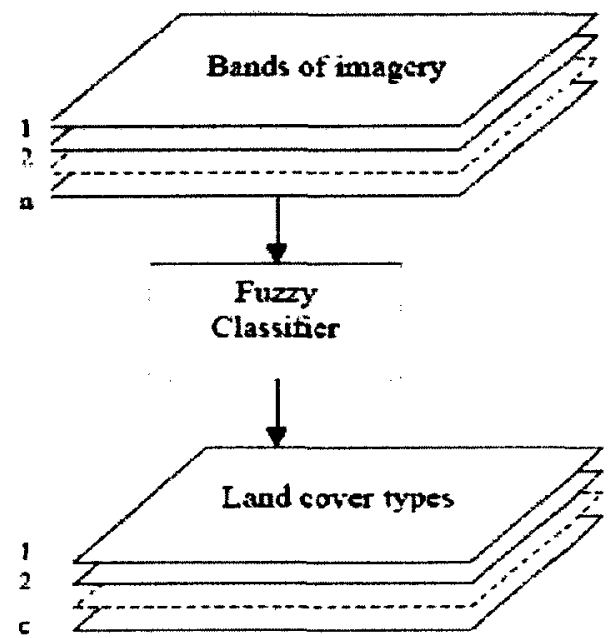

Figure 1: The relationship between the input layers and the output layers when a fuzzy classifier is used (Fisher and Pathirana, 1990). 
Within the field of remote sensing, fuzzy logic is not a new concept. It has been used for defining soil classes and geographical objects, as well as for enhancing classification methods (Burrough et al., 1992; Davidson et al., 1994; Wang and Hall, 1996; Brandtberg, 2002; Lucieer and Kraak, 2004; Bone et al., 2005). The most commonly used method of fuzzy classification is the fuzzy $c$-means clustering method (FCM) (Foody, 1996; Lucieer and Kraak, 2004). Developed by Bezdek et al. (1984), it is similar in overall process to the $k$-means algorithm discussed in Section 2.2.1. FCM differs from the standard hard clustering methods in that, instead of having discrete boundaries between each class, membership values are assigned that describe how close a pixel measurement is to the means of all classes. The distance measure that is commonly used is Euclidean distance. This clustering technique can be used for either supervised or unsupervised classification (Foody, 1996). This method of fuzzy $c$-means clustering has been employed in many studies (e.g. Fisher and Pathirana, 1990; Brown, 1998; Zhang and Foody, 1998; Burrough et al., 2001; Lucieer and Kraak, 2004; Droj, 2007; Maulik and Saha, 2010). In addition, Cannon et al. (1986) and Lee (2006) both used a FCM algorithm to analyze sub-pixel composition using a medium spatial resolution satellite image. Irvin et al. (1997) and Burrough et al. (2000) used fuzzy c-means clustering to create and outline spatially coherent landform classes from high resolution digital elevation models.

\subsubsection{Fuzzy Membership Creation}

Gath and Geva (1989) developed an algorithm that accounts for the variability in cluster densities, cluster shapes, as well as the number of data points in each of the clusters. The algorithm begins by randomly identifying the location of cluster centroids through a 
process of unsupervised learning. It then clusters the data based on the minimization of the generalized least-squared error $\left(J_{q}(U, V)\right)$ :

$$
J_{q}(U, V)=\sum_{j=1}^{N} \sum_{i=1}^{c}\left(u_{i j}\right)^{q} d^{2}\left(X_{j}, V_{i}\right) ; \quad C \leq N
$$

Where $u_{i j}$ is the fuzzy membership value of an observation $X_{j}$ of the $i$ th cluster; $q$ is the weighting exponent that controls the degree of 'fuzziness' within the clusters (increasing $q$ decreases fuzziness); $X_{j}$ is the $j$ th $m$-dimensional feature vector, $V_{i}$ is the centroid of the $i$ th cluster, $d^{2}\left(X_{j}, V_{i}\right)$ is the distance between $X_{j}$ and $V_{i} ; c$ is the number of clusters and $N$ is the number of data points (Gath and Geva, 1989).

The iterative optimization of the above formula is achieved by the selection of the initial centroids, $V_{i}$ :

$$
V_{j}=\frac{\sum_{j=1}^{N}\left(u_{i j}\right)^{q} X_{j}}{\sum_{j=1}^{N}\left(u_{i j}\right)^{q}}
$$

Whereby the degree of membership $\left(u_{i j}\right)$ is given by:

$$
U_{i j}=\frac{\left[\frac{1}{d^{2}\left(X_{j}, V_{i}\right)}\right]^{1 /(q-1)}}{\sum_{c=1}^{n}\left[\frac{1}{d^{2}\left(X_{j}, V_{i}\right)}\right]^{1 /(q-1)}}
$$

At each iteration, the number of clusters $(c)$ is increased and new centroids and degrees of membership are computed until optimum values are obtained. 
The distance measure is calculated in one of two ways. The first utilizes the standard fuzzy $c$-means method, where the distance term is Euclidean.

$$
\mathrm{d}^{2}\left(\mathrm{X}_{j}, \mathrm{~V}_{i}\right)=\left(\mathrm{X}_{j}-\mathrm{V}_{i}\right)^{\mathrm{l}} \mathrm{A}\left(\mathrm{X}_{j}-\mathrm{V}_{i}\right)
$$

This occurs when A equals the identity matrix. However, in the case where the clusters are hyperellipsoidal and when clusters have variable cluster densities and unequal number of data points, a distance measure that is based on maximum likelihood estimation is used:

$$
\mathrm{d}^{2}\left(\mathrm{X}_{j}, \mathrm{~V}_{i}\right)=\frac{\left[\operatorname{det}\left(\mathrm{F}_{i}\right)\right]^{1 / 2}}{\mathrm{P}_{i}} \exp \left[\left(\mathrm{X}_{j}-\mathrm{V}_{i}\right)^{x} \mathrm{~F}_{i}^{-1}\left(\mathrm{X}_{j}-\mathrm{V}_{i}\right) / 2\right]
$$

Where $P_{i}$ is the a priori probability of selecting the $i$ th cluster and $F_{i}$ is the fuzzy covariance matrix of the ith cluster, given by:

$$
F_{i}=\frac{\sum_{j=1}^{N}\left(u_{i j}\right)^{\mathrm{w}}\left(X_{j}-V_{i}\right)\left(X_{j}-V_{i}\right)^{T}}{\sum_{j=1}^{N}\left(u_{i j}\right)^{w}}
$$

Where $w$ another weighting exponent that controls the degree of fuzziness within the clusters (similar to $q$ ).

When this second distance measure is used, a fuzzy derivation of the maximum likelihood estimation (FMLE) is employed. This results in the probability of selecting the $i$ th cluster given the $j$ th feature vector, $h\left(i / X_{j}\right)$, replacing $E q(5)$. 


$$
\mathrm{H}\left(i \mid X_{\mathrm{j}}\right)=\frac{\left[\frac{1}{d^{2}\left(X_{j}, V_{i}\right)}\right]}{\sum_{i=1}^{N}\left[\frac{1}{d^{2}\left(X_{j j}, V_{i}\right)}\right]}
$$

This two-stage algorithm, with the unsupervised tracking of initial cluster centres (based on the fuzzy $c$-means algorithm) as the first stage and the fuzzy partitioning achieved by use of the FMLE algorithm as the second stage, results in the optimal fuzzy clustering of the data (Gath and Geva, 1989).

\subsubsection{Advantages of Fuzzy Classification}

Typically, within the classification processes of remotely sensed data, each pixel is allocated a single, discrete value. However, this crisp and deterministic method of classification is not always ideal, as it assumes homogeneity and does not allow for the inclusion of mixed pixels - especially at coarser spatial resolutions (Zhang and Foody, 2001). Due to the inherent complexity found in landscapes, this 'hard' method of classification can result in reduced accuracy. While cover types can be easily differentiated in their pure states, as the borders of these entities are approached, they become less distinct (Gopal and Woodcock, 1994). This results in pixels being categorized as one specific type of land cover when in reality other land cover types may be present within the same area. Since these types of crisp classification methods cannot appropriately represent mixed pixels, they cannot provide a realistic or accurate depiction of the land cover. Mixed pixels are therefore typically considered undesirable. However, since land cover maps at regional to global scales typically use coarse resolution sensors, 
the inclusion of mixed pixels may be unavoidable (Foody, 1997). It is for this reason that fuzzy classification approaches have been proposed and successfully used in providing a depiction of the landscape (Wang, 1990; Zhang and Foody, 2001).

Fuzzy classification can be used as a means of assessing the degree of confusion between classes for the given input data and has been shown to better represent the heterogeneity of landscapes (Foody, 1997). The advantage of fuzzy classification is that it allows for multiple and partial memberships for each location within the thematic map, thereby allowing for sub-pixel information to be extracted (Foody, 1997; Zhang and Kirby, 1997). This is especially relevant since a pixel, as an arbitrary spatial unit, is likely to represent an area on the ground comprising more than one discrete land cover class (Foody, 1997). Inherent in fuzzy classification is the notion that the 'transition from membership to non-membership is seldom a step function. Rather, there is a gradual but specifiable change from membership to non-membership' (Gopal and Woodcock, 1994). This avoids the arbitrary sharp thresholds that are present within a hard classification method (Gao, 2009). Fuzzy classification allows for the heterogeneous complexity of a landscape to be preserved and in turn, generally has the potential to lead to more accurate results.

Another advantage of using fuzzy set theory in land cover classification is that, unlike the classic 'hard' classification methods, fuzzy logic is not as dependent on high spatial resolution. Although the spatial distribution of the classes within a pixel remains unknown, this method of fuzzy classification is able to use a coarser spatial resolution 
remote sensor while still representing sub-pixel land cover class proportions (McMahan et. al., 2003). As high-resolution spatial data can be costly, using a fuzzy approach to classification can be a cost-effective way to obtain accurate results while still using a coarser resolution remote sensor. Using a fuzzy classification method, greater amounts of diversity within each pixel can be recognized, with the goal of obtaining similar results to that of a higher resolution sensor, but at a lower cost.

\subsubsection{Texture Analysis}

Texture is an important characteristic in image analysis and has often been used to add spatial information to the image classification process (Haralick, 1979). Defined as the frequency of tonal change on an image, texture is influenced by the arrangement and placement of repetitions of colour and tone within an image (Lillesand et al., 2008; Jensen, 2007). It is the product of a feature's overall shape, pattern, shadow, tone and size, and is scale dependent (Lillesand et al., 2008). In homogeneous and uniform areas, the texture can be described as smooth, whereas it is described as rough in more coarse and heterogeneous areas (Jensen, 2007). When two features have similar spectral characteristics, textural features can be used to further distinguish them (Geomatica manual; Jensen, 2007). Texture has, therefore, been used in many studies to enhance classification algorithms (Augusteijn et al., 1995; Franklin et al., 2000; Shackleford and Davis, 2003; Myint et al., 2006; Berberoglu et al., 2007; Pan et al., 2010).

There are a variety of types of texture measures used to aid in classifications. A common group of measures are based on the grey level co-occurrence matrix (GLCM). This 
matrix provides the probabilities of all pair-wise combinations of grey levels (pixel brightness values) within a defined sample window (Haralick, 1979). Some of the more frequently used GLCM texture measures include: homogeneity (measuring uniformity), contrast (measuring heterogeneity), mean (measuring average grey-levels), standard deviation (measuring grey-level standard deviations), entropy (measuring value constancies), and correlation (measuring linear dependencies of grey-levels in neighboring pixels) (PCI Geomatics, 2010).

\subsection{Accuracy Assessment}

In the context of land cover maps derived from remotely sensed data, classification accuracy can be defined as 'the degree to which the derived image classification agrees with reality' (Foody, 2002). Accuracy assessment involves the comparison of a site on a map against reference information for the same site. A commonly specified goal is to achieve an accuracy of at least $85 \%$ because the more accurate a classification is, the closer the classification is to the true and accepted values (Conglaton and Green, 1999; Foody, 2008).

Since the mid-1980's, accuracy assessment has become a critical component to studies using remotely sensed data (Congalton and Green, 1999). Such assessments are important in that they enable the comparison of various techniques and analyses. As well, accuracy assessment allows for an improvement in the quality of map information by identifying sources of error, thereby providing the user opportunities to correct the error or utilize the 
magnitude and spatial distribution of error in further analysis and decision making (Congalton and Green, 1999).

\subsubsection{Accuracy Assessment for 'Hard' Classifiers}

Accuracy within a thematic map is typically assessed by the creation of an error matrix. This error matrix (also called a confusion matrix or contingency table) compares the relationship between known reference data, obtained from ground data or other reference data deemed to be more accurate that the map being evaluated, and the classified map (Gopal and Woodcock, 1994; Lillesand et al., 2008). The number of samples required for the reference data depends on the data being used. Typically, 50 samples per class is optimal. However, if the number of classes is higher than 12 , then $75-100$ samples are recommended. As well, if the classes are homogeneous, fewer samples are required (Congalton and Green, 1991). The two most commonly used sampling schemes to obtain reference data are random and stratified. In random sampling, each item in the population has an equal chance of being included in the sample. Stratified sampling is similar, however, prior knowledge about the study area is used to divide the area into groups. Each group is then randomly sampled. The advantage is that each group (i.e. land cover type) will be included in the sample (Congalton and Green, 1999; Hall, 2007).

Once the reference data has been obtained, summary metrics of classification accuracy can be derived. The end product is an estimate of the accuracy of the entire land cover classification (Foody, 1995). These summary statistics include: overall accuracy (the sum of correctly classified sample pixels divided by total number of sample pixels), 
commission errors (errors arising when a pixel is included in an incorrect category) and omission errors (errors arising when a pixel is excluded from the category to which it belongs) (Congalton and Green, 1999). Another frequently used statistic obtained from the error matrix is the Kappa coefficient $(E q(10))$. This statistic is a measure of the difference between the actual agreement between reference data and the classified map, and the chance agreement between the reference data and a random classifier (Lillesand et al., 2008).

$$
K=\frac{P_{0}-P_{c}}{1-P_{c}}
$$

Where $P_{0}$ is the overall agreement $(E q(11))$, and $P_{c}$ is the chance agreement $(E q(12))$.

$$
\begin{gathered}
P_{o}=\frac{1}{\mathrm{n}} \sum \mathrm{n}_{i i} \\
P_{c}=\frac{1}{\mathrm{n}^{2}} \sum \mathrm{n}_{i+} \mathrm{n}_{+i}
\end{gathered}
$$

Where $n$ is the number of reference pixels, $\mathrm{n}_{i i}$ is the number of pixels belonging to the reference class $i$ that were correctly classified, $n_{i+}$ is the total number of pixels classified as class $i$, and $\mathrm{n}_{+i}$ is the total number of pixels belonging to class $i$.

As well, the kappa statistic can also be calculated for each class. As a class-level accuracy measurement, the conditional kappa is based on the idea that the map 'knows' the proportion of pixels in each class; therefore the map should assign pixels to that class according to those known proportions (Stehmen, 1997). The conditional kappa $\left(K_{i}\right)$ is given by: 


$$
K_{\mathrm{i}}=\frac{\mathbf{n} \mathbf{n}_{\mathrm{ii}}-\mathbf{n}_{i+} \mathrm{n}_{+i}}{\mathbf{n} \mathbf{n}_{i+}-\mathbf{n}_{i+} \mathbf{n}_{+i}}
$$

Essentially, kappa values indicate the proportion of agreement after chance agreement is removed (Liu et al., 2007). Values of zero indicate that the classifier is no better than a random assignment of pixels, while values approaching 1 indicate higher classification accuracies.

\subsubsection{Accuracy Assessment for Fuzzy Classifiers}

A map derived from fuzzy classification, unfortunately, cannot use the same methods of accuracy assessment described in Section 2.3.1 because these methods are geared only for hard classifiers (Gao, 2009; Foody, 1995). As an alternative, a measure of entropy is often used to assess a fuzzy classification (Foody 1995; Zhang and Kirby, 1997). Measures of entropy indicate the 'degree to which the class membership [values] are partitioned between defined classes' (Foody, 1995). Entropy is a measure of information content formulated in terms of probability theory (Klir and Folger, 1988).

Entropy $(\mathrm{H})$ is calculated using the following formula:

$$
\mathrm{H}=-\sum_{i=1}^{\mathrm{c}} p(x) \log _{2} p(x)
$$

Where $c$ is the number of classes and $p(x)$ is the class membership probabilities.

Entropy is maximized when the probability of class membership is partitioned evenly between all classes in the classification and minimized when it is associated entirely with 
one class. It should be noted, however, that even with high entropy values, the classification could still be considered accurate. Higher entropy values mean that each pixel will have a high probability of membership with multiple classes (Foody, 1995). Therefore, in heterogeneous areas where mixed pixels are abundant, entropy values will be high.

When multiple and partial class memberships are possible for the ground (reference) data, a measure of cross-entropy is typically used (Foody, 1995). Cross-entropy provides a measure of the closeness of a fuzzy classification to a fuzzy ground dataset (Foody, 1996). It is calculated from the probability distributions of class membership obtained from the classified and ground datasets (Foody, 1995). While the implementation of a fully-fuzzy approach (i.e. one that takes fuzziness into account in the ground data as well as in the classification stages) has been used in studies such as those conducted by Foody (1997) and Zhang and Foody (2001), cross-entropy is only appropriate to use when both the classified data and the ground data are fuzzy. However, creating the fuzzy ground data is not straightforward - it requires obtaining sufficiently detailed ground data to allow for the sub-pixel proportions to be assessed, which may not always be attainable (Zhang and Foody, 1998). 


\subsection{Methodology}

In this chapter the study area is outlined and described. As well, information on how the data were obtained and the types of data used are provided. This chapter also includes details on how the classifications and accuracy assessments were conducted.

\subsection{Study Area}

As the results of this thesis are to be used for further research within GLEL, it was important that the study area selected be compatible with the research currently being conducted. The study area is, therefore, a portion of eastern Ontario, Canada. This broad region, depicted in Figure 2, spans $45.01^{\circ}$ to $45.42^{\circ} \mathrm{N}$ to $75.12^{\circ}$ to $75.64^{\circ} \mathrm{W}$.

The eastern Ontario region encompasses a wide range of land cover classes including agricultural and forested areas, as well as urban centers. There are extensive agricultural areas in the landscapes between eastern Ottawa and the Quebec border as well as near the Ottawa and St. Lawrence Rivers - spanning approximately 528,646 ha for the entire region. (Dingle Robertson and King, 2011; Statistics Canada, 2011). Of this, there are 8,007 farms, with sizes ranging from less than 4 ha to more than 1,425 ha. As well, there were approximately 133,800 ha seeded for soybeans, 146,000 ha seeded for corn and 236,700 ha seeded for hay in 2011 (Statistics Canada, 2011). 


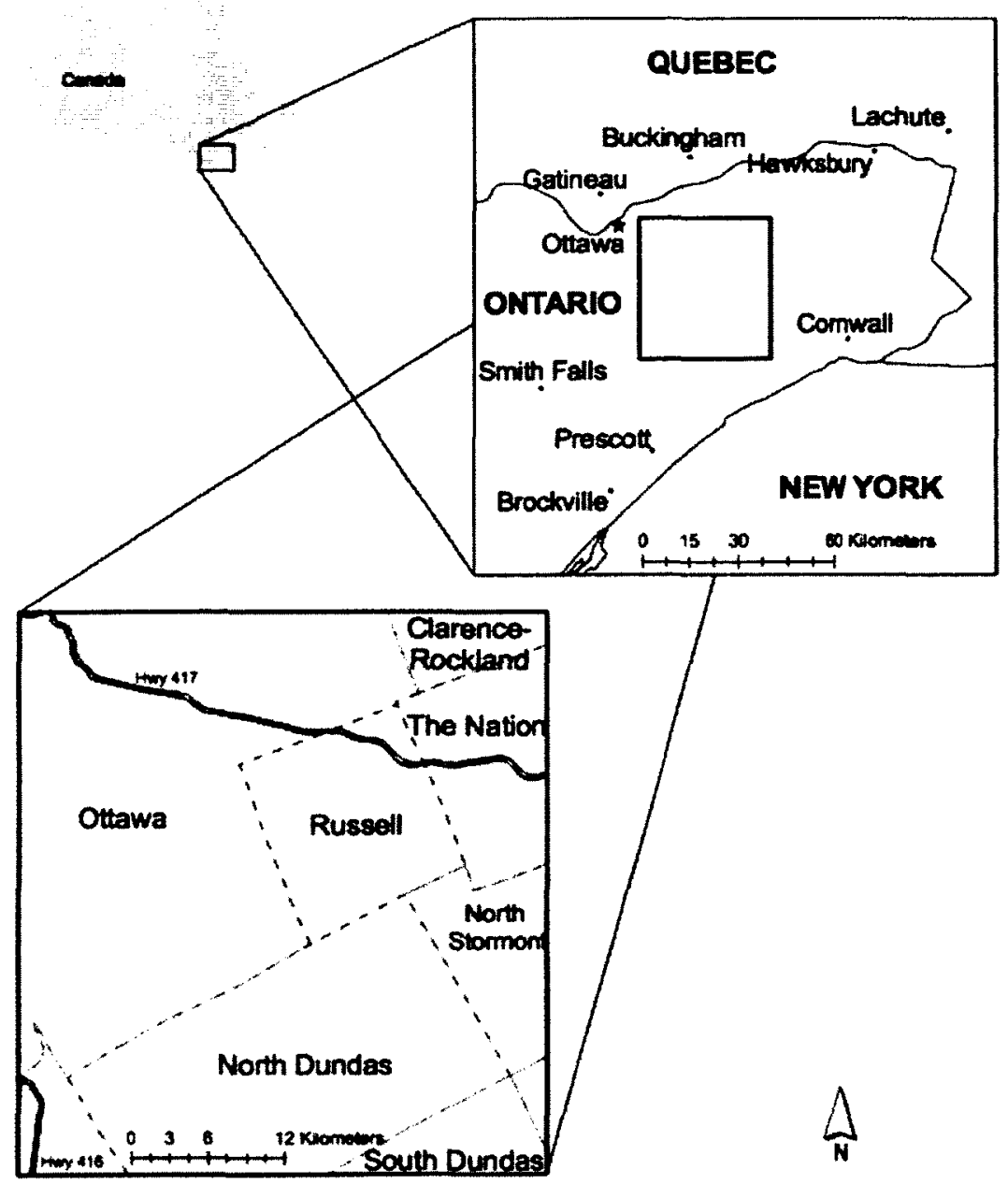

Figure 2. Study area of eastern Ontario, Canada.

The forested areas, which account for approximately $46,000 \mathrm{ha}$, are predominantly located at the northern edge. This region is comprised of mostly deciduous trees (including sugar maple (Acer saccharum), red oak (Acer saccharum), American basswood (Tilia americana), etc.) with a mix of coniferous trees (including eastern white pine (Pinus strobus), red pine (Pinus resinosa), white cedar (Thuja occidentalis), etc.) 
(Pasher and King, 2006; EOMF, 2006). There are also a wide variety of ferns, mosses, shrubs and fungi in this region (EOMF, 2006).

The study area encompasses many urban areas including a southeast portion of the city of Ottawa. The Ottawa metropolitan area is $2,778.13 \mathrm{~km}^{2}$ and has a population of 921,823 (Statistics Canada, 2011). The smaller towns located within the study region include the township of Russell as well as Clarence-Rockland, The Nation, North Stormont and North Dundas.

\subsection{Data Acquisition}

Data for this project were obtained from multiple satellites and sources. A high resolution satellite image, aerial photographs and field data were obtained in order to create reference data for the supervised classification methods. To create the high-resolution maximum likelihood classification (MLC) map, Quickbird satellite data were used. To create the lower-resolution MLC map, as well as the Fuzzy classification map, Landsat-5 TM Satellite data were used. Due to the restrictions resulting from availability of satellite data and locations for field data collection, the study area was reduced into five separate subsections. This refined study area (which depicts the five scenes that correspond to the areas where Quickbird data was obtained) is shown in Figure 3. Due to the fact that there have been numerous studies that focus solely on the Mer Bleue region and since the focus of this thesis is primarily on the agricultural areas of eastern Ontario, this wetland region was not included. 


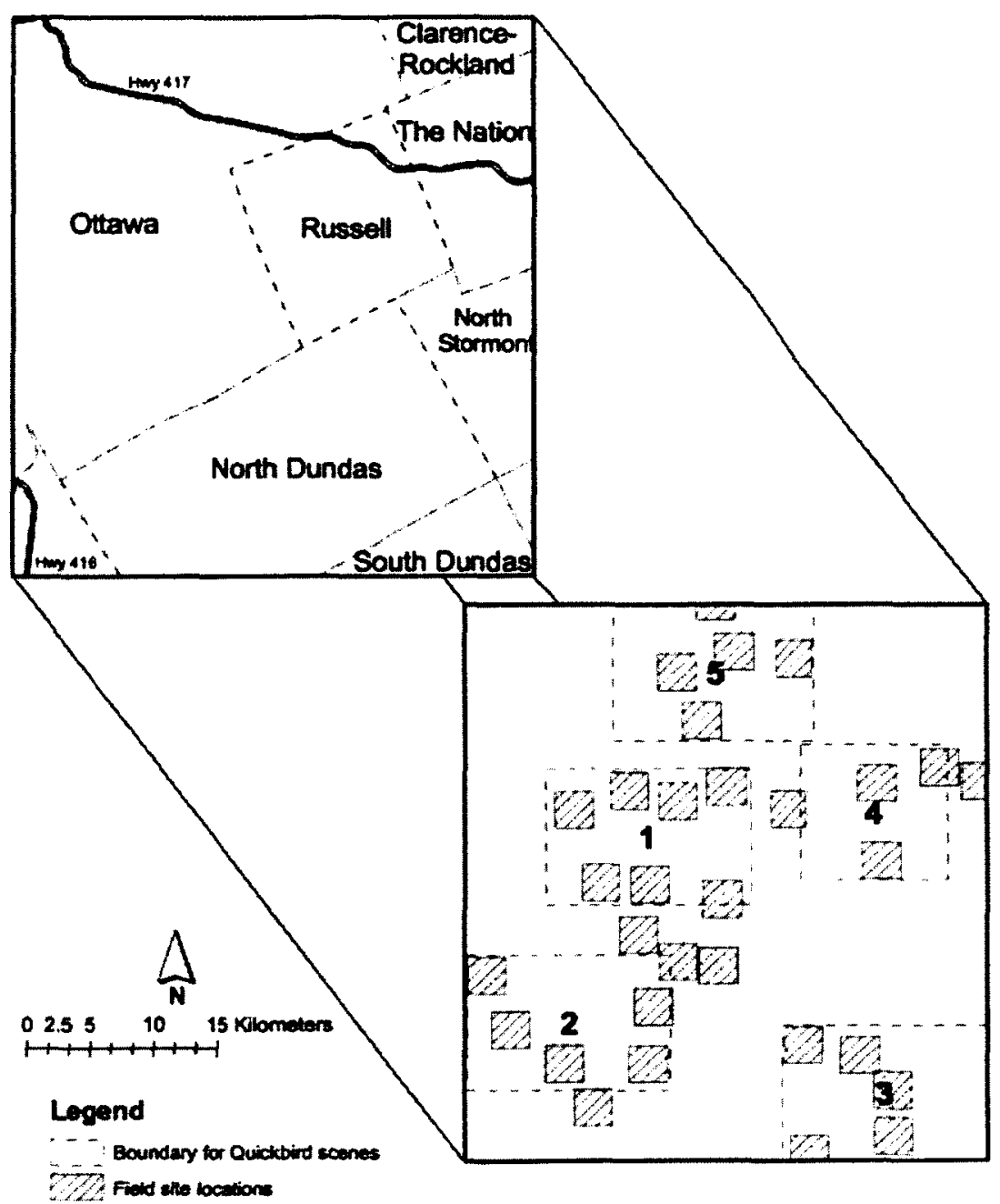

Figure 3. Reduced study area due to satellite data acquisition restrictions. The five boundaries for the Quickbird scenes represent the new study areas.

\subsubsection{Reference Data}

Reference data were obtained by interpreting aerial photographs and high-resolution satellite images, as well as through the collection of field data. The purpose of collecting reference data is to derive a 'true' label/class for a given site for training and validation purposes (Congalton and Green, 1999). It forms the foundation for the classification scheme in that it is used for both training and validation purposes. Reference data should 
therefore be representative of the spectral characteristics of all the informational classes used within the study (Gao, 2009).

The interpretation of high resolution Quickbird images and aerial photographs provided the main source of reference data. Based on the visual interpretation of these images, training and validation areas were delineated. Visual interpretation, with the aid of field visits, is a commonly used technique for delineating training and validation areas (Congalton and Green, 1999; Gao, 2009). Therefore, to aid in the interpretation process for this project, fieldwork was also conducted. The field data was useful in clearing up any ambiguities detected within the images. The data obtained through conducting fieldwork was used to validate the interpretations of the satellite images and aerial photographs.

Field data was collected from 30 different areas across the eastern Ontario region, with each area spanning $3 \mathrm{~km}^{2}$. As this thesis is part of the larger research initiative within GLEL, the details of how these locations were selected are outlined by Pasher et al. (submitted). For each of the $3 \mathrm{~km}^{2}$ areas, all visible land cover types were recorded including crop fields, field edges, roads, forested areas, residential and industrial buildings, etc. A full list of the recorded visible land cover types can be found in Table 1 .

Aerial photographs were obtained to cover all 30 of the $3 \mathrm{~km}^{2}$ areas. The images were taken between July $1^{\text {st }}$ and July $10^{\text {th }}, 2011$ at an altitude of approximately 6,500 to 7,000 ft. There were four photographs obtained for each of the 30 sites. The dimensions of 
each photograph spanned a $20.44 \mathrm{~m} \times 27.25 \mathrm{~m}$ area and had an overlap of $60 \%$ between photographs.

\subsubsection{Classification Scheme}

There were 38 different land cover types observed in the field data. These 38 classes, described in Table 1, were then grouped into a more manageable 14 classes based on similarities. For example, classes such as Clover and Alfalfa were combined because spectrally, they were very similar. Table 2 lists the 14 classes and shows how the 38 classes were merged to obtain 14 classes. With the aid of field visits and photographs, training polygons were delineated for the 14 classes. Table 4 provides the number of sample pixels for each of the 14 classes. Examples of these training polygons for selected classes can be found in the Appendix (Figure I-A).

Once the polygons were delineated, with the aid of the transformed divergence, along with an analysis of the reference data histograms to identify any overlapping or bi-modal distributions, eight normally distributed and statistically separable classes were obtained. These were: Built-up, Water, Forest, Grass, Corn, Soybean, Cereal, and Mixed Vegetable (Table 3). There was a distinct change in separability when the 14 classes were combined into the final eight classes. For example, classes such as Grass, Hay and Pasture all displayed very low separability with each other (less than 300 ). However, once these classes were merged together, the separability between the combined Grass class and the other classes greatly increased. 
Table 1. List and brief description of the 38 land cover classes observed in the field.

\begin{tabular}{|c|c|c|c|}
\hline & & Observed Class & Description \\
\hline \multirow{11}{*}{$\begin{array}{l}\text { Non-agricultural } \\
\text { Areas }\end{array}$} & 1 & Sports field & \\
\hline & 2 & Residential & Houses, small roads, sidewalks, lawns, trees, grasses \\
\hline & 3 & Railway & \\
\hline & 4 & Quarry & Sand, rock, gravels, pits \\
\hline & 5 & Industrial & Farm houses and structures \\
\hline & 6 & Highway & \\
\hline & 7 & Golf Course & grass/sod with sand pits \\
\hline & 8 & Dump & \\
\hline & 9 & Commercial & Paved lots, large factory buildings, stores \\
\hline & 10 & Cemetery & Grass with rocks and a few trees \\
\hline & 11 & Airport & \\
\hline \multirow{8}{*}{ Natural Areas } & 12 & Bare Soil & Bare, dirt, construction areas \\
\hline & 13 & Bush & $\begin{array}{l}\text { Woody plant of low height, with several stems arising } \\
\text { from the base (i.e. lacking a single trunk); a shrub. }\end{array}$ \\
\hline & 14 & Grass & $\begin{array}{l}\text { Cultivated field, mowed lawns, mowed grasses, } \\
\text { grasses not used as pasture or hay }\end{array}$ \\
\hline & 15 & Tree & $\begin{array}{l}\text { Woody plant that has many secondary branches } \\
\text { supported clear of the ground on a single main stem } \\
\text { or trunk. Minimum height of } 3 \mathrm{~m}\end{array}$ \\
\hline & 16 & Water & River, lake, pond \\
\hline & 17 & Wetland & Cattails, small shrubs/grasses, small amount of water \\
\hline & 18 & Ditch & $\begin{array}{l}\text { Permanently or intermittently wetted. Altered } \\
\text { watercourses }\end{array}$ \\
\hline & 19 & Stream & $\begin{array}{l}\text { Meandering channel, riparian vegetation, not altered, } \\
\text { low gradient }\end{array}$ \\
\hline \multirow{19}{*}{ Crops } & 20 & Alfalfa & \\
\hline & 21 & Apple & \\
\hline & 22 & Berries & \\
\hline & 23 & Cabbage & \\
\hline & 24 & Canola & \\
\hline & 25 & Clover & \\
\hline & 26 & Corn & \\
\hline & 27 & Milkweed & \\
\hline & 28 & Mixed vegetable & \\
\hline & 29 & Oats & \\
\hline & 30 & Peas & \\
\hline & 31 & Raspberries & \\
\hline & 32 & Sod & \\
\hline & 33 & Soybeans & \\
\hline & 34 & Strawberries & \\
\hline & 35 & Wheat/Cereal & \\
\hline & 36 & Pasture 1 & Grass or legume. Evidence of animals grazing, fenced \\
\hline & 37 & Pasture 2 & $\begin{array}{l}\text { Wetland or riparian. Evidence of animals grazing, } \\
\text { fenced }\end{array}$ \\
\hline & 38 & Hay & Grass or legume used for fodder \\
\hline
\end{tabular}


Table 2. List and description of the 14 land cover classes after the original 38 were grouped together.

\begin{tabular}{cll}
\hline & $\begin{array}{l}\text { Combined } \\
\text { Classes }\end{array}$ & Description \\
\hline 1 & Built-up & $\begin{array}{l}\text { 2. Residential, 3. Railway, 5. Industrial, 6. Road, 9. Commercial, 11. Airport, } \\
\text { 4. Quarry }\end{array}$ \\
\hline 2 & Water & 16. Water, 18. Ditch, 19. Stream \\
\hline 3 & Bush & 13. Bush \\
\hline 4 & Tree & 15. Tree \\
\hline 5 & Grass & 1. Sports field, 7. Golf course, 10. Cemetery, 14. Grass, 32. Sod \\
\hline 6 & Hay & 38. Hay \\
\hline 7 & Pasture & 27. Milkweed, 36. Pasture 1, 37. Pasture 2 \\
\hline 8 & Alfalfa/Clover & 20. Alfalfa, 25. Clover \\
\hline 9 & Corn & 26. Corn \\
\hline 10 & Soybean & 33. Soybean \\
\hline 11 & Cereal & 29. Oats, 35. Wheat/Cereal \\
\hline 12 & Mixed Vegetable & 21. Apple, 22.Berries, 23. Cabbage, 24. Canola, 28. Mixed vegetable, \\
\hline 13 & Bare soil & 12. Bare soil, 8. Dump \\
\hline 14 & Wetland & 17. Wetland \\
\hline
\end{tabular}

Table 3. List and description of the final 8 land cover classes.

\begin{tabular}{lll}
\hline & Combined Classes & Description \\
\hline 1 & Built-up & 1. Built-up, 13. Bare soil \\
\hline 2 & Water & 2. Water, 14. Wetland \\
\hline 3 & Forest & 3. Bush, 4. Tree \\
\hline 4 & Grass & 5.Grass, 6. Hay, 7. Pasture, 8. Alfalfa/Clover \\
\hline 5 & Corn & 9.Corn \\
\hline 6 & Soybean & 10. Soybean \\
\hline 7 & Cereal & 11. Cereal \\
\hline 8 & Mixed Vegetables & 12. Mixed vegetable \\
\hline
\end{tabular}


Table 4. Number of training pixels for each of the 14 classes.

\begin{tabular}{cc}
\hline Class & $\begin{array}{c}\text { Number of training } \\
\text { pixels }\end{array}$ \\
\hline Built-up & 381 \\
Water & 558 \\
Bush & 107 \\
Tree & 827 \\
Grass & 406 \\
Hay & 554 \\
Pasture & 589 \\
Alfalfa/Clover & 152 \\
Corn & 1071 \\
Soybean & 1168 \\
Cereal & 808 \\
Mixed Vegetable & 577 \\
Bare Soil & 102 \\
Wetlands & 65 \\
\hline Total & 7365 \\
\hline
\end{tabular}

\subsubsection{Satellite Data}

Over the years, satellite imagery has been successfully used for land cover mapping at a variety of spatial scales (Foody, 2002). As mentioned previously, two types of satellite data were used throughout this thesis; the first dataset is from the high resolution remote sensor, Quickbird; the second was from the coarser resolution remote sensor, Landsat-5 TM.

As one of the highest resolution satellite sensors currently available, Quickbird was used to aid in the reference data collection, as well as to create a high-resolution MLC map for comparison with the coarser Landsat derived maps. The Quickbird satellite has an 
altitude of $450 \mathrm{~km}$ and the sensor records radiance over a nominal swath width of 18.0 $\mathrm{km}$. The sensor has five bands: 1 panchromatic band with a $61 \mathrm{~cm}$ nominal ground pixel size and four multi-spectral bands, each with a pixel size of $2.44 \mathrm{~m}$ (DigitalGlobe, 2011). This thesis utilized all four multi-spectral bands (Table 5) in five scenes that encompassed all 30 reference sites (Table 6). These scenes were obtained during the middle of the 2011 growing season, when the crops were nearing or in full development. Note that due to excessive cloud cover, the usable image area for Scene 4 was reduced.

Table 5. Outline of the Quickbird bands used in this research.

\begin{tabular}{lc}
\hline \multicolumn{1}{c}{$\begin{array}{c}\text { Spectral } \\
\text { Location }\end{array}$} & $\begin{array}{c}\text { Spectral Bandwidth } \\
(\mu \mathrm{m})\end{array}$ \\
\hline Blue & $0.43-0.55$ \\
Green & $0.47-0.62$ \\
Red & $0.59-0.71$ \\
Near-Infrared & $0.72-0.92$ \\
\hline
\end{tabular}

Table 6. Acquisition data and area for each of the 5 Quickbird scenes.

\begin{tabular}{clc}
\hline Scene & \multicolumn{1}{c}{$\begin{array}{c}\text { Acquisition } \\
\text { date }\end{array}$} & \multicolumn{1}{c}{ Area } \\
\hline Scene 1 & July 11,2011 & $11 \mathrm{~km} \times 16 \mathrm{~km}$ \\
Scene 2 & August 29,2011 & $11 \mathrm{~km} \times 16 \mathrm{~km}$ \\
Scene 3 & August 12,2011 & $11 \mathrm{~km} \times 16 \mathrm{~km}$ \\
Scene 4 & July 16, 2011 & $11 \mathrm{~km} \mathrm{x} \mathrm{11} \mathrm{km}$ \\
Scene 5 & July 02, 2011 & $11 \mathrm{~km} \times 16 \mathrm{~km}$ \\
\hline
\end{tabular}

The data used to classify the landscape for the fuzzy classification came from the medium to coarse resolution satellite sensor, Landsat-7 Enhanced Thematic Mapper (ETM+). This sensor was selected due to its spatial coverage as well as its reduced cost in comparison 
to both aerial and high resolution satellite imagery. The Landsat-5 TM sensor is at an altitude of $705 \mathrm{~km}$ and has a nominal swath width of $185 \mathrm{~km}$. It has 6 bands in the visible, near-infrared and mid- infrared spectral regions (Table 7), each with a nominal ground pixel size of $30 \mathrm{~m}$, one panchromatic band with a ground pixel size of $15 \mathrm{~m}$ and one thermal band with a ground pixel size of $60 \mathrm{~m}$ (Lillesand et al., 2008). The specific scene selected for this research was path 15 , row 29 and was acquired on July $5^{\text {th }}, 2011$. As well, the selected scene displayed less than $10 \%$ cloud cover.

Table 7. The Landsat-5 TM bands used in this research.

\begin{tabular}{ccl}
\hline Band & $\begin{array}{c}\text { Spectral } \\
\text { Bandwidth } \\
(\mu \mathrm{m})\end{array}$ & $\begin{array}{c}\text { Spectral } \\
\text { Location }\end{array}$ \\
\hline 1 & $0.45-0.52$ & Blue \\
2 & $0.52-0.60$ & Green \\
3 & $0.63-0.69$ & Red \\
4 & $0.76-0.90$ & Near Infrared \\
5 & $1.55-1.75$ & Mid Infrared \\
7 & $2.08-2.35$ & Mid Infrared \\
\hline
\end{tabular}

Due to the restriction in availability of the Quickbird data, only the portion of the Landsat-5 TM data that intersected with the Quickbird scenes was used, as shown in Figure 3.

\subsection{Data Pre-processing}

A realistic representation of a scene cannot be created if there are image distortions. These can stem from image acquisition errors such as the curvature of the Earth and inaccuracies caused by sensor motion, which are common in remotely sensed data. As 
well, image distortions can also occur if a dataset does not contain the correct (or even any) spatial reference information, which is common with aerial photographs (Lillesand et al., 2008; ESRI, 2007). In addition, according to Foody (2002), error in overall thematic map accuracy can be attributed to mis-registration of the reference data. Therefore, before any data manipulation or analysis can be conducted, certain data preprocessing techniques, such as geometric corrections, need to be implemented. The purpose of geometrically correcting an image is to ensure that all of the pixels in one dataset correspond to the same position in another dataset (Jensen, 2005).

For this research, the aerial photographs had no spatial reference at all and were therefore registered to the Quickbird data. The Quickbird data had a map projection of Universal Transverse Mercator (UTM) zone 18 with a World Geodetic System 1984 (WGS 84) datum. For each aerial photograph, a minimum of 12 GCPs was used. These points were found at easily identifiable locations present on both the photographs and on the Quickbird data. As well, they were evenly distributed throughout each image - at corner, edge and center locations. Because the aerial photographs needed to be rotated, scaled and because there appeared to be differential scale distortions with respect to the satellite images, a second (quadratic) order transformation was applied. The average root mean squared error (RMSE) for the model (in metres) was 1.0728. The RMSE was calculated from the sample GCPs used in the second order transformation and not from independent check points. 


\subsection{Classification Methods}

In order to address the research questions outlined at the beginning of this thesis, two classifiers were employed. The first was the maximum likelihood classifier (MLC) and the second was the fuzzy classifier.

\subsubsection{Quickbird Maximum Likelihood Classification}

The first step in this supervised classification method was to delineate training and validation areas. Due to the fact that there were 5 Quickbird scenes, each obtained on a different date, each individual scene was analyzed separately. This meant that no atmospheric corrections needed to be done. It did, however, mean that each scene required its own reference data. Training polygons were delineated for all 14 classes evenly across each scene. As noted in Section 3.2.2, these 14 classes were then merged until 8 spectrally distinct classes were obtained.

The average transformed divergence values for the Quickbird data for each combination of the eight classes can be seen in Table 8. This table also shows the minimum and maximum values obtained. It was found that the Corn and Built-up classes had the highest separability, having an average transformed divergence value of 1999.85. The classes that showed the least separability were Corn and Grass, having a transformed divergence value of only 667.86 . 
Table 8. Transformed divergence values using Quickbird data.

\begin{tabular}{|c|c|c|c|c|c|c|c|}
\hline $\begin{array}{l}\text { Average: } \\
\text { Minimum: } \\
\text { Maximum: }\end{array}$ & $\begin{array}{r}1551.59 \\
667.86 \\
1999.85 \\
\end{array}$ & & & & & & \\
\hline & Water & Forest & Grass & Corn & Soybeans & Cereal & $\begin{array}{c}\text { Mixed } \\
\text { Vegetable }\end{array}$ \\
\hline Built-up & 1613.12 & 1585.64 & 1733.26 & 1999.85 & 1974.89 & 848.70 & 1992.33 \\
\hline Water & & 1346.64 & 1641.16 & 1956.77 & 1968.63 & 1085.66 & 1952.82 \\
\hline Forest & & & 999.18 & 1883.47 & 1451.76 & 1475.77 & 1863.29 \\
\hline Grass & & & & 667.86 & 1205.17 & 1449.10 & 1133.82 \\
\hline Corn & & & & & 1552.88 & 1910.32 & 1016.64 \\
\hline Soybeans & & & & & & 1763.87 & 1653.95 \\
\hline Cereal & & & & & & & 1718.02 \\
\hline
\end{tabular}

Using these 8 land cover classes, the MLC algorithm was then run on each of the 5 Quickbird scenes. The resulting classifications were mosaicked together to create one classification map for all of the Quickbird scenes.

The resulting Quickbird MLC map was to be compared with the Landsat classifications. However, due to the large difference in pixel size, Quickbird with $2.4 \mathrm{~m}$ pixels spacing and Landsat with a pixel size of $30 \mathrm{~m}$, the Quickbird MLC was re-sampled to the coarser resolution based on a majority re-sampling algorithm. While keeping the extent of the dataset constant, this algorithm works by altering the proportions of the dataset by changing the cell size (ESRI, 2007). The result was a reduced resolution raster that matched the resolution of Landsat pixels. 


\subsubsection{Landsat Maximum Likelihood Classification}

The same basic steps that created the Quickbird MLC were applied to the Landsat data, only this time, an additional texture band was added to the analysis to ensure distinction between features (Jensen, 2007; PCI Geomatics, 2010). It should be noted that an analysis of texture was conducted on the Quickbird data as well, however, the results did not show improvement so it was removed from the analysis.

After examining the transformed divergence values for each of the different texture measures available in the PCI Geomatica program, it was found that the GLCM mean texture provided the highest separability between classes. Therefore, it was selected for use in classification. The signature separabilities with and without the texture band can be found in Appendix I (Table I-A and Table I-B, respectively).

Using a $5 \times 5$ window, the mean texture of Landsat's near infrared band (Band 4) was computed. Transformed divergence values were again used to ensure that all 8 classes were statistically distinct. The MLC algorithm was then run on the Landsat data using all 6 Landsat bands plus the additional GLCM mean texture band. 


\subsubsection{Fuzzy Classification}

In order to create the fuzzy images, fuzzy membership functions were needed. The development of the fuzzy membership function is an important aspect of using fuzzy sets. Although this process is subjective in nature, functions should not be assigned arbitrarily - they should be representative of the data and the problem being considered (Robinson, 2003). Therefore, the membership function is typically defined using expert opinion and available data (Bone et al., 2005). Since the fuzzy $c$-means clustering algorithm is often used to define the membership values in these types of studies (Foody, 1996; Lucieer and Kraak, 2004), it was used for this research as well.

\subsubsection{Fuzzy Membership Creation}

PCl Geomatica's adaptation of the Gath and Geva model was used to obtain the fuzzy membership values for this research. The algorithm used all 6 Landsat bands plus the additional GLCM mean texture band as input data. In addition, the algorithm requires two separate values, referred to as fuzzy norms, to be provided. The first is the fuzzy $c$ means norm - which is the weighting exponent that controls the degree of 'fuzziness' within the clusters (variable $q$ in $E q(3)$ ). The second is the fuzzy MLE norm - which is the exponent that is applied to the squared Mahalanobis distance before it is used in the MLE equation $(E q(9))$. According to Gath and Geva (1989), both fuzzy norm values should lie within the interval $[1,5]$, with higher values resulting in less fuzziness. However, there is no optimal choice for values. Bezdek (1984) suggests that for most cases, a value for $q$ within the interval of 1.5 to 3.0 provides the best results. For the purposes of this research, the value for the weighting exponent was set to 2 , as $q=2$ was 
the most commonly used value found in the literature (Bezdek and Dunn, 1975; Gustafson and Kessel, 1979; Bezdek, 1982; Gath and Geva, 1989; Foody, 2002; Dutta, 2009). As it is recommended that the value for the fuzzy c-means norm should be at least half as large the fuzzy MLE norm, a value of 1.1 was used for this parameter (PCI Geomatica, 2010). Note that had there been more time, further analyses of these parameters would have been conducted to determine the optimal values for the given the specific study area used in this research (see Section 5.5 for more details).

The program also required values for the maximum number of clusters and the maximum number of iterations to be provided. The maximum number of clusters was set to 16 (the maximum that the program would allow). This allowed for twice as many clusters to be created compared to the final number of land cover classes defined. These clusters were then merged together based on spectral similarities as well as an evaluation of the reference data. This method of combining clusters into a reduced number of clusters to be consistent with the classification legend employed throughout the research is common throughout the literature (Cannon et al., 1986; Irvin et al., 1997; and Beabien et al., 1999).

The maximum number of iterations specifies the total number of iterations used when calculating the cluster mean positions after each additional cluster has been added. For the specific software used, values for this parameter ranged from 0 to 1001 . After experimentation was conducted, the default value of 20 was found to be acceptable. 
Therefore, for the purposes of this thesis, the maximum number of iterations was set to 20.

Once the 16 clusters were identified, the next step was to relate them to the a priori land cover types outlined in Section 3.2.2. Using methodology outlined by Fisher and Panthinara (1990), the statistics from the resultant fuzzy maps (including cluster means) were examined, and the locations where high membership values were observed were identified. The goal was to combine the 16 spectral clusters into 8 clusters - each of which would represent one of the land cover classes.

\subsubsection{Hardening Procedure}

When a fuzzy classification method is used, the result is one membership layer for each class present; i.e. for the 8 land cover classes in this study, the result is 8 data layers where the value for each pixel within each layer is the fuzzy membership value for that particular class (Fisher and Pathirana, 1990). Unfortunately, the interpretability of all these layers is not straightforward. For this reason, many studies generate a hard classification from the membership values (Cannon et al., 1986; Kent and Mardia, 1988; Fisher and Pathirana, 1990; Gopal and Woodcock 1994; Zhang and Foody, 1998; Zhang, 2004; Wang and Shen, 2009). By transforming the fuzzy classification results into hard classifications, a more direct comparison can be made with other hard classifiers (for example MLC) and an assessment of the accuracy can be computed using conventional methods such as the error matrix and the kappa statistic. 
The most common method of achieving a hardened fuzzy map is by applying a maximum decision rule. In this method, the class with the maximum fuzzy membership value for a given pixel is identified and assigned to that specific pixel. Of course a major concern with implementing a hardening procedure is that much of the detail obtained from the fuzzy classification will be lost, as is the potential for detecting sub-pixel information (Fisher and Pathirana, 1990).

In order to address this concern, secondary hardened fuzzy maps were also created. While the first hardened map (henceforth referred to as Fuzzyl) contained the classes with the highest fuzzy membership values, the second hardened map contained the classes with the second highest fuzzy membership values (henceforth referred to as Fuzzy2). In addition, a threshold for the minimum membership value was implemented for each hardened image. This value, which was set to 0.10 , indicates that a minimum membership value of 0.10 must be achieved in order for a class to be assigned to a pixel. This hardening method allowed for not only the dominant classes to be examined, but the successively subordinate classes as well. By looking at these different levels, a truer picture of the character of each pixel can be seen and therefore some of the sub-pixel information is maintained (Eastman, 2009).

\subsection{Accuracy Assessments}

Accuracy assessments are a critical component of image classification studies (Campbell, 1996). To assess the accuracy of the hard classification results, error matrices, kappa statistics and overall accuracies were obtained. To do this, both Quickbird and Landsat 
MLC's were used, as well as the hardened fuzzy map, Fuzzy1. The validation data consisted of 7,365 random points throughout the study area. In order to more efficiently assess the heterogeneity seen in the fuzzy maps - without hardening them and consequently losing the sub-pixel information - a measure of entropy was used. Entropy, as given by $E q(14)$, was calculated in this case instead of cross-entropy. The creation of fuzzy ground data (which is critical in the computation of cross-entropy) requires the acquisition of sufficiently detailed ground data (Zhang and Foody, 1998). This means that sub-pixel component land cover proportions for the entire study area would be necessary, which, for the purposes of this study, was not feasible. Therefore the standard entropy measure was used.

\subsubsection{Agreement}

Another way of assessing the classifiers is to look at the agreement between the Quickbird MLC and the other classified maps. To do this, each class label was assigned a unique numerical value from 1 to 8 . A subtraction operator was applied between the Quickbird MLC and the Landsat MLC. From the resulting raster, locations where pixel values equal 0 indicate agreement between the two classified maps. All other pixel values indicate disagreement. The same procedure was conducted between the Quickbird MLC and the Fuzzy1 and the Quickbird MLC and the Fuzzy2.

In addition, due to the fact that so much of the sub-pixel information was lost during the fuzzy membership hardening procedure, a 'softer' assessment of the agreement was conducted. This included comparison of the classes with either the first or the second 
highest membership values (Fuzzyl or Fuzzy2) and the Quickbird MLC, as opposed to only the class with the highest fuzzy membership value (Fuzzy1). 


\subsection{Results}

This chapter describes the results of both the Quickbird and Landsat maximum likelihood classifications, as well as the results of the fuzzy classification.

\subsection{Overall Classified Map Analyses}

Figure 4 shows the final thematic maps of the Quickbird MLC, Landsat MLC and the hardened fuzzy classification, Fuzzy1. For the purposes of analysis, only Scene 2 is depicted. The finalized thematic maps for the remaining scenes display similar results and can be found in the Appendix. Since aerial photographs for the entire Scene 2 area were not available, the unclassified Quickbird image is displayed in Figure 4a for comparison purposes.

Not surprisingly, the Quickbird MLC (Figure 4b) appears to have the most well-defined field boundaries. The majority of the fields can be easily identified. This is less true of the Landsat MLC (Figure 4c); many of the fields cannot be easily distinguished from one another. This is also seen in the Fuzzyl image (Figure 4d). In fact, because there is so much speckling in this fuzzy image, it is difficult to distinguish the majority of the fields. When looking at the specific classes, the Built-up class in the Quickbird MLC appears to be surrounded by Grass and Forested areas (and some Cereal). This is to be expected. However, the distribution for the few areas in the Landsat MLC image where the Built-up class is present is interspersed predominantly by the Corn class - which indicates confusion between these classes. 

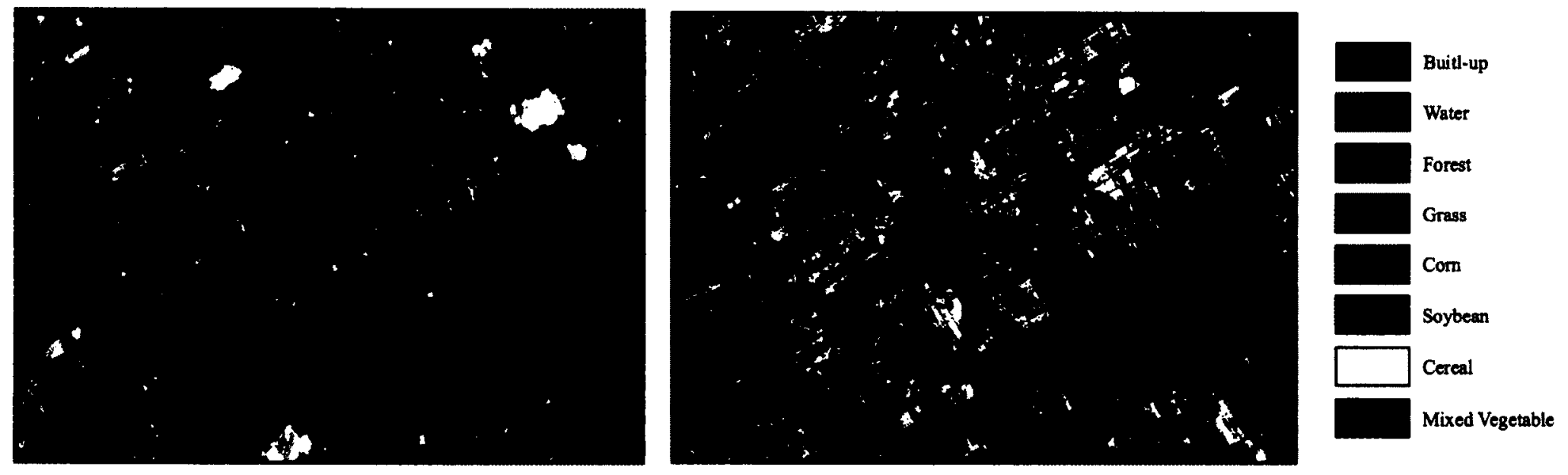

(a) Unclassified Quickbird

(b) Quickbird MLC
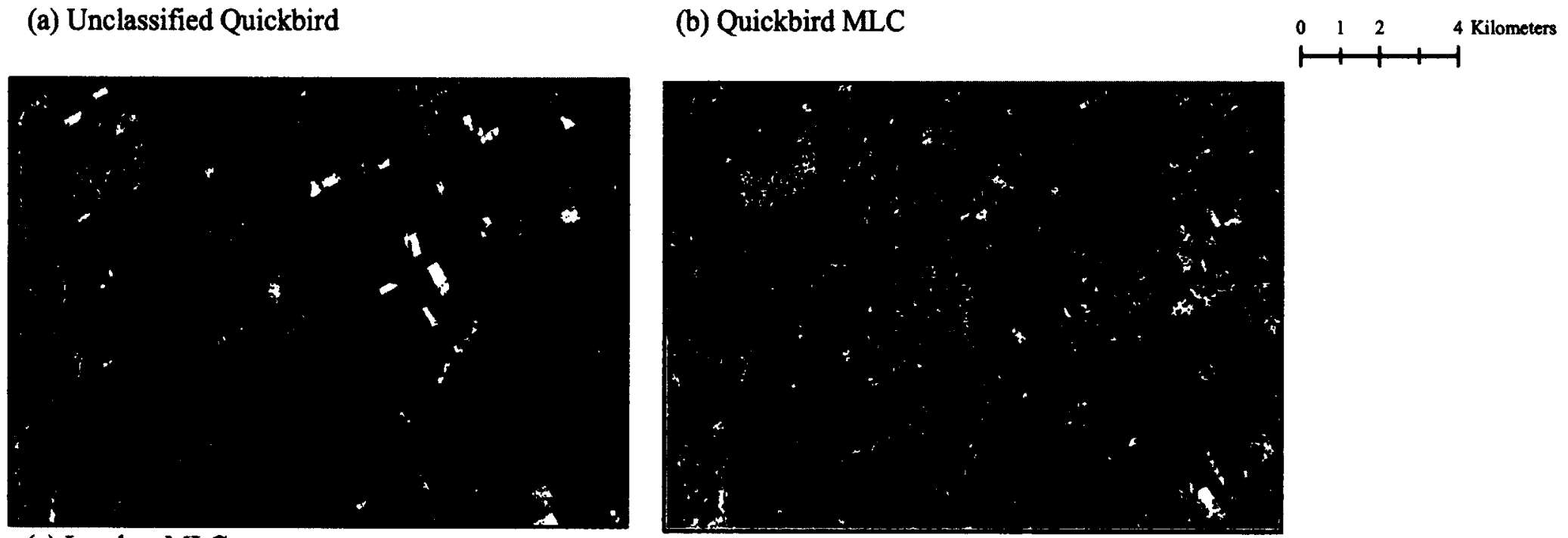

(c) Landsat MLC

(d) Fuzzy1

Figure 4. Original unclassified Quickbird image and classified images for Scene 2. 
From both the Scene 2 classified images (Figure 4) and the total percentages for each class for all 5 scenes (Figure 5), it is clear that the commission errors for the Landsat MLC are high for the Corn and Soybean classes. It is also clear that the omission errors for both the Forest and Grass classes are high. On the other hand, the commission errors for Fuzzy 1 are high for the Water and Soybean classes, while the omission errors are only high for the Grass class. However, considering the Grass class takes into account wild grasses as well as hay and pasture fields, it is expected that omission errors are due to the fact that many of the second and third highest memberships are in fact Grass. Overall, the average difference in percentage of pixels for each class is $4.04 \%$ and $4.97 \%$ between the Quickbird MLC and the Landsat MLC and the Quickbird MLC and the Fuzzy1, respectively. The class with the smallest change in percentage of pixels observed between the Quickbird MLC and the Landsat MLC is Water $(0.08 \%)$ and between the Quickbird MLC and the Fuzzy 1 is Corn (0.12\%). The class with the largest change is Grass with a value of $10.50 \%$ and $16.50 \%$ between the Quickbird MLC and the Landsat MLC and the Quickbird MLC and the Fuzzy1, respectively.

The No Value category in Figure 5(d) represents the percentage of pixels that did not meet the minimum threshold of 0.10 imposed during the hardening processes (outlined in Section 3.4.3.2). The No Value percentage given for the Fuzzy 2 image means that only $32.85 \%$ of the pixels have membership values greater than 0.9 and that the remaining pixels are all, to various degrees, mixed pixels.

Of the No Value pixels found in Fuzzy2, the percentage of pixels corresponding to each Fuzzy 1 class are given in Figure 6. The Forest class accounts for the majority, at $29.05 \%$, 
followed by the Soybean class at $23.41 \%$. This means that these two classes represent the classes with the highest numbers of pure or nearly pure pixels. The Mixed Vegetable class, having a percentage of only $3.51 \%$, represents the class with the most heterogeneous pixels. 


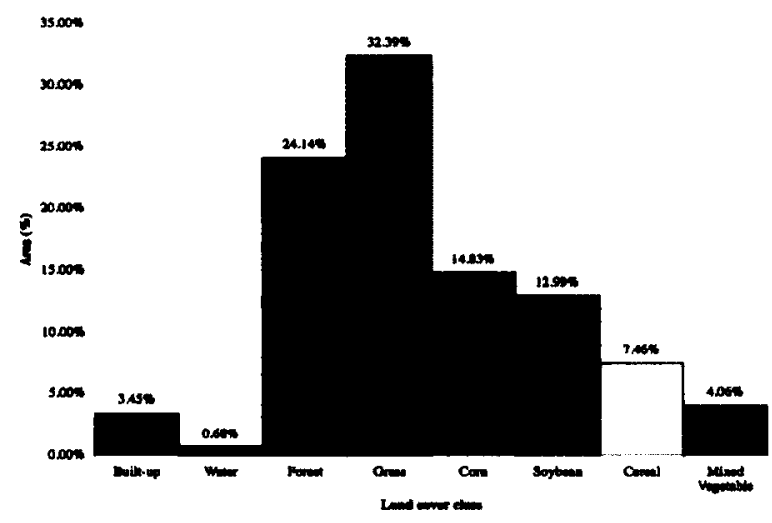

(a) Quickbird MLC

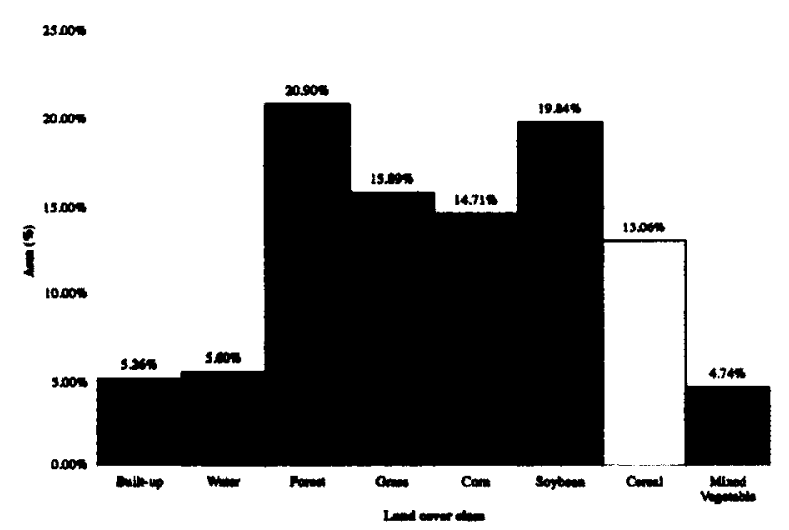

(c) Fuzzy1

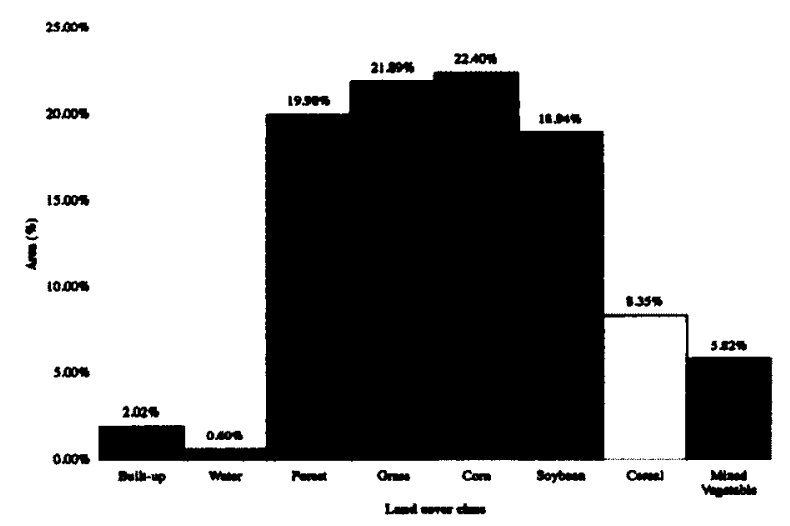

(b) Landsat MLC

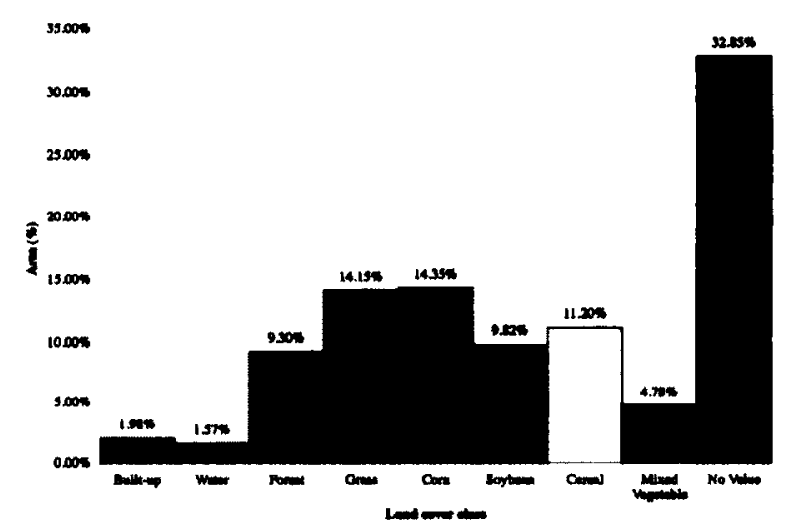

(d) Fuzzy2

Figure 5. Percentage of total area based on class frequencies for (a) the Quickbird MLC, (b) Landsat MLC, (c) Fuzzyl and (d) Fuzzy2. 


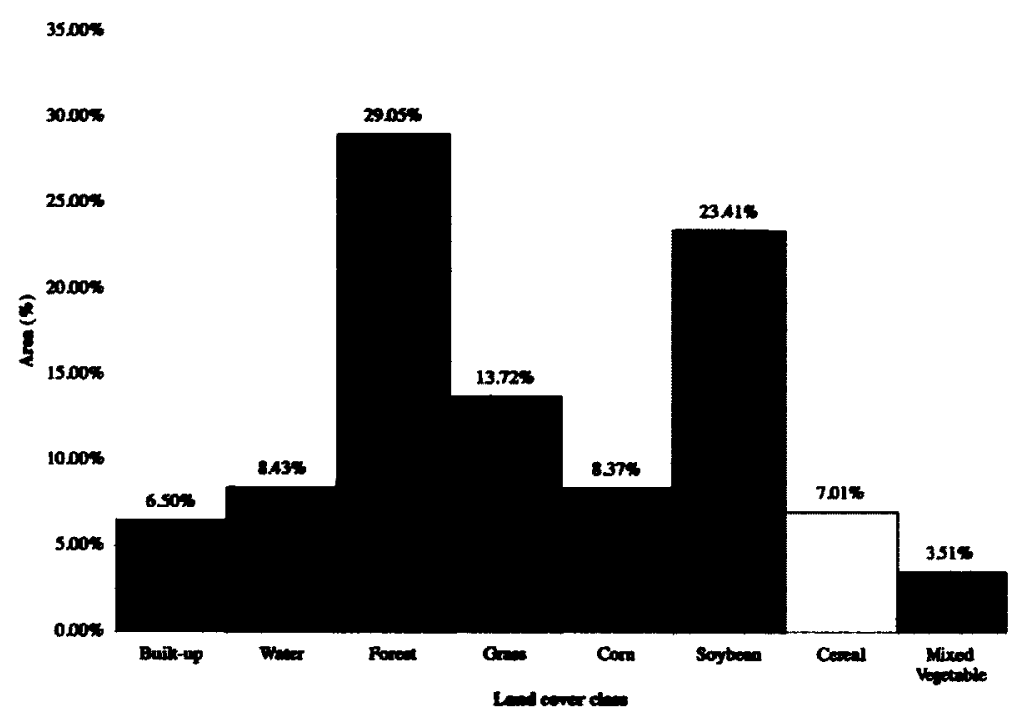

Figure 6. Percentage of total area from Fuzzyl based on the No Value pixels from Fuzzy2.

\subsection{Class Statistics}

Once the maximum likelihood classification was performed on the Landsat data, the mean digital numbers for each band per class were obtained. These values (Table 9) were used in conjunction with the reference data in order to group the 16 fuzzy clusters into the more representational 8 clusters. The centres of the resulting merged clusters are seen in Table 10. It is apparent that there is more class overlap present in the fuzzy clusters compared to the Landsat MLC classes - especially for the Soybean and Mixed Vegetable classes. In addition, it should be noted that the high values observed in the Near Infrared (Band 4) for the Water class are likely a result of the fact that this class encompasses deep and shallow waters, as well as wetland areas. 
Table 9. Mean digital number for each class per band analyzed for the Landsat MLC.

\begin{tabular}{|c|c|c|c|c|c|c|c|}
\hline \multirow{2}{*}{ Land cover class } & \multicolumn{6}{|c|}{ Mean Digital Number (per band) } & \multirow{2}{*}{ Texture } \\
\hline & 1 & 2 & 3 & 4 & 5 & 7 & \\
\hline Built-up & 110.3 & 52.9 & 58.6 & 67.0 & 95.1 & 59.2 & 1.5 \\
\hline Water & 79.7 & 31.5 & 26.0 & 31.6 & 16.6 & 7.8 & 0.6 \\
\hline Forest & 80.7 & 34.3 & 27.6 & 114.1 & 77.1 & 23.1 & 23.9 \\
\hline Grass & 84.5 & 38.8 & 34.3 & 108.0 & 100.3 & 35.8 & 17.7 \\
\hline Com & 84.8 & 37.7 & 32.9 & 106.8 & 89.3 & 33.4 & 18.8 \\
\hline Soybean & 95.8 & 46.5 & 50.2 & 90.3 & 131.8 & 65.4 & 8.1 \\
\hline Cereal & 83.6 & 37.2 & 31.5 & 111.1 & 72.6 & 26.0 & 21.0 \\
\hline Mixed Vegetable & 103.2 & 51.3 & 58.0 & 89.2 & 128.3 & 75.6 & 8.6 \\
\hline
\end{tabular}

Table 10. Location of cluster centre for each class per band analyzed for the fuzzy classification.

\begin{tabular}{|c|c|c|c|c|c|c|c|}
\hline \multirow{2}{*}{ Land cover class } & \multicolumn{6}{|c|}{ Mean Digital Number (per band) } & \multirow{2}{*}{ Texture } \\
\hline & 1 & 2 & 3 & 4 & 5 & 7 & \\
\hline Built-up & 90.2 & 41.1 & 39.8 & 82.9 & 87.9 & 39.8 & 6.1 \\
\hline Water & 40.4 & 17.3 & 14.3 & 44.8 & 31.0 & 10.5 & 5.5 \\
\hline Forest & 80.7 & 34.8 & 28.1 & 114.3 & 78.6 & 24.2 & 23.3 \\
\hline Grass & 86.6 & 39.7 & 35.7 & 110.2 & 100.5 & 39.0 & 18.6 \\
\hline Corn & 85.9 & 38.9 & 34.5 & 105.7 & 94.0 & 35.7 & 17.8 \\
\hline Soybean & 95.7 & 46.1 & 48.9 & 92.3 & 126.8 & 62.7 & 9.9 \\
\hline Cereal & 83.3 & 36.9 & 31.6 & 102.2 & 81.6 & 28.7 & 16.1 \\
\hline Mixed Vegetable & 94.9 & 45.7 & 48.4 & 89.9 & 127.3 & 63.0 & 8.6 \\
\hline
\end{tabular}

The geographic distribution of the fuzzy membership vales for each of the 8 land cover classes identified can be seen in Figure 7. High fuzzy membership values are indicated by black, while white represents low membership values. It is evident that the Built-up, Water, Forest, Soybean and Mixed Vegetable classes all have clear distinctions between high and low membership values. The Grass class (Figure 7d) shows a wide distribution of medium/low membership values. This is expected as this class not only incorporates hay and pasture areas, but wild grasses as well. The highest membership areas (which are easily distinguishable) correspond to the hay and pasture fields identified in the field. For the Corn class, (Figure 7e), there are a few areas with high membership values. These areas also correspond well with cornfields identified in the field. However, there appears to be a lot of speckling with low/medium membership values. 


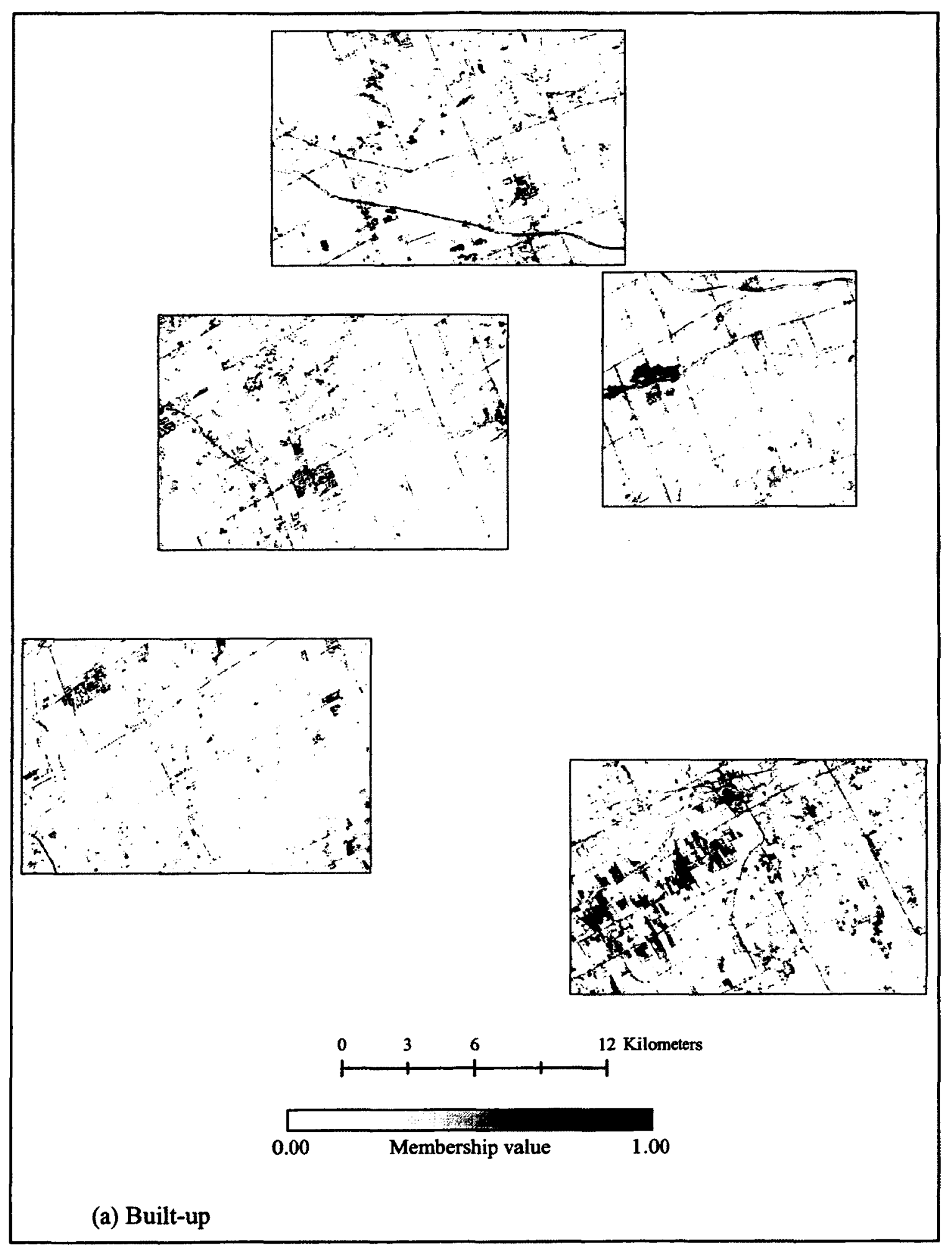

Figure 7. 


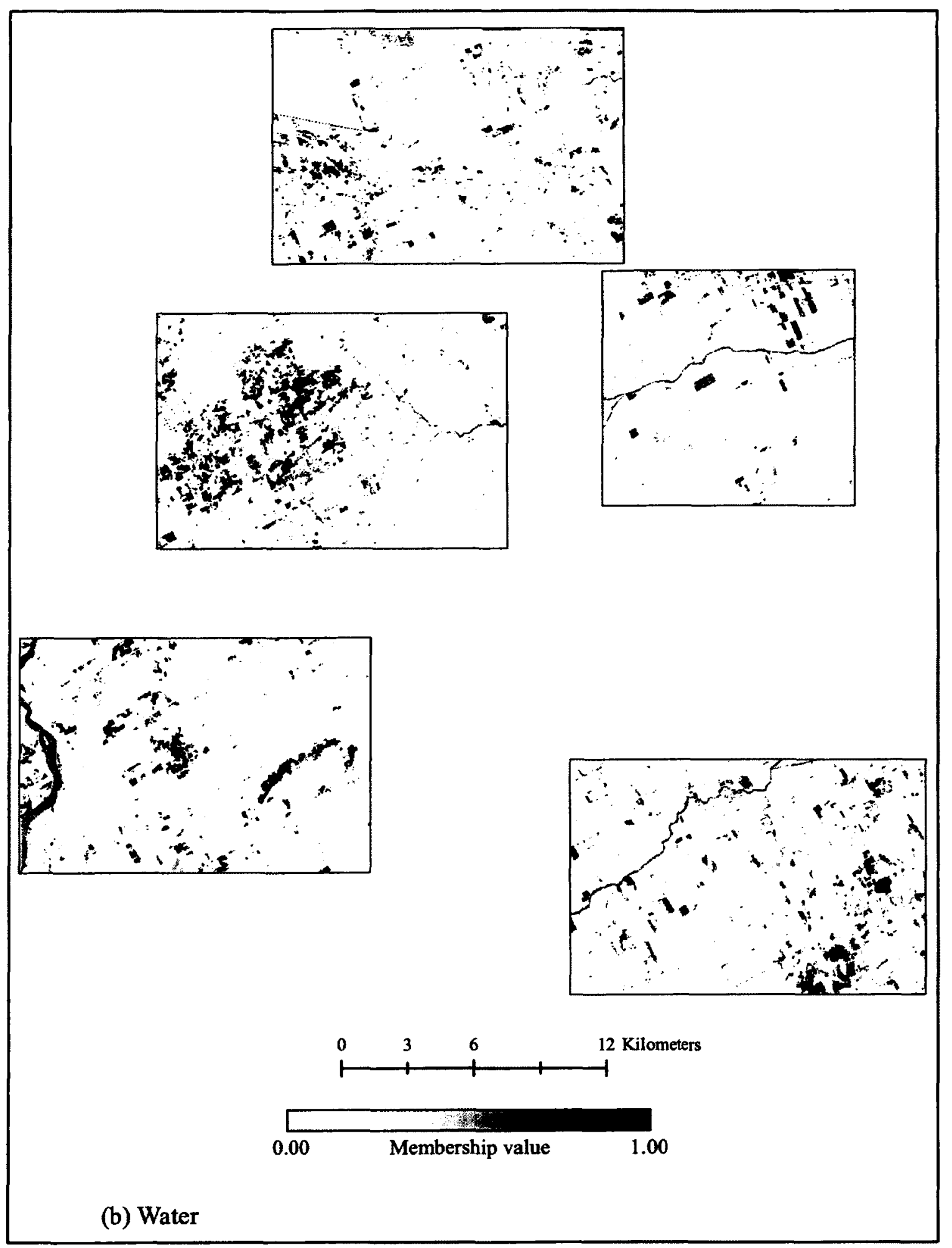

Figure 7. 


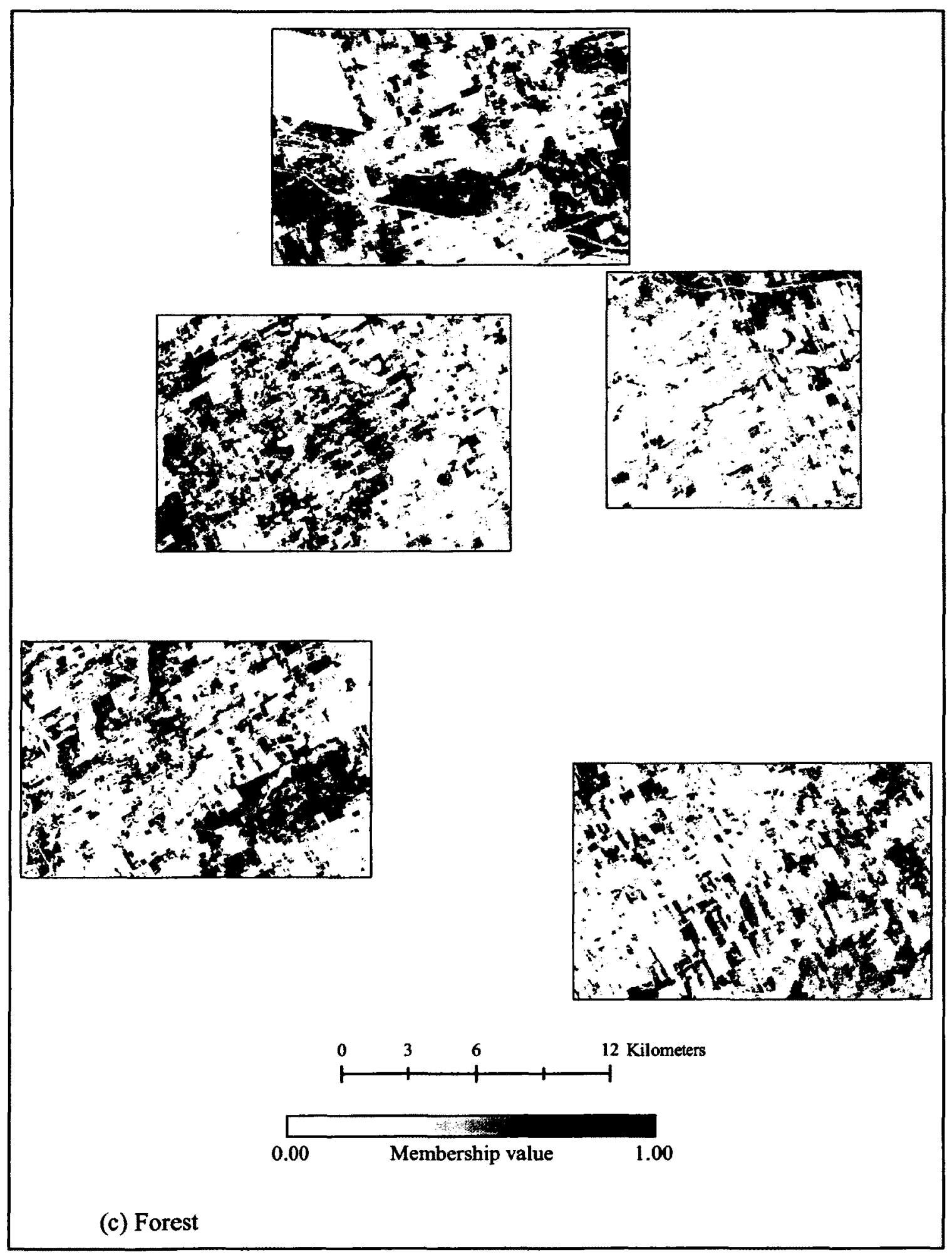

Figure 7. 


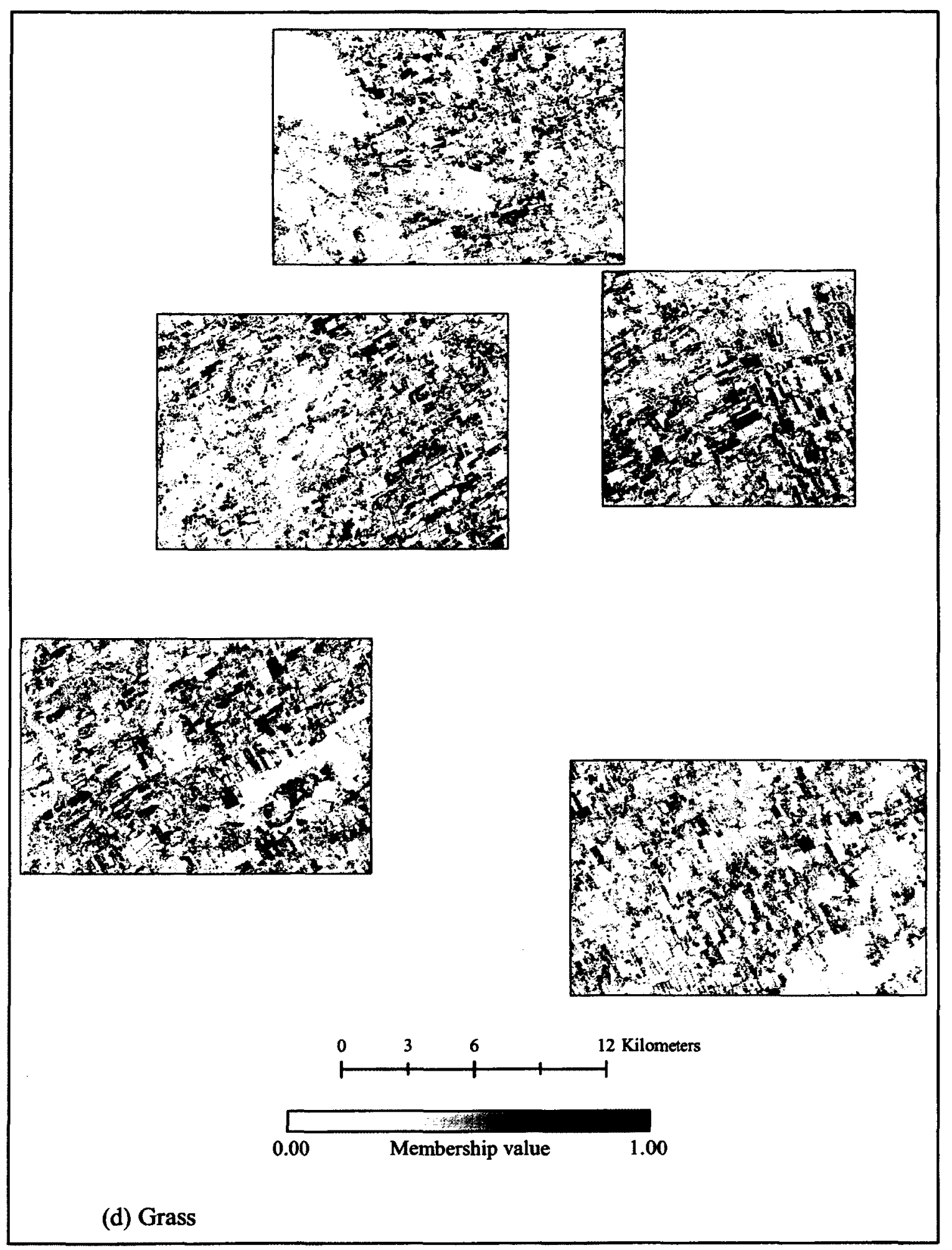

Figure 7. 


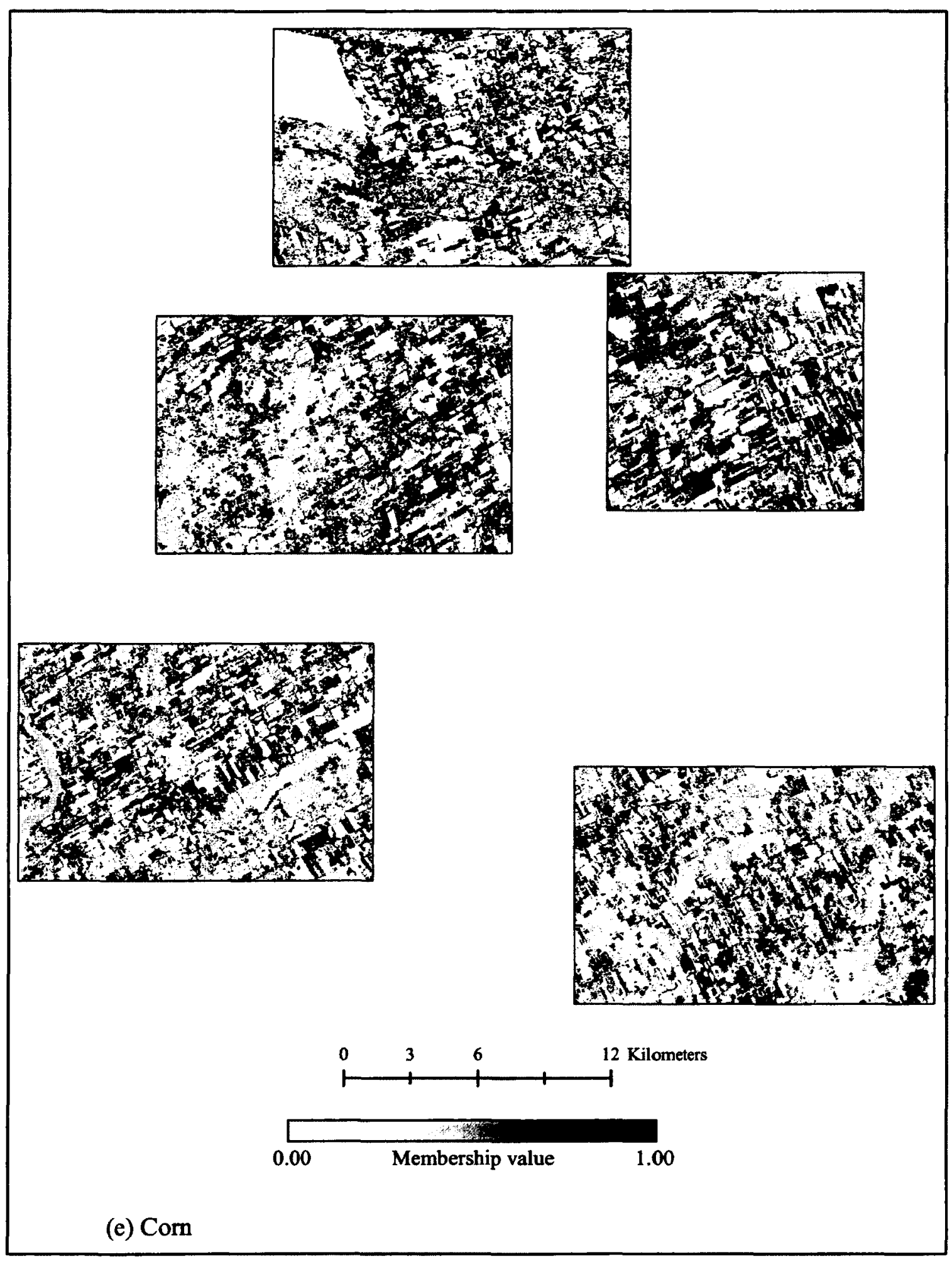

Figure 7. 


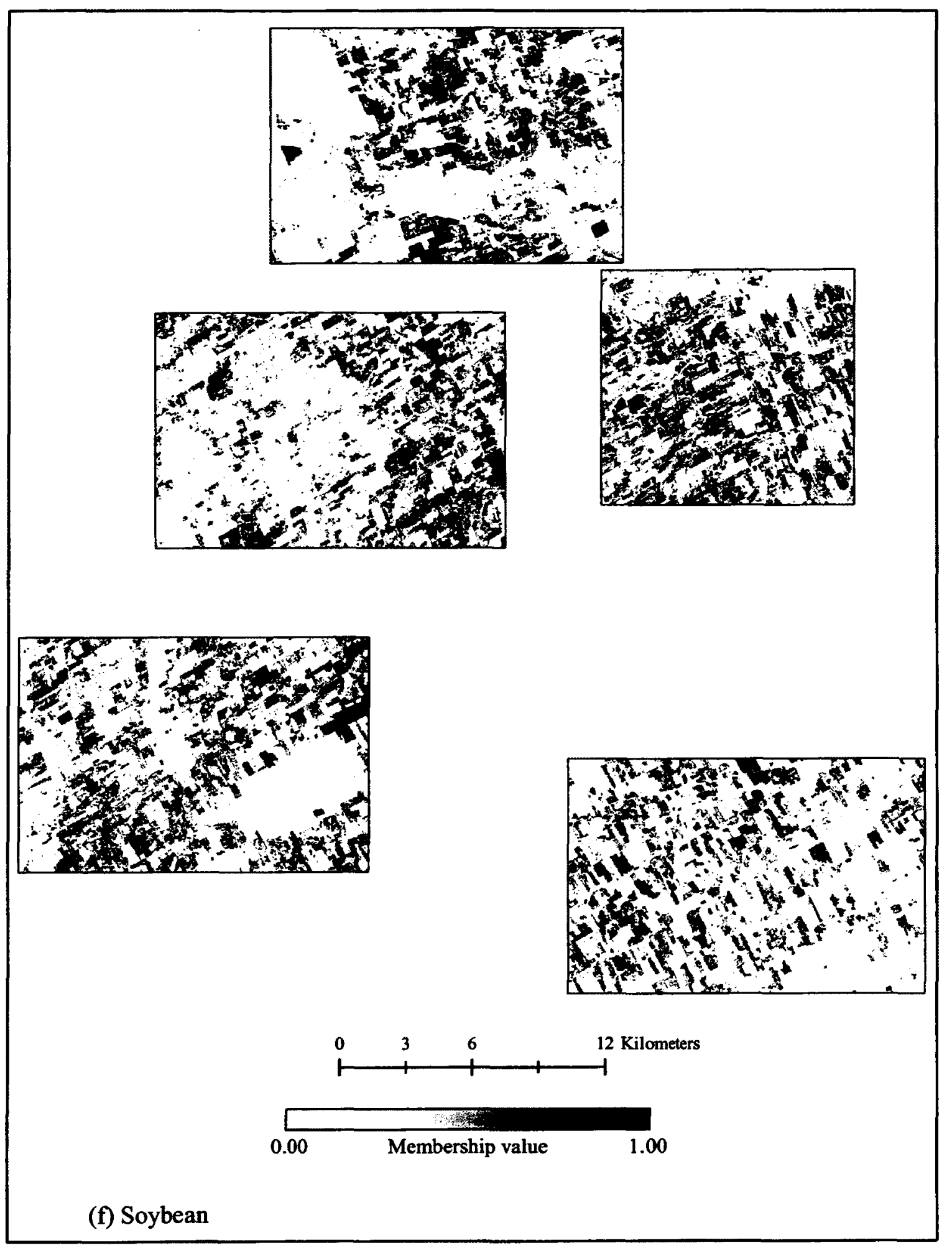

Figure 7. 


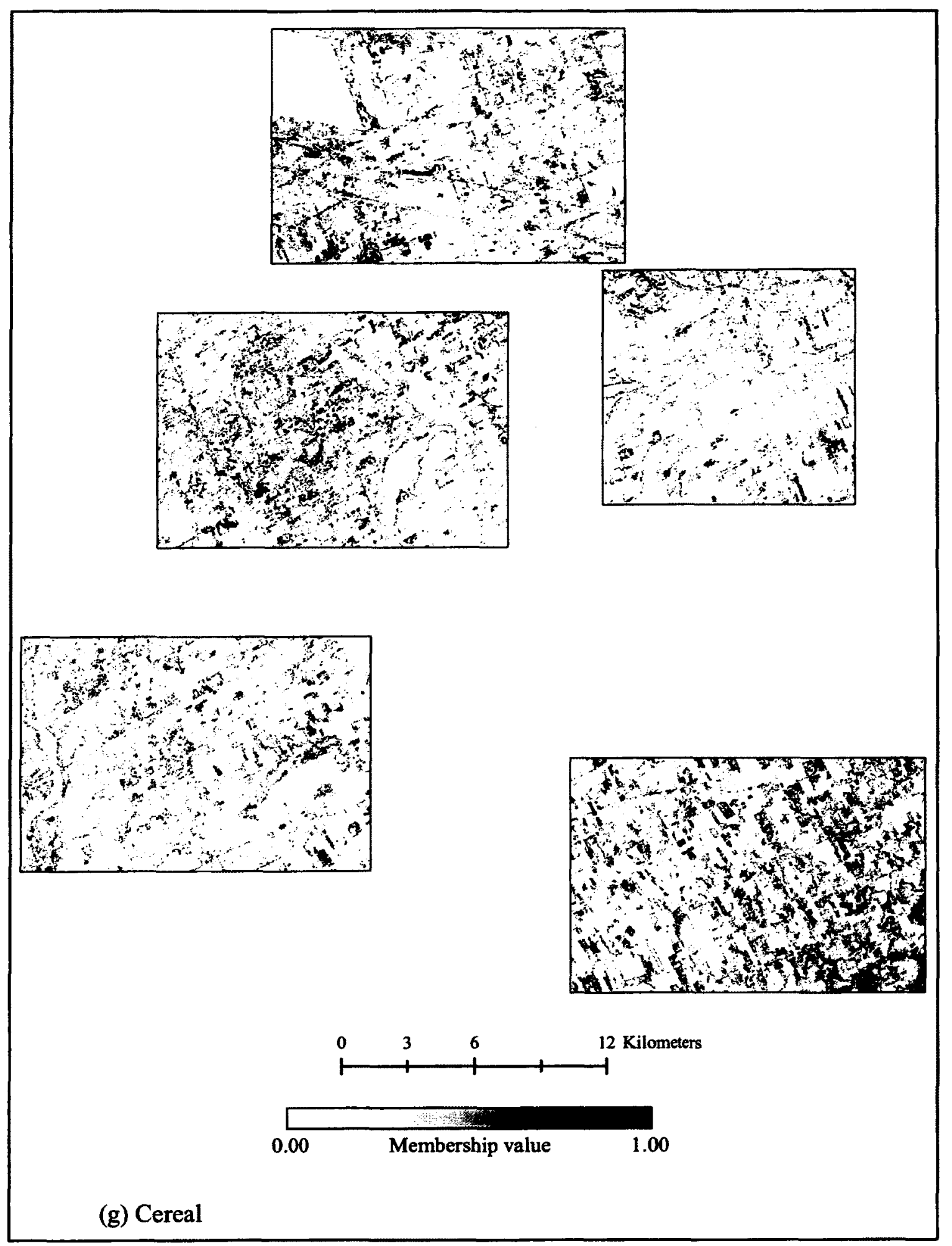

Figure 7. 


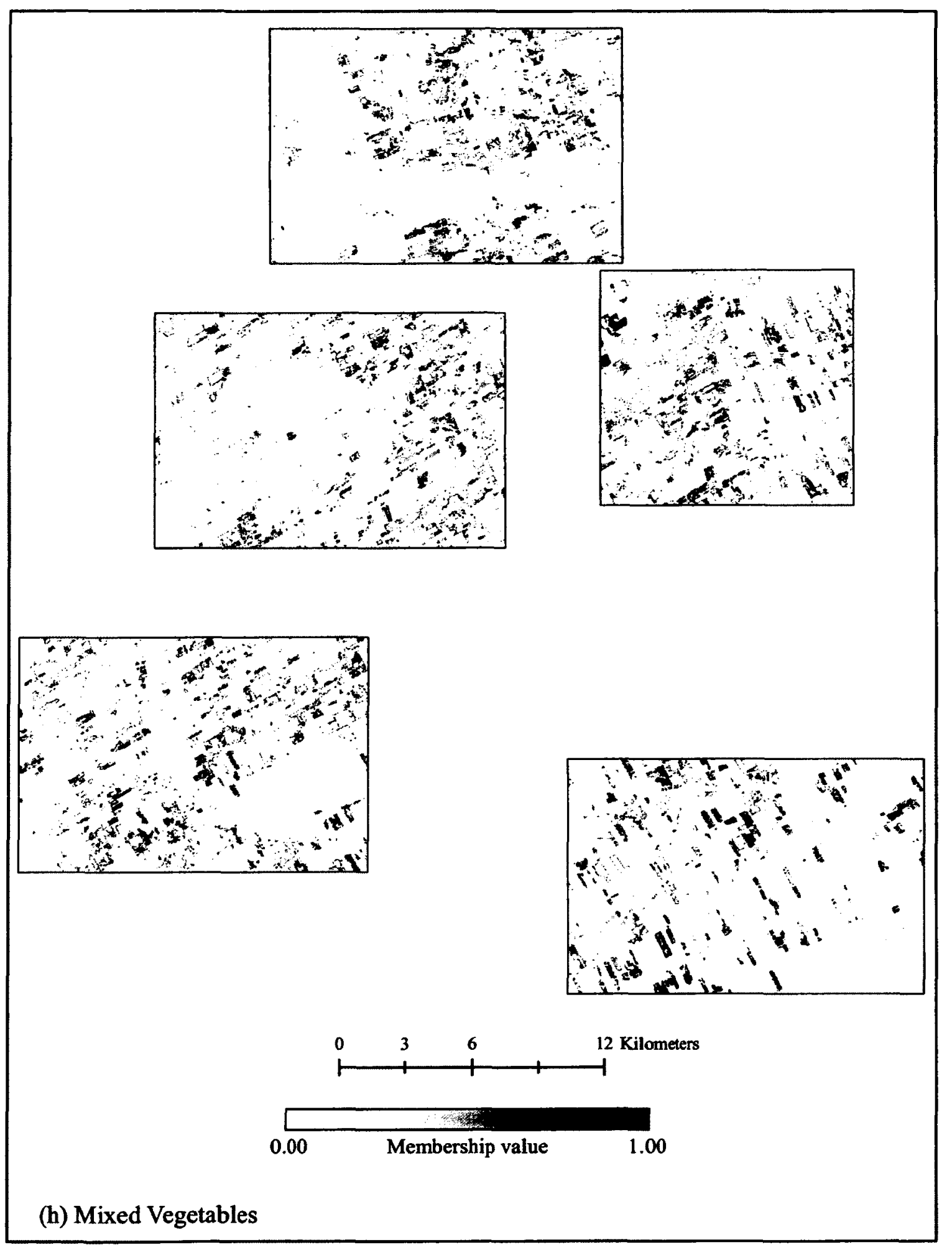

Figure 7. Images of the fuzzy membership values in each of the 8 land cover classes identified: (a) Built-up, (b) Water, (c) Forest, (d) Grass, (e) Corn, (f) Soybean, (g) Cereal and $(h)$ Mixed Vegetable. 
Vegetable clusters are best defined. These clusters (as well as the Grass cluster) all have bimodal frequency distributions for the fuzzy membership values. Overall, the majority of the pixels for each of the 8 classes have low membership values. For the nearly pure to pure pixels (i.e. pixels with memberships between 0.8 and 1.0), the percentage of pixels within each class is given in Table 12. In accordance with the results seen in Figure 6, Table 12 shows that the Forest class has the highest percent of pure pixels, while the Mixed Vegetable class has the lowest. Even with the 0.0-0.09 range removed from the analysis, the percentage of pixels for each class with high membership values is still very low, further indicating a high frequency of mixed pixels.

Table 11. Frequency of occurrence of fuzzy membership values in the 8 classes identified.

\begin{tabular}{lrrrrrrrrr}
\hline $\begin{array}{c}\text { Membership } \\
\text { Values }\end{array}$ & Built-up * & Water* & \multicolumn{1}{c}{ Forest* } & \multicolumn{1}{c}{ Grass* } & Corn & Soybean* & Cereal & $\begin{array}{c}\text { Mixed } \\
\text { Vegetable* }\end{array}$ \\
\cline { 2 - 9 }$y$ & 1839877 & 1807613 & 1386010 & 1224661 & 1312412 & 1377646 & 1571052 & 1852013 \\
\hline $0.0-0.09$ & 60930 & 39240 & 115929 & 319175 & 253740 & 125933 & 214512 & 52066 \\
$0.1-0.19$ & 31786 & 19584 & 58717 & 132565 & 122090 & 81322 & 72968 & 33678 \\
$0.2-0.29$ & 24035 & 22359 & 54065 & 82536 & 93696 & 76330 & 47332 & 25885 \\
$0.3-0.39$ & 19909 & 12321 & 50369 & 61849 & 74176 & 62951 & 36474 & 21794 \\
$0.4-0.49$ & 17681 & 10856 & 48530 & 50552 & 55443 & 58765 & 33461 & 18287 \\
$0.5-0.59$ & 16521 & 11097 & 51283 & 46000 & 47274 & 51771 & 27229 & 15359 \\
$0.6-0.69$ & 16245 & 15407 & 57115 & 44809 & 41395 & 51780 & 22784 & 14413 \\
$0.7-0.79$ & 18001 & 23388 & 75082 & 46717 & 37274 & 59290 & 20373 & 15338 \\
$0.8-0.89$ & 19467 & 102587 & 167352 & 55588 & 26952 & 118664 & 18267 & 15619 \\
$0.9-1.00$ & & & & & & & &
\end{tabular}

\footnotetext{
* = bimodal distribution
} 
Table 12. Percentage of pure pixels, defined by frequency of membership values greater than 0.8 , for each class.

\begin{tabular}{ccccccccc}
\cline { 2 - 7 } & \multicolumn{7}{c}{ Land Cover Class } \\
\cline { 2 - 8 } & Built-up & Water & Forest & Grass & Com & Soybean & Cereal & $\begin{array}{c}\text { Mixed } \\
\text { Vegetable }\end{array}$ \\
\hline $\begin{array}{c}\text { Percentage of } \\
\text { pure pixels }\end{array}$ & $1.81 \%$ & $6.10 \%$ & $11.74 \%$ & $4.96 \%$ & $3.11 \%$ & $8.62 \%$ & $1.87 \%$ & $1.50 \%$ \\
\hline
\end{tabular}

\subsection{Accuracy Assessments}

The histograms shown in Figure 8 depict the frequency of occurrence of each class for each classification method used, in comparison to the ground reference data. The histograms are essentially a visual representation of the error matrix (Appendix III). The validation data was used and the frequency with which the reference data matched the classified data was presented. Due to the fact that these types of accuracy assessments can only be performed on 'hard' data, the fuzzy result that is used here and for the error matrix is the hardened fuzzy classification result, Fuzzyl. The black bars represent the class that should be displaying the highest frequency. For Built-up, Water, and Forest classes, the Fuzzy classification out-performed the Landsat MLC. The reference Built-up class was often classified as Grass and Mixed Vegetable, Water was often classified as the Built-up class, and the reference class for Forest was often classified as Corn for the Landsat MLC results.

In the hardened fuzzy classification the Cereal class was frequently classified as the Forest class. In addition, none of the classification methods preformed particularly well for the Mixed Vegetable class - it was often classified as Grass, Soybean and Cereal classes. However, this was expected due to the wide range of vegetables that this class 
incorporates. As well, since many of the mixed vegetable fields are quite small or straddle other fields, they only take up a small portion of a Landsat pixel.

The kappa statistic and overall accuracy for each classification method were obtained. As expected, based on the validation data, the overall accuracy and overall kappa values for the Quickbird MLC are the highest, being $76.21 \%$ and 0.673 , respectively. The Landsat MLC had an overall accuracy of $61.85 \%$ and an overall kappa value of 0.478 . The hardened fuzzy classification overall accuracy was only $32.91 \%$ and the overall kappa value was 0.146 . However, since most of the detail and information obtained from the fuzzy classification is lost when applying a hardening procedure that is based solely on the highest membership values, these accuracy statistics are not a representative measure of the fuzzy classification. Therefore, mean normalized entropy is more appropriate to assess the fuzzy results.

As seen in Table 13, the normalized entropy has a mean of 0.4023 with a standard deviation of 0.2076 (i.e. $95 \%$ of the values lie on the interval of $[0.00,0.8175]$ ). This indicates that the normalized entropy is highly variable across this landscape, with some areas displaying an abundance of pure pixels, while others are dominated by mixed pixels.

Table 13. Statistics for the normalized entropy values for the fuzzy membership values.

\begin{tabular}{ccccc}
\hline & Min & Max & Mean & $\begin{array}{c}\text { Standard } \\
\text { Deviation }\end{array}$ \\
\hline Normalized entropy & 0.0000 & 0.9668 & 0.4023 & 0.2076 \\
\hline
\end{tabular}


Fuzzy 1

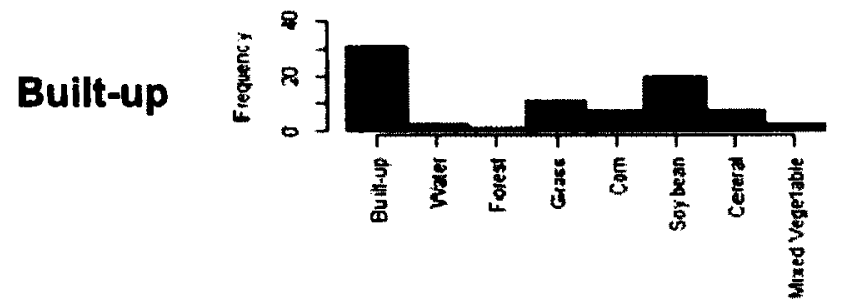

Water

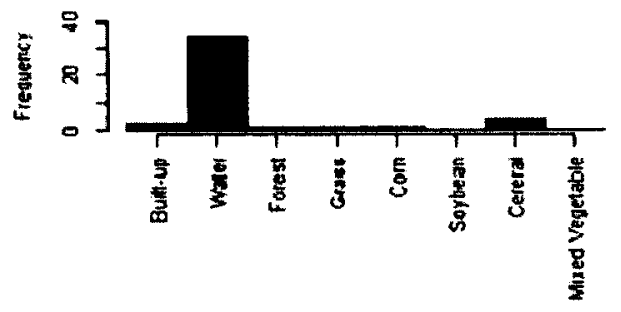

Forest

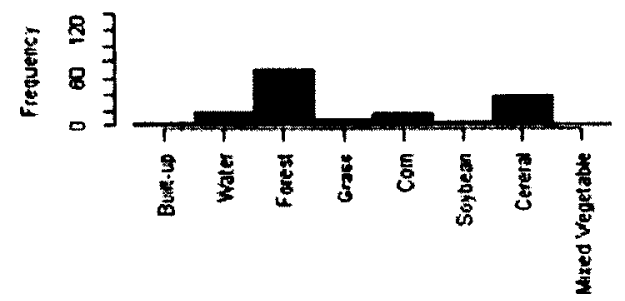

Grass

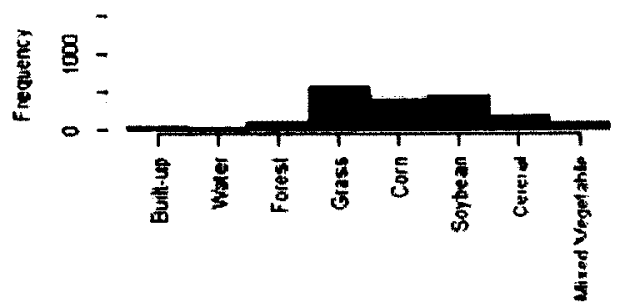

Landsat MLC
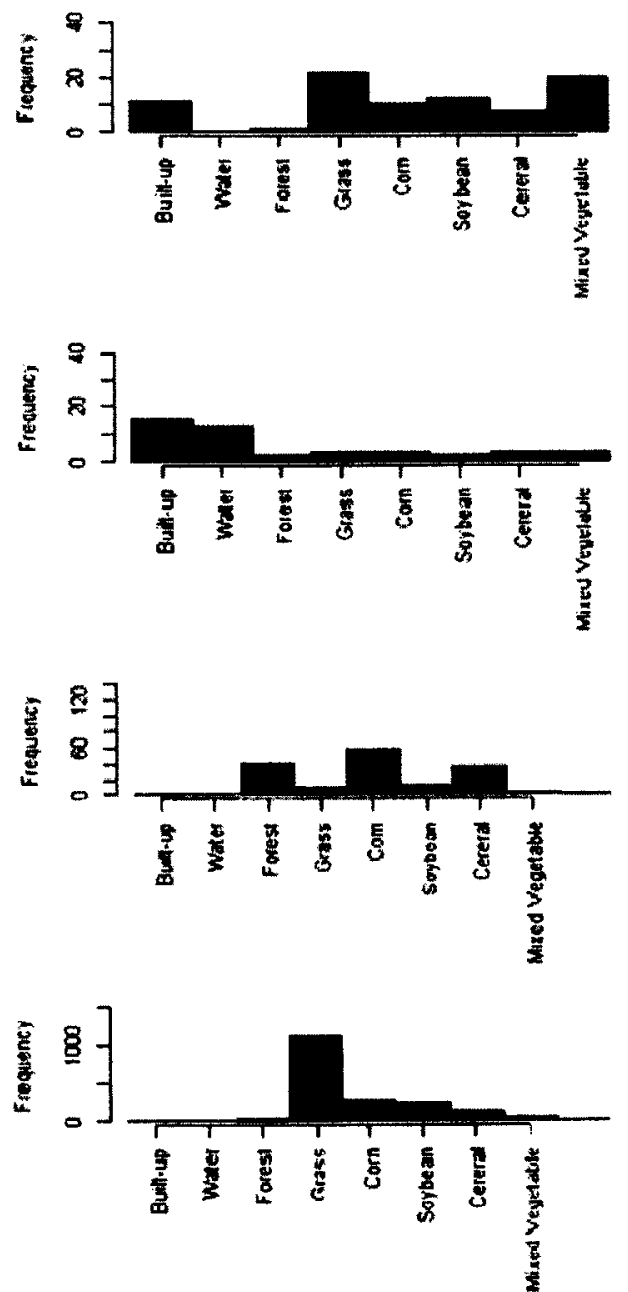

Quickbird MLC
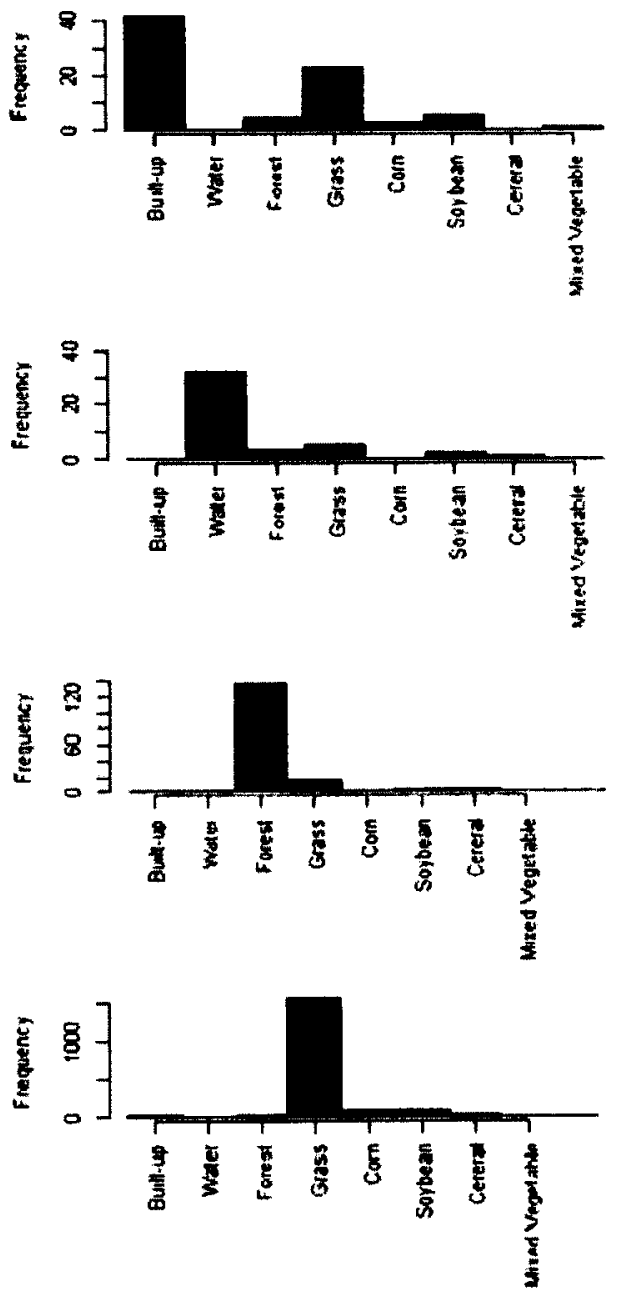

Figure 8. The frequency of occurrence of each class for each classification method used, in comparison to the ground data. 
Fuzzy 1
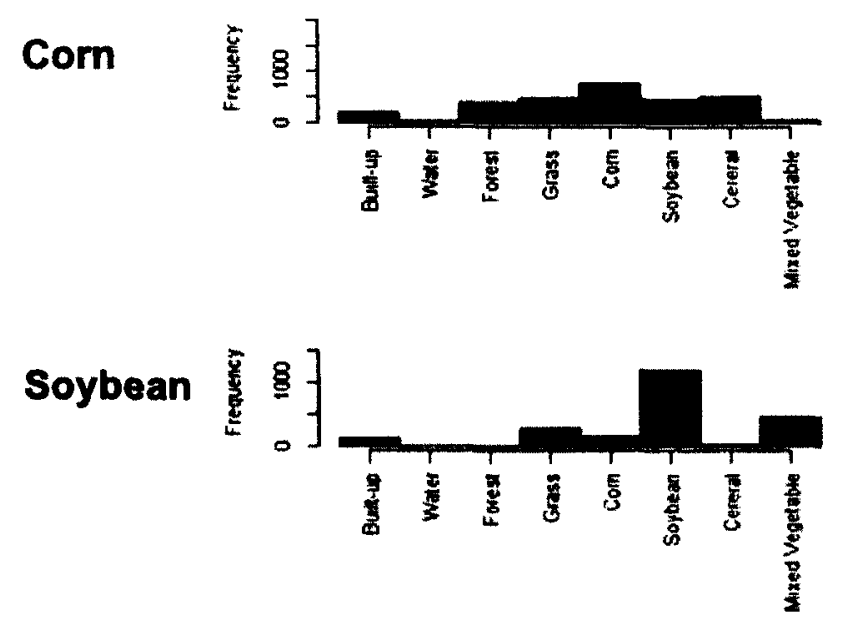

Cereal
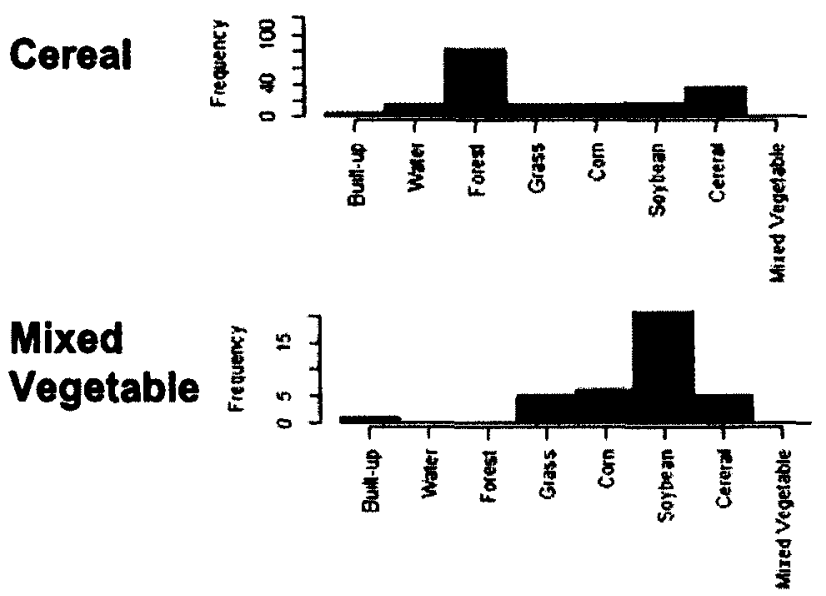

Landsat MLC
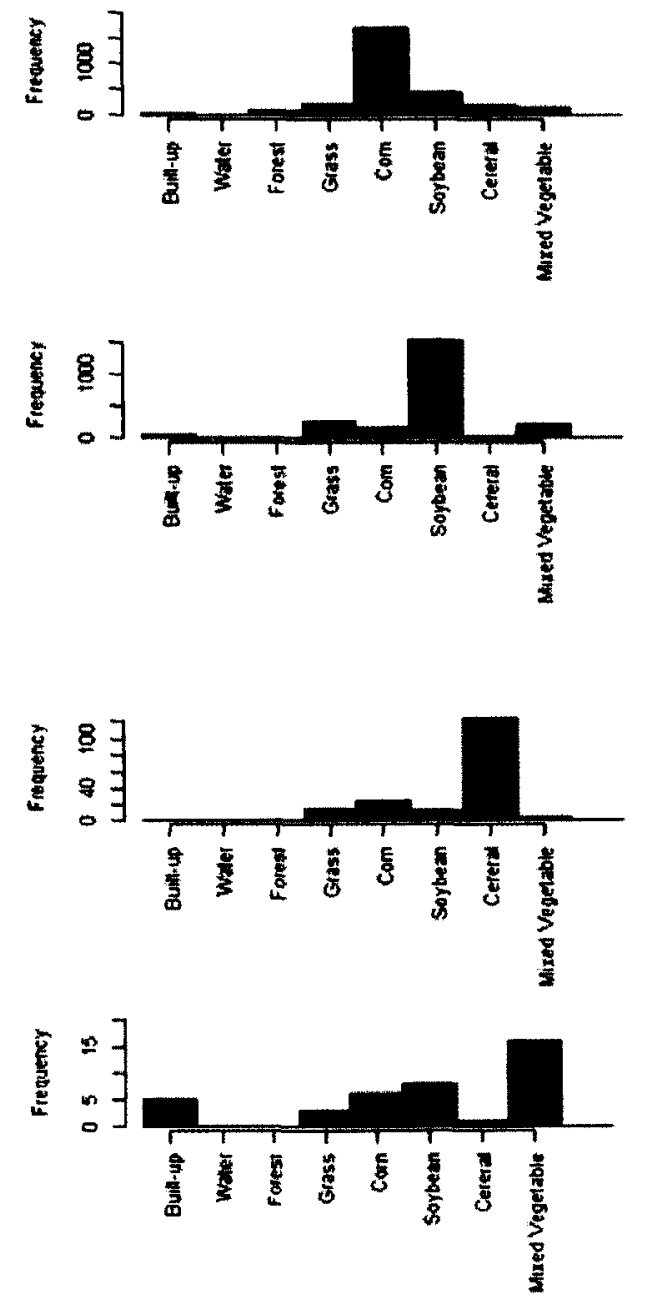

Quickbird MLC
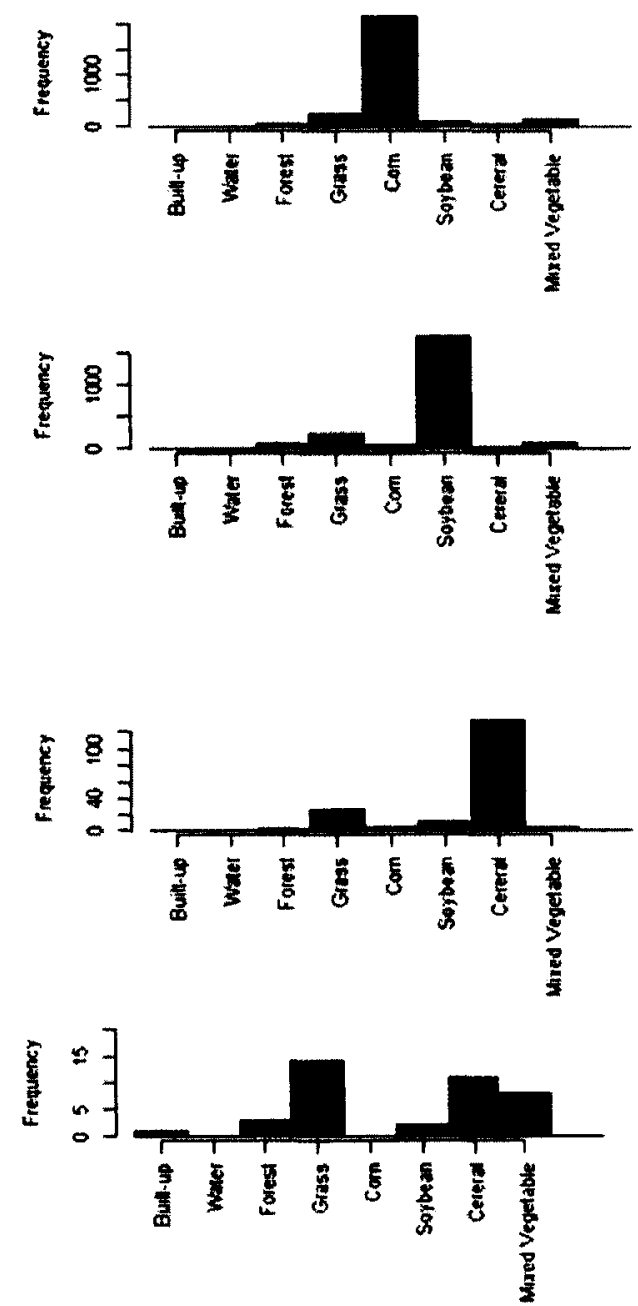

Figure 8 (cont.). The frequency of occurrence of each class for each classification method used, in comparison to the ground data. 
Figure 9 shows the distribution of the normalized entropy for the fuzzy membership values for Scene 2. The results from the other 4 scenes were very similar and can be found in Appendix II (Figure II-A, Figure II-B, Figure II-C and Figure II-D). This image, Figure 9, allows for a spatial distribution of the partitioning of class membership values between the classes to be assessed. Upon first inspection, it appears that crop fields have the lowest normalized entropy values (represented in black) indicating purer classes, whereas the Water and Built-up classes have much higher normalized entropy values (represented in white), indicating less pure classes. Figures 10 and 11 show the normalized entropy values for a subset of a predominantly built-up area and a predominantly cropland area, respectively. It is clear from Figure 10 that in regions that should be classified as Built-up, the fuzzy membership values are more ambiguous and that no one class clearly dominates. Of course, due to the fact that roads and residential buildings tend to only take up a portion of a Landsat pixel, the fact that the normalized entropy values are high in these types of areas is not surprising. Figures 10 and 11 also show very high normalized entropy values for the areas where water is present. The cropland areas, on the other hand, show much lower entropy values. The soybean fields seen in Figure 11 indicate a strong presence of a dominant class. The field edges are easily identifiable as they cut through the soybean field with their slightly higher entropy values. The distribution of wild grasses, lawns, trees and bushes in the remaining portion of Figure 11 results in higher entropy values for these areas. 


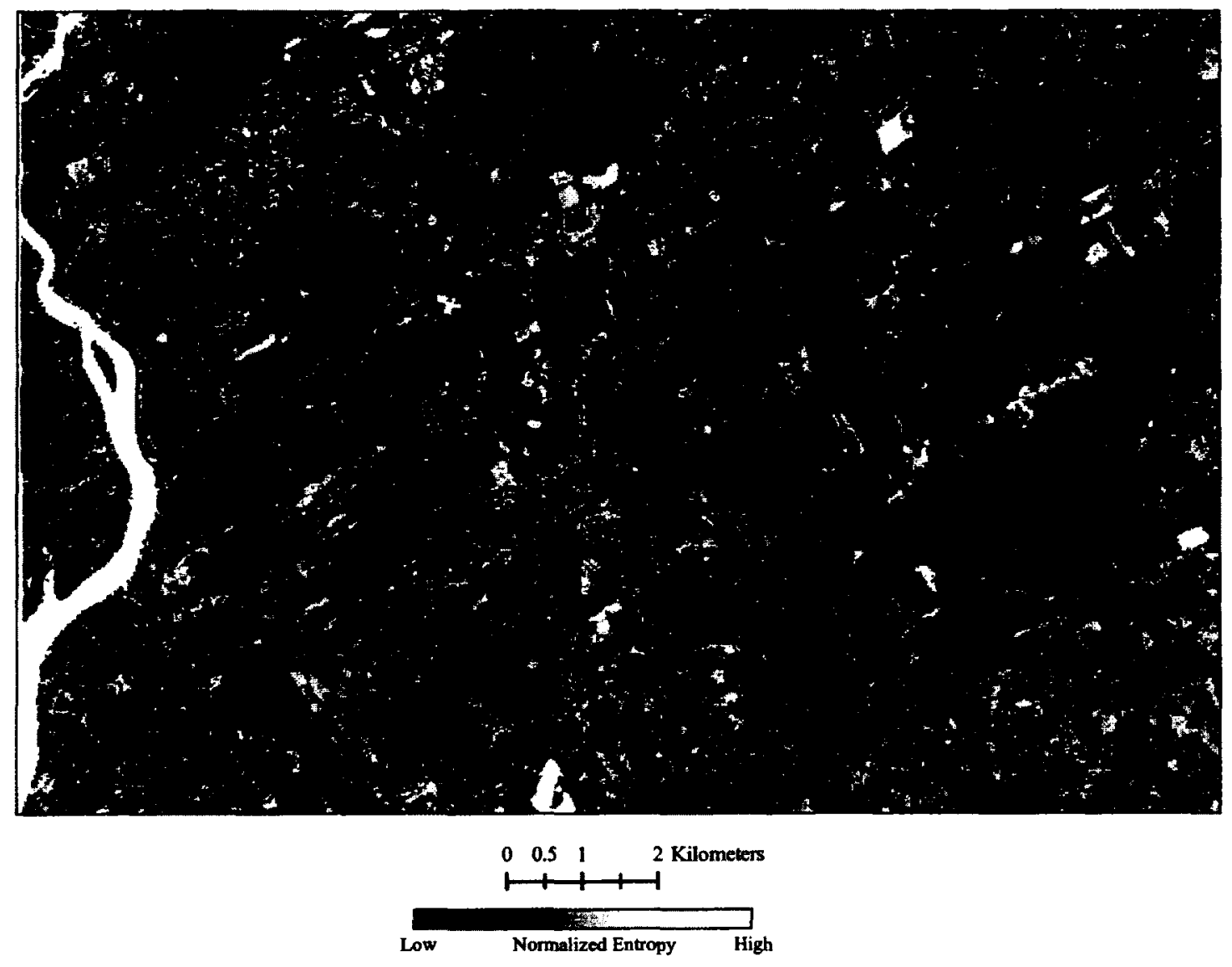

Figure 9. Distribution of the normalized entropy for the fuzzy membership values for Scene 2 


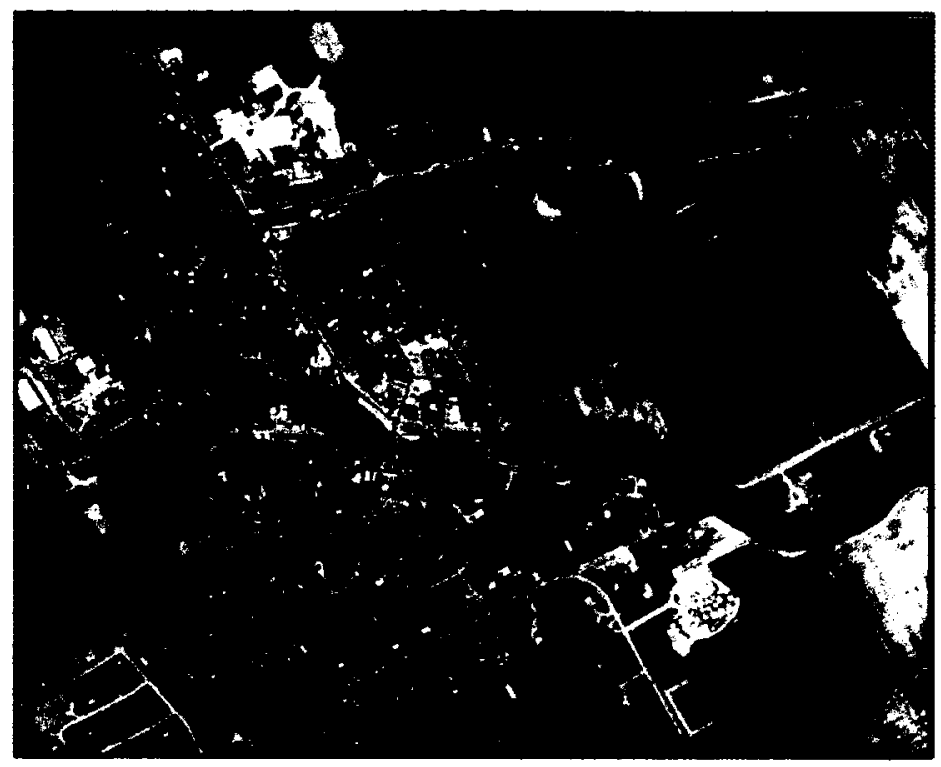

(a) Aerial photograph

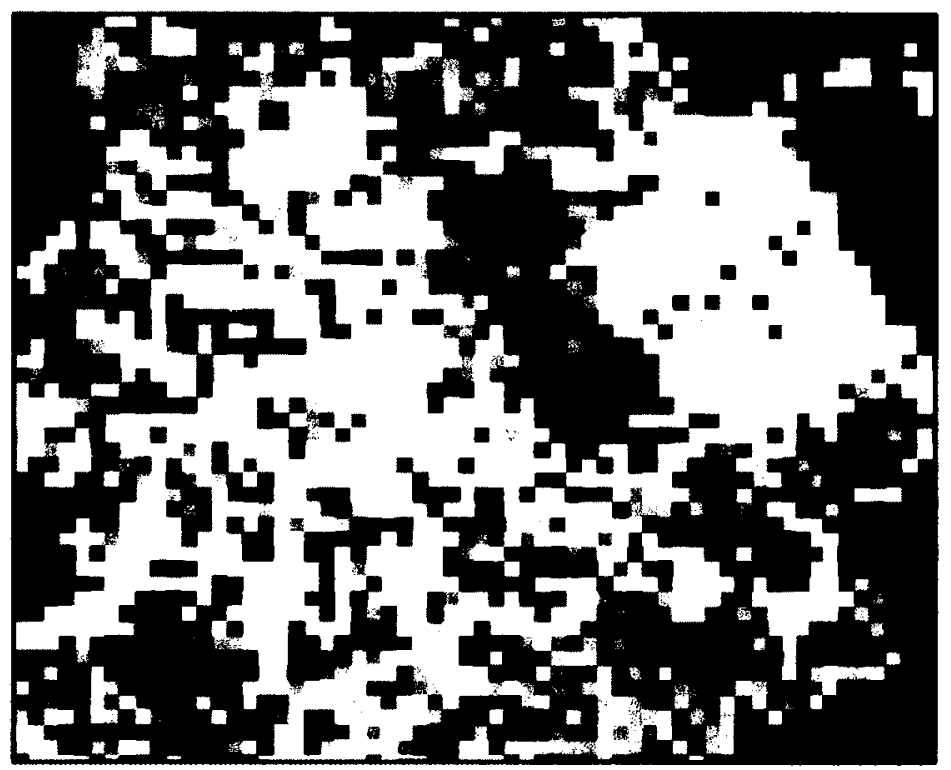

(b) Normalized entropy

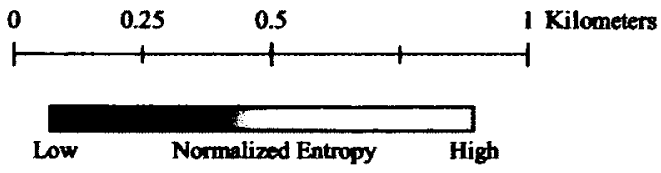

Figure 10. Close up distribution of the normalized entropy for a Built-up area. 


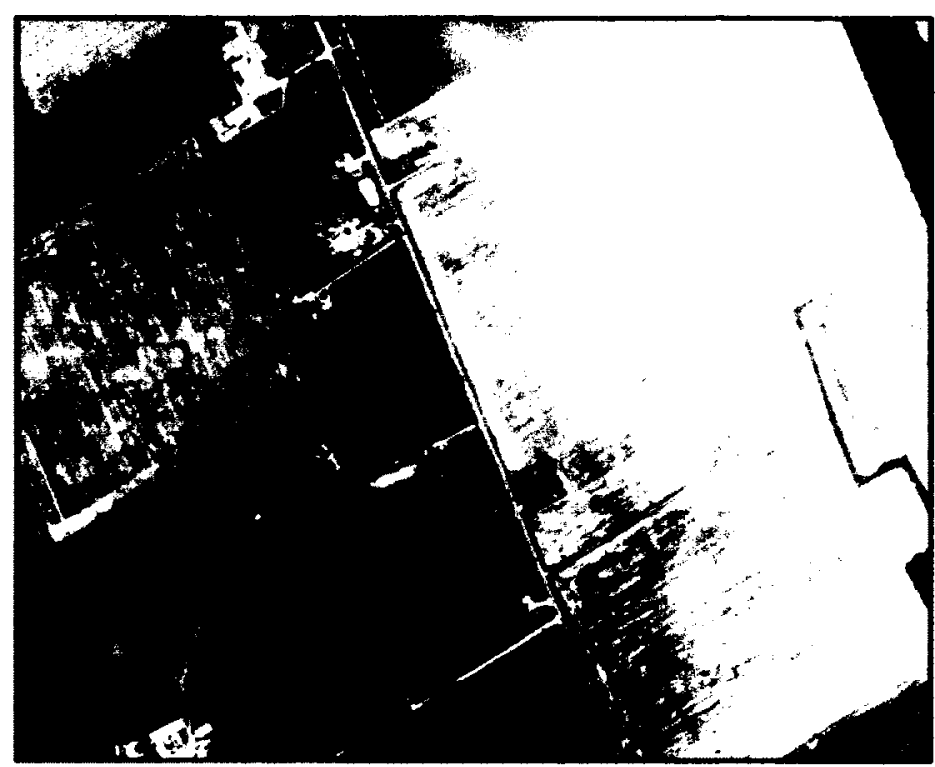

(a) Aerial photograph

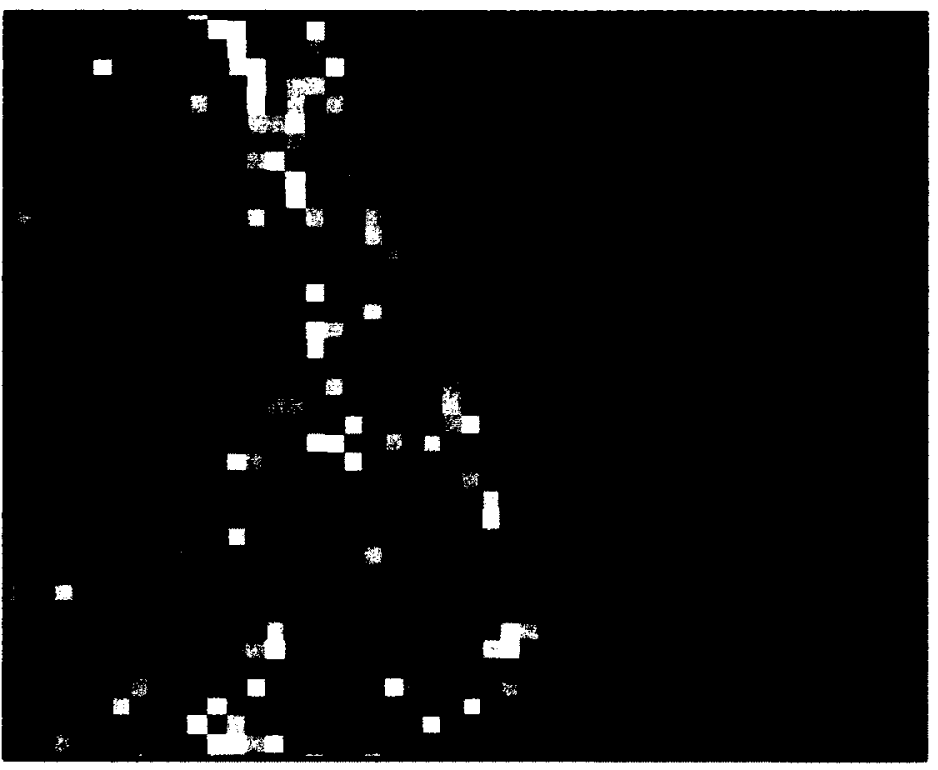

(b) Normalized entropy

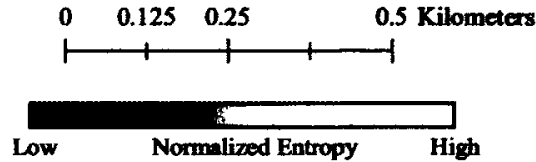

Figure 11. Close up distribution of the normalized entropy for a cropland area 


\subsubsection{Percent Agreement}

An assessment of the agreement between the Quickbird MLC and the other classified maps was conducted. It was found that the Landsat MLC values agreed with the Quickbird MLC values $39.5 \%$ of the time, whereas the Fuzzy1 map (the map with the highest fuzzy membership values) only agreed $30.31 \%$ of the time with the results of the Quickbird MLC. The results of the 'softened' agreement analysis between the highest or second highest membership values (Fuzzy1 or Fuzzy2) and the Quickbird MLC show a much higher degree of agreement, $52.91 \%$. This represents a $22.6 \%$ increase in agreement compared to the Fuzzy1 image and a $13.4 \%$ increase compared to the Landsat MLC. In addition, when looking at the distribution of the agreements for Scene 2 (Figure 12), it is clear that there is the smallest degree of disagreement in the soft hardened method. By taking into account the most likely and second most likely class memberships, a substantial increase in classification accuracy is seen.

Figure 13 shows a subset of the study area. For the most part, there is strong agreement between the Quickbird MLC and both the Landsat MLC and the Soft hardened fuzzy images. The majority of the disagreement for the Landsat MLC subset is occurring along the field edges and in areas of transition. This is not surprising, since these are the locations where the presence of mixed pixels is abundant. While similar results are seen in the soft hardened fuzzy subset, the disagreement exists to a lesser extent.

Table 14 presents a summary of the overall accuracy and kappa values, mean and standard deviation of the normalized entropy, and the overall percentage of agreement. 


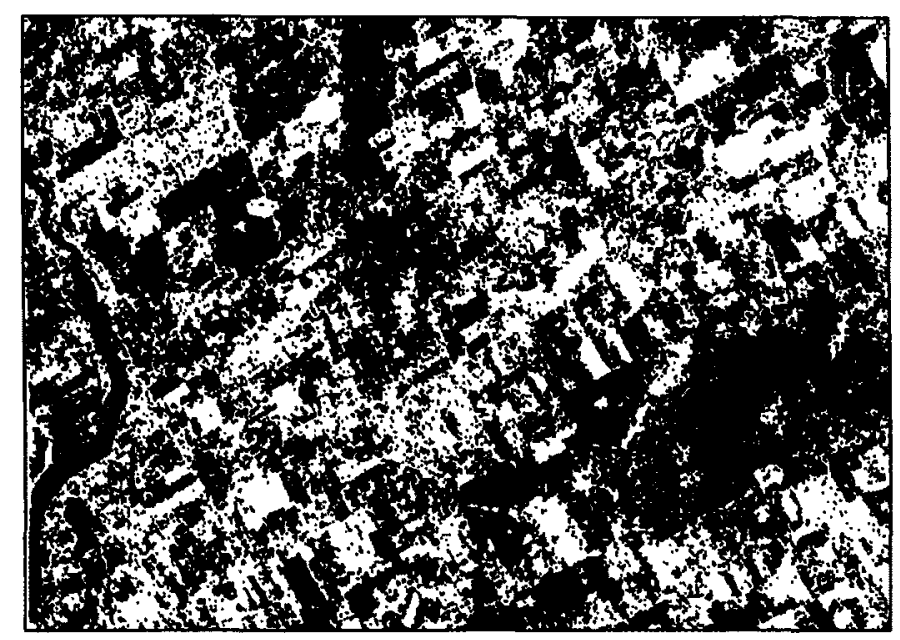

(a) Quickbird MLC and Landsat MLC

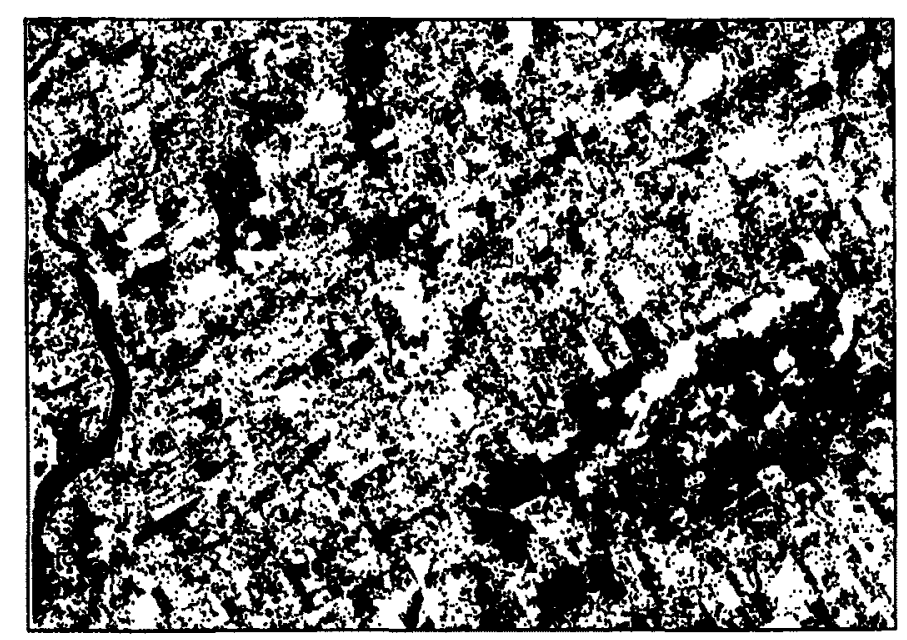

(b) Quickbird MLC and Fuzzyl
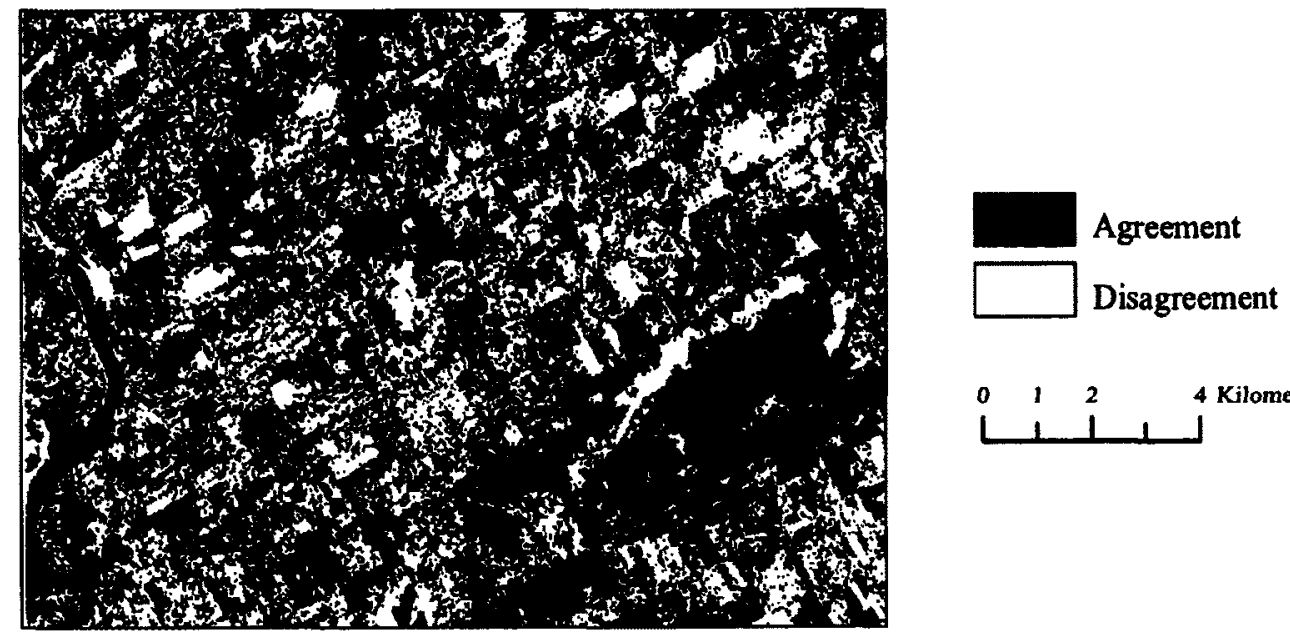

(c) Quickbird MLC and the soft hardened fuzzy

Figure 12. A subset of the study area showing the distribution of agreement between (a) Quickbird MLC and Landsat MLC, (b) Quickbird MLC and FuzzyI and (c) Quickbird MLC and the soft hardened fuzzy. 
Table 14. Summary statistics for the classified maps.

\begin{tabular}{|c|c|c|c|c|c|}
\hline & $\begin{array}{l}\text { Quickbird } \\
\text { MLC }\end{array}$ & $\begin{array}{l}\text { Landsat } \\
\text { MLC }\end{array}$ & Fuzzy1 & Fuzzy2 & $\begin{array}{l}\text { Soft hardened } \\
\text { fuzzy }\end{array}$ \\
\hline Overall Accuracy & $76.21 \%$ & $61.85 \%$ & $32.91 \%$ & -- & -- \\
\hline Overall Kappa & 0.673 & 0.478 & 0.146 & -- & - \\
\hline Entropy (mean) & - & -- & \multirow{2}{*}{\multicolumn{3}{|c|}{$\begin{array}{l}0.4023 \\
0.2076\end{array}$}} \\
\hline Entropy (std. dev.) & - & - & & & \\
\hline $\begin{array}{c}\text { Agreement } \\
\text { (with Quickbird MLC) }\end{array}$ & - & $39.50 \%$ & $30.31 \%$ & -- & $52.91 \%$ \\
\hline
\end{tabular}

\subsection{Selected Areas}

Figure 14 displays the aerial photograph, the Quickbird and Landsat MLCs and the Fuzzy 1 and Fuzzy 2 maps for a residential area. The Quickbird MLC is classified as predominantly Grass, with some Built-up areas as well. There are also some Soybean pixels erroneously classified throughout. Looking at the Landsat MLC scene, there are no Built-up areas seen at all. In fact, the Built-up class is being significantly confused with the Grass and Corn classes, as was also seen in the histograms in Figure 8.

On the other hand, looking at both Fuzzy images, it is clear that there is a Built-up area in this scene. This is clearly seen in the Fuzzyl image (which depicts the highest fuzzy membership values). For the second highest membership values, depicted in Fuzzy2, there is a significant amount of grass present. This corresponds well with the results from the Quickbird MLC. As well, the black pixels in the Fuzzy2 scene indicate that these pixels did not meet the minimum threshold value of 0.1 . This means that those pixels are not mixed pixels and that they are, for this case, at least close to $100 \%$ Built-up. The remaining pixels, in fact the majority of the pixels within this scene, are mixed pixels. 


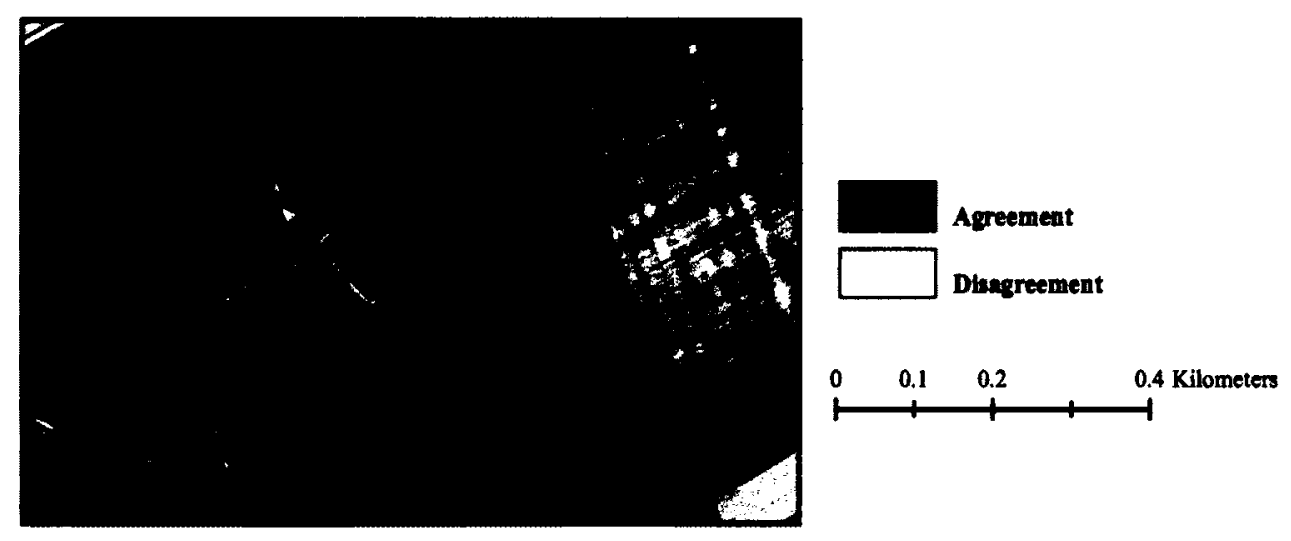

(a) Aerial photograph

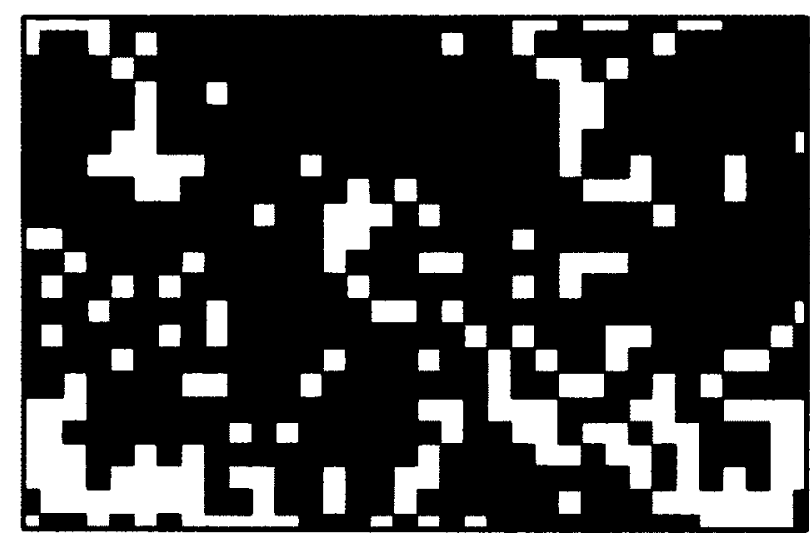

(b) Landsat MLC

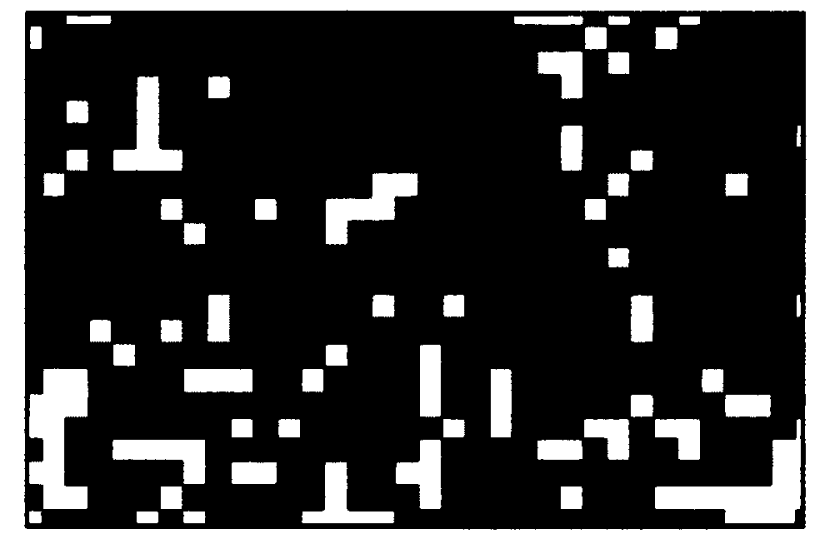

(c) Soft hardened fuzzy

Figure 13. (a) Aerial photograph and distribution of agreement between (b) Quickbird MLC and Landsat MLC and (c) Quickbird MLC and the soft hardened fuzzy for a subset of the study area that highlights areas of transition and field edges. 


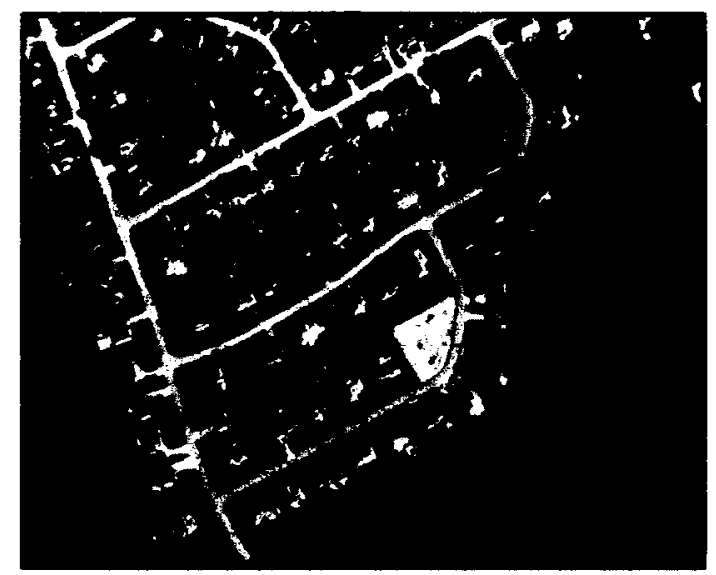

(a) Aerial photograph

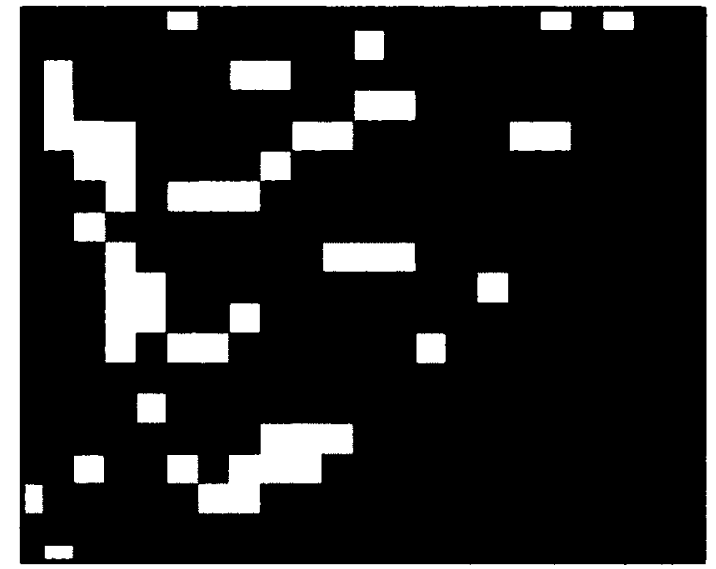

(c) Landsat MLC

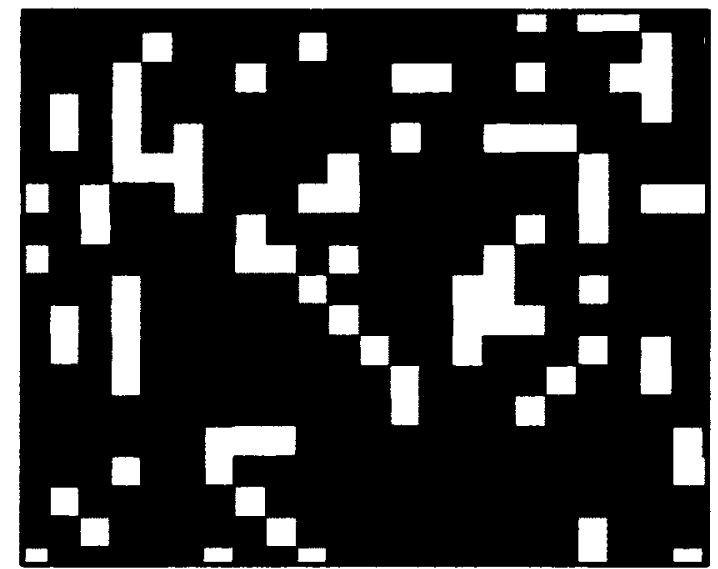

(e) Fuzzy2

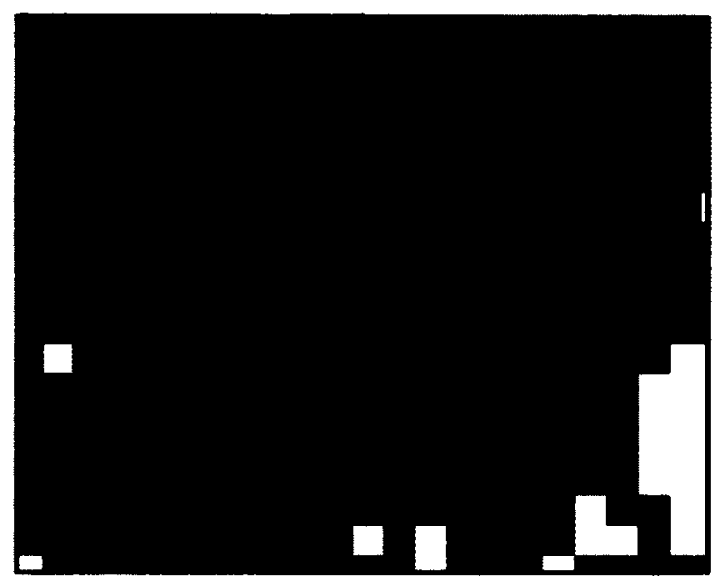

(b) Quickbird MLC

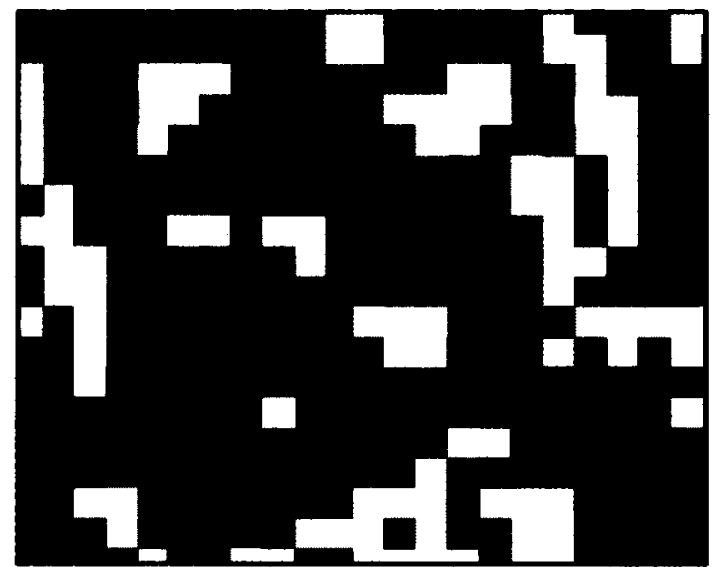

(d) Fuzzy1
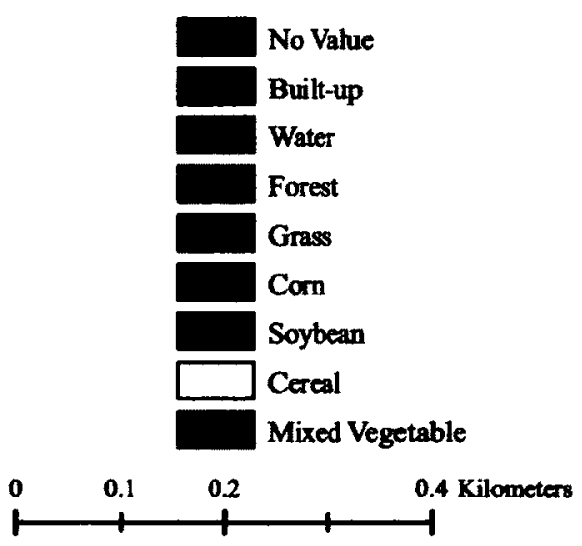

Figure 14. Sub-set of a residential area showing the aerial photograph, the Quickbird and Landsat MLC's, and the Fuzzyl and Fuzzy2 images. 
A sub-section of a cropland area is depicted in Figure 15. Due to fluctuations in the weather conditions during the 2011 growing season, there were many problems with corn, and as a result, many of the cornfields were patchy and had significant amounts of grass in them. This is clearly seen in the Quickbird MLC map, where the Corn field at $A$ is classified as with Corn (pink) and Grass (light green). In fact, for the Quickbird MLC map, the majority of that field is classified as Grass. The Landsat MLC, however, classified the entire field as Corn and there is no indication that the Grass class is present. In the Fuzzy maps, this field is predominantly classified as Corn, but many of the second highest memberships are Grass.

Another interesting aspect about this scene is the presence of field edges. From the aerial photo it is clear that all of the fields have grass and tree-lined edges. This is also clear in the Quickbird MLC. In the Landsat MLC however, there is no indication that the soybean fields are in fact 3 separate and distinct fields (as indicated by $B 1, B 2$ and $B 3$ ). In the Fuzzy images, these edges are clearly displayed. Although these pixels are unfortunately being classified as Mixed Vegetable, they still show that not only are those specific pixels mixed, but they also have different spectral characteristics from their neighbouring pixels. 

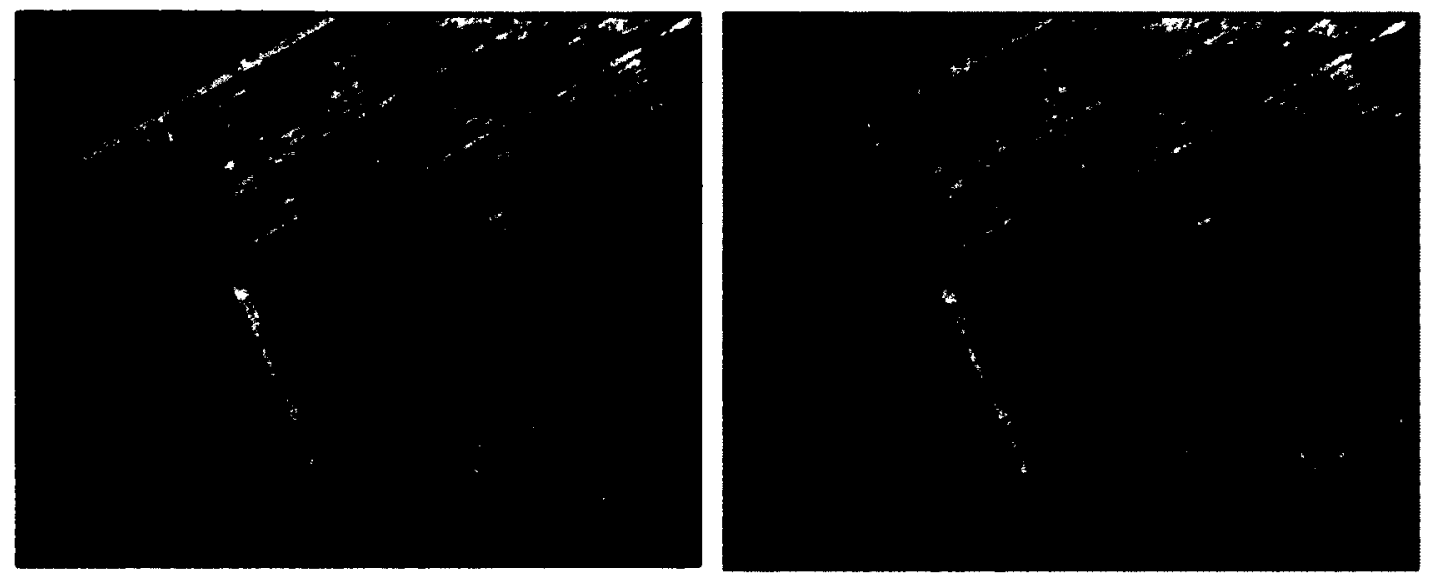

(a) Aerial photograph

(b) Quickbird MLC
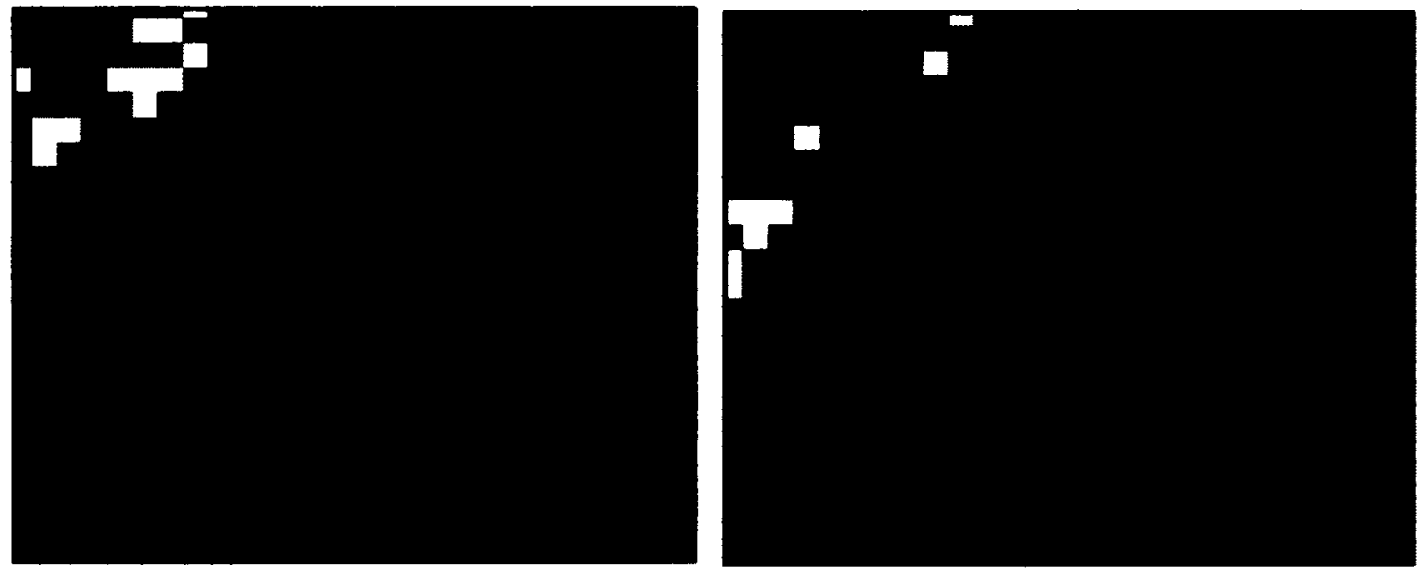

(c) Landsat MLC

(d) Fuzzy1
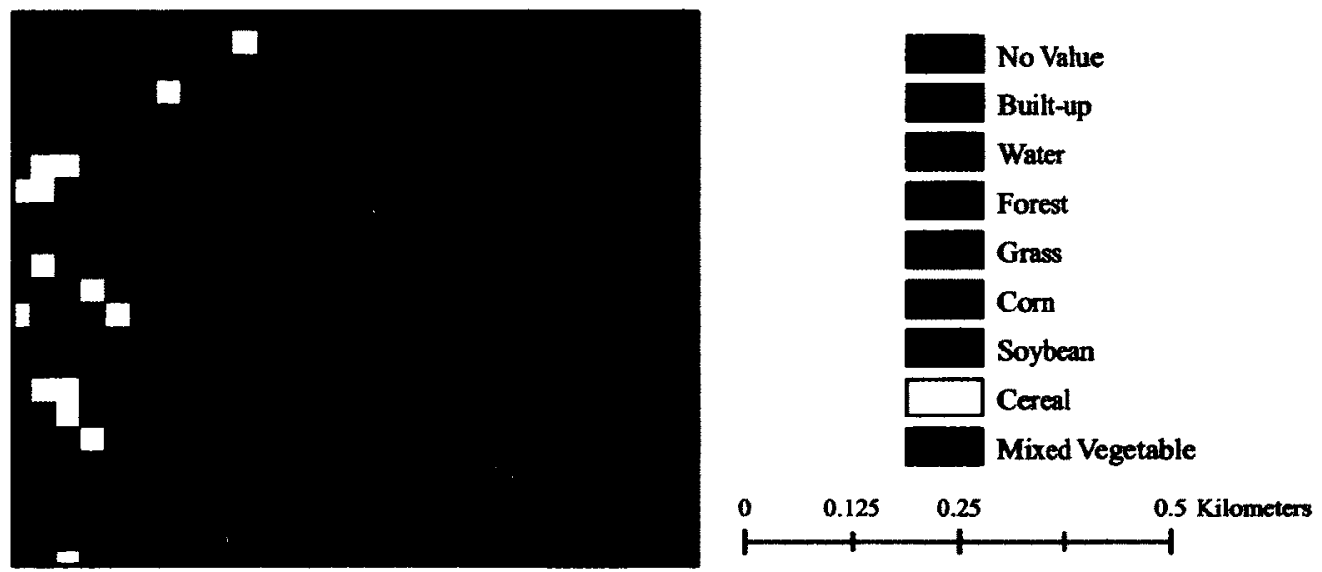

(e) Fuzzy2

Figure 15. Sub-set of a cropland area showing the aerial photograph, the Quickbird and Landsat MLCs, and the Fuzzy1 and Fuzzy2 images. 
In Figure 16, The Quickbird MLC has correctly classified all the corn and soybean fields (Figure 16b). As well, for the most part, the Grass and Forest pixels are correctly classified. With the exception of the road that is being confused with the Grass class and a few of the field edges not being represented, the Quickbird MLC has classified this subset region well. Similar results are seen in the Landsat MLC image; the main fields are correctly classified, however, there is confusion with the field edges (Figure 16c). Although Figures 14 and 15 showed good results for the fuzzy classification, this was not always the case. As seen in Figure 16d and Figure 16e, the fuzzy images show significant confusion between classes. While many of the second highest membership values are classified as Soybean in the Fuzzy 2 image, the Soybean fields are predominantly being classified as Mixed Vegetable in Fuzzy1. On the other hand, the Fuzzy1 image is the only one that accurately classifies the road as Built-up. 


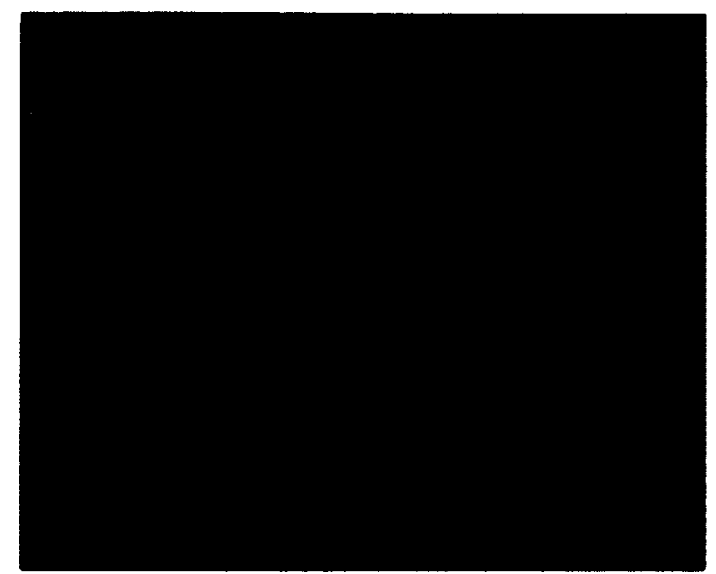

(a) Aerial photograph
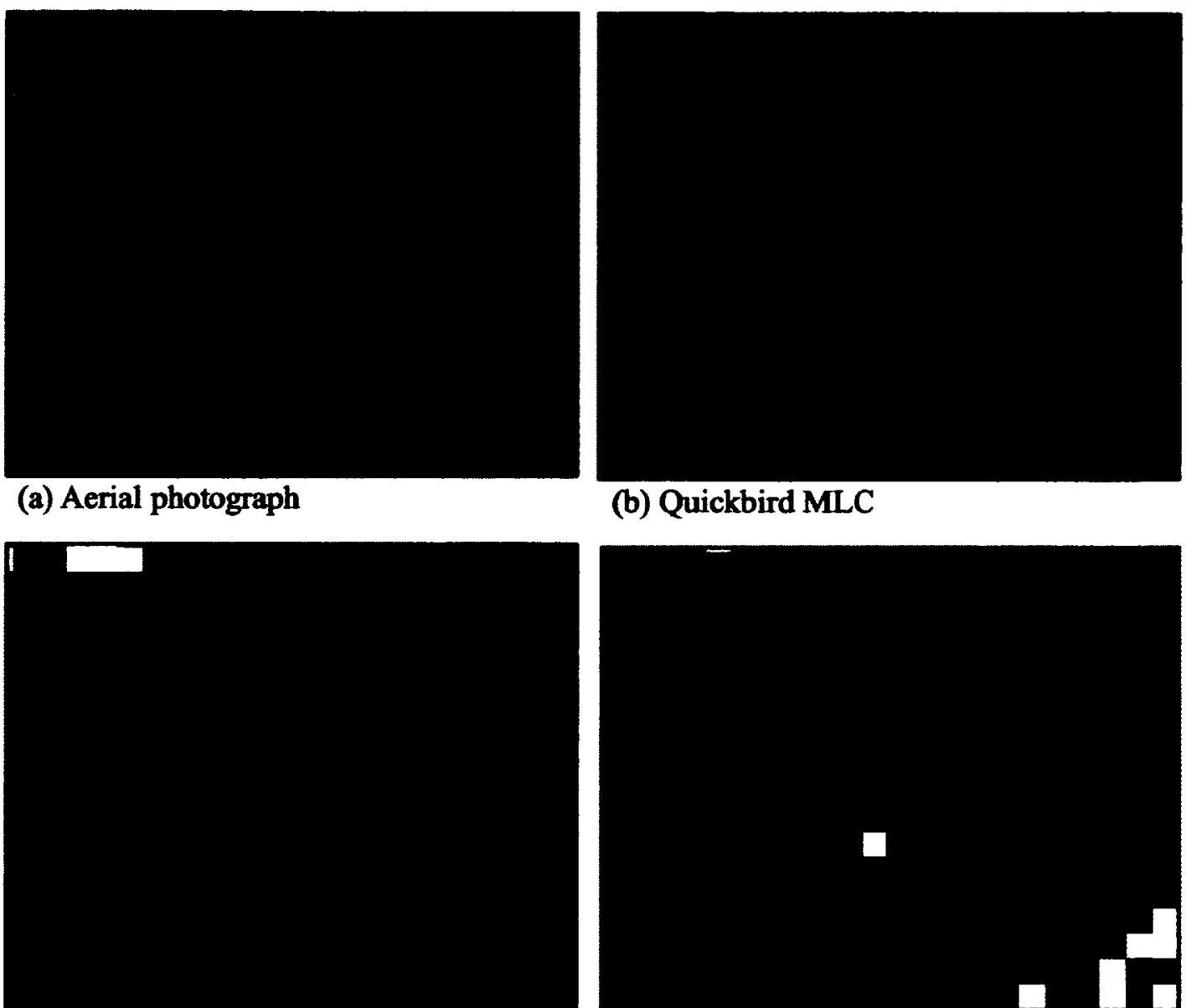

(c) Landsat MLC

(b) Quickbird MLC

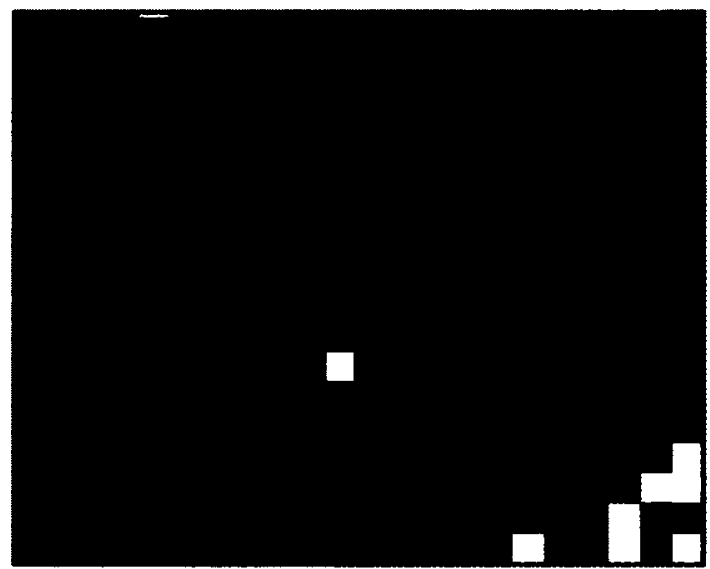

(d) Fuzzy1
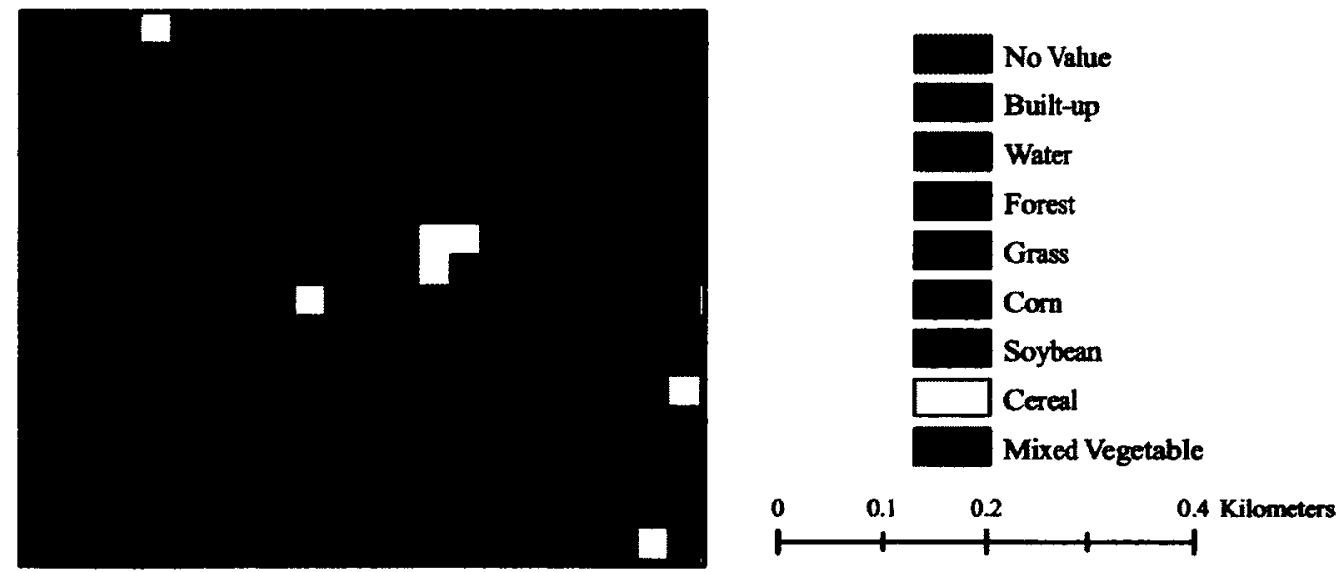

(e) Fuzzy2

Figure 16. Sub-set of a cropland area showing the aerial photograph, the Quickbird and Landsat MLCs, and the Fuzzyl and Fuzzy2 images. 


\subsection{Discussion and Conclusion}

This chapter presents a discussion of the results presented in Chapter 4. First, an analysis of the fuzzy classification method and the resulting maps will be presented. Then, the fuzzy maps will be compared to both MLC maps. A summary of the overall limitations and the contributions of this research will also be presented.

\subsection{Fuzzy classification}

In order to address the first research question that focuses on the ability of fuzzy classification to accurately depict the heterogeneity of agriculturally dominated areas in eastern Ontario, the FCM classifier was employed. Although the overall accuracy of the hardened fuzzy image was only $32.91 \%$, this low value was to be expected, as so much of the sub-pixel information is lost during the hardening procedure. As well, having $95 \%$ of the normalized entropy values lie between 0.00 and 0.82 indicates high variability in entropy throughout the scene. While some pixels are composed of one dominating class, other pixels display a strong presence of mixed pixels. The distribution of the normalized entropy for the fuzzy membership values (Figure 9) provided valuable information regarding the spatial distribution of the heterogeneity. It was clear that the heterogeneity was higher in certain regions, especially in areas of transition and along field boundaries. Looking at the classes themselves, the Forest and Soybean classes were classified as the purest classes, having a strong bimodal frequency distribution and the highest percentage of pixels classified as pure or nearly pure. The classes containing cropped fields showed the lowest entropy, while the Built-up and Water classes tended to show higher entropy. 
The Water class produced unexpected results. It had a much wider distribution than was expected. This is likely due to the fact that the definition of this class was not refined enough. The Water class combined not only deep and shallow water, but wetlands as well. This meant that there was likely vegetation included - which is why the near infrared values were uncharacteristically high. It should also be noted that although the maximization hardening procedure resulted in $16.5 \%$ more pixels being labelled as Water than there were in the Quickbird MLC, the membership values for these pixels were still quite low. This resulted in areas classified as Water having very high entropy values. In this situation, the high normalized entropy values indicate uncertainty in the class assignment.

Corn was also inconsistently classified. While areas with high membership in this class tended to correspond well with cornfields identified in the field, there were several regions where lower membership values were observed. This may reflect the issues with corn growth throughout the 2011 growing season. According to the Ontario Field Crop Report from the 2011 Corn Seasonal Summary, the wet spring conditions resulted in the extension of the corn-planting season, and the hot and dry July weather added extra stress to the growth of the corn crops (Ontario Field Crop Report, 2011). Due to these factors, the growth of the corn crop was variable across fields. The diversity of planting dates led to the growth stages not being consistent, and the hot and dry weather negatively impacted the health of the crop. 
The ability to obtain and analyze sub-pixel information is one key benefit of fuzzy classification. This ability proved quite useful for both the Built-up and Grass classes. The Built-up class contains small features such as roads and buildings that often represent a minority of a $30 \mathrm{~m}$ by $30 \mathrm{~m}$ area (the size of a Landsat pixel). This class can therefore often be under-represented, which leads to high errors of omission. The higher entropy values observed in Built-up areas further demonstrate that while a given area may be Built-up, it may also have high probabilities of membership in multiple other classes. For example, in residential areas, there may be a strong presence of houses and roads, however, there is an abundance of grasses and trees present. The higher entropy values illustrate the degree of heterogeneity within a given pixel. The Grass class includes wild grasses in addition to hay and pasture fields. As well, it includes smaller fields such as abandoned fields, field edges and lawns. As with the features in the Built-up class, these land covers would generally not be the dominant land cover in a Landsat sized pixel and would therefore not necessarily be appropriately represented using standard classification methods.

While some classes did show confusion, overall, the fuzzy classification method was able to effectively depict the heterogeneity of the selected landscape.

\subsection{Comparative Analysis: Fuzzy1 and Landsat MLC}

In order to address the research question, the fuzzy classified image was compared to one created using a maximum likelihood classification method. Clearly the overall accuracy of the Landsat MLC was higher than that of the Fuzzyl image (61.85\% versus $32.91 \%$, 
respectively). However, as the Fuzzyl image only depicts the classes with the highest membership values (and not any of the sub-pixel information), the lower overall accuracy value was expected. Despite this, when looking at individual classes, greater amounts of confusion between classes were seen in the Landsat MLC compared to Fuzzy 1, with the Landsat MLC having 3 out of the 8 classes showing significant confusion. Further, the overall agreement between the high-resolution classification and the soft hardened fuzzy classification showed a $13.40 \%$ increase compared to the Landsat MLC. This suggests that a large proportion of the disagreement stems from the inability to appropriately represent the sub-pixel information.

In addition, the results obtained from the agreement analyses are in line with those obtained by Zhang and Foody (1998). The percent of overall agreement when using Landsat data was higher for the soft comparisons than the percent overall agreement obtained by using standard hard methods. Further, from the results of both this thesis and the study conducted by Zhang and Foody (1998), it is clear that the majority of the disagreement produced from the hard classification methods occurred near class boundaries (i.e. field edges). Therefore, in areas of transition, the fuzzy classifier was able to more realistically represent the mixed pixels compared to when the conventional hard classifier was used. The fuzzy classifier was able to better differentiate between the classes, especially between the Grass and Built-up classes. Producing more realistic results increases the validity of the study being conducted. As well, these results support the conclusions found by Cannon et al. (1986): the use of the fuzzy $c$-means clustering algorithm for image classification provides a viable alternative to the standard per pixel 
maximum likelihood classification. Overall, while some areas performed better using the maximum likelihood classification, the FCM was able to classify the bulk of the study region more consistently.

\subsection{Comparative Analysis: Fuzzy1 and Quickbird MLC}

The third and final research question for this thesis dealt with the comparison of the fuzzy classified image with an image created using higher resolution data. As expected, the overall accuracy of the image created using the high-resolution sensor, Quickbird, was the highest out of all the classifications produced, at $76.21 \%$. As well, out of all the classifiers used, the Quickbird MLC showed superior results for all classes when the ground data was compared to the frequency of occurrence of each class (Figure 6). The Quickbird MLC did have some difficulty in classifying some of the smaller classes (such as the Built-up and Mixed Vegetable classes). This was due in part to the fact that the original MLC performed on the Quickbird data was re-sampled to match the coarser resolution of the Landsat data. Because a majority re-sampling strategy was used, some details, especially for the smaller classes, were removed. Despite this, the Quickbird MLC was most able to display field boundaries, compared with the other classification methods. While the Fuzzy1 could, on many occasions, identify the location of these field boundaries, the specific class assigned to the given pixels was not always correct. Overall, with the exception of a few misclassified areas (see Figure 16), the combination of the results from the highest and second highest membership values resembled the results obtained from using the high-resolution data. 


\subsection{Limitations}

The fuzzy classifier provided an effective representation of the heterogeneity of the eastern Ontario landscape. There were, however, several limitations inherent with this type of analysis.

A drawback in using fuzzy approaches for classification lies in the difficulty of interpreting and visualizing the results. Displaying the results is not straightforward because each layer represents a single class. As well, the standard and most commonly used methods for accuracy assessment (such as the error matrix and kappa statistic) cannot be appropriately used on a fuzzy map. These accuracy assessments are designed for hard classification methods only (Gao, 2009 and Foody, 1995). It is for this reason that the process of hardening the fuzzy maps is a commonly employed method. Consequently, this results in the loss of much of the sub-pixel information obtained.

Another limitation with FCM lies in the selection of control parameters, specifically the choice of the number of clusters, $c$. Many studies (including Cannon et al., 1986; Gath and Geva, 1989; Fisher and Pathirana, 1990; Wilkinson, 2005; and Carlotto, 2009) have dealt with the concern regarding the ideal number of clusters (and classes) that should be used. In fact, obtaining optimal classification results may be contingent on the selection of the best or most appropriate number of classes (Burrough and McDonnell, 1998). While the use of pre-existing classification schemes and expert knowledge may help, obtaining optimal values is still very site-specific. 
In addition, when using this fuzzy $c$-means method, the final clusters are a result of analysis of the data, rather than the input to the algorithm (Burrough and McDonnell, 1998). Although the purpose of fuzzy classification is to create a non-crisp classification, clustering that is mathematically optimal is only truly achieved through the use of crisp classification (Fisher and Pathirana, 1990). Therefore, clusters get assigned to pre-defined classes. The result is that these pre-defined classes may have no clear-cut relationship to their membership values. While pixels assigned to a given class can have identical membership values, the reverse is not necessarily true (Burrough and McDonnell, 1998).

\subsection{Future Work}

While the results of the fuzzy classification used in this thesis did, for the most part, rival the results of the maximum likelihood classification, due to the above-mentioned limitations, more work needs to be conducted. To begin with, further refinement of the land cover classes should be conducted. Obtaining spectrally distinct classes is a key aspect of accurately classifying a given area (Lillesand et al., 2008). This is not always a straightforward task since, for example, different types of trees have different reflectances, the spectral characteristics of crop fields differ based on aspects such as growth stage or soil type, and even the reflectance of water bodies varies based on depth and turbidity (Cannon et al., 1986). For the purposes of this thesis, eight classes were identified and used. However, some of these classes were more spectrally distinct than others, and as such, the study may benefit from using more classes. As an example, the Mixed Vegetable class could be separated according to the more dominant crops. The Water class could be separated into deep and shallow waters, since, as was seen in the 
results, having even small amounts of vegetation present (for example from wetland areas) in the definition and training of the Water class greatly influences the results. In fact, a study that solely focuses on identifying the most spectrally distinct and the optimal number of classes for this specific region would be very beneficial.

Further, since multi-temporal data is often preferred for crop classification studies, another avenue for future research would be to obtain data from multiple dates throughout the growing season. For example, if data could be acquired at three different times, once at the beginning of the season, once in the middle and once at the end of the season, this would allow for the diversity of crop growth stages to fully be represented and may improve crop type classification. Due to limitations in data acquisition, this type of multi-temporal study was not feasible. However, had it been available and accessible, a more accurate depiction of the classes could have been achieved.

As well, analysis on the parameters used in the FCM algorithm could be conducted. For example, depending on the type of cluster detected (either clusters of similar shape and orientation, or clusters of different geometrical shapes), different distance measures are applied. A sensitivity analysis to determine the impact of using these different distance measures could be beneficial.

Another parameter to look at would be the degree of fuzziness, $q$. While the FCM method did allow for the heterogeneity of the landscape to be represented, it might not have appropriately estimated the amount of mixed pixels in certain areas or for certain classes. 
For example, it is expected that the Grass class would inherently be a fuzzier class than the Soybean class. However, because the FCM algorithm assumes that the degree of fuzziness is equal for all classes, it imposes a constant fuzziness factor on all the classes. This can lead to over- or under-simplifying the class' actual characteristics. One way of offsetting this issue would be to segment the area of interest based on the heterogeneity and then perform the fuzzy classification. Similar to the approaches used by Lucas et al. (2007), object-based segmentation could be used to divide the landscape into more homogeneous areas. A fuzzy clustering method could then be used on specific objects. By conducting multiple fuzzy classifications on similar groups of objects, the degree of fuzziness could be set per group of objects and the results could therefore more appropriately represent the diversity within each of the classes.

Although it was beyond the scope of this thesis, another avenue for future work would be to analyze the pixels from the original Quickbird MLC (before the resolution was reduced). In the same way that the fuzzy results were hardened to create the highest and the second highest membership values, a majority and successive majority re-sampling procedure could be conducted on the original Quickbird classification. The majority resampled Quickbird MLC could be compared to Fuzzy1 and the Quickbird MLC based on secondary majority re-sampling could be compared to Fuzzy2. This would allow for a more thorough comparison between the Quickbird classification and the fuzzy results. As well, the original data obtained from the classified Quickbird could itself be used as subpixel information. Assuming a highly accurate classification, those pixels could be used as a way of assessing the proportion of classes within a Landsat pixel and those 
proportions could then be compared to the fuzzy membership values. This would provide an additional method of testing the accuracy of the fuzzy classification.

Lastly, an assessment of the validity of the actual FCM method should be conducted. As stated by Gopal and Woodcock (2000), one way of obtaining a fuzzy classification is by softening the output of a hard classifier such as the MLC. Therefore, the fuzzy membership values obtained from the FCM method could then be compared to those obtained from a softened maximum likelihood classification.

\subsection{Contributions}

The heterogeneous nature of the landscape is well represented, despite the final FCM classification displaying some confusion between classes. In fields where the crop was struggling (and consequently had significant amounts of grass present), the Fuzzy1 and Fuzzy2 results appropriately display this by showing a strong presence of a secondary class, the Grass class. This information could not have been obtained by simply looking the Landsat MLC results. As well, the distinction of grass-lined and tree-lined edges is predominantly seen in the fuzzy images, allowing for the heterogeneity of the landscape to be depicted.

This research is part of the GLEL research initiative, and as such, its goal is to create a land cover map through which heterogeneity measures can be extracted. The FCM results are able to show the presence of mixed pixels, as well as allow for the representation of the heterogeneity within that area. An important goal of the GLEL research initiative is to 
determine the link between spatial heterogeneity and biodiversity. Knowing the location within this agricultural landscape where heterogeneity is present allows researchers to focus their efforts more specifically. Although the results obtained from the highresolution data provided superior class assignments, the fuzzy classification method provided an abundance of sub-pixel information. It is therefore recommended that the results from the distribution of normalized entropy be passed along to the GLEL research team, since it provided an accurate depiction of the heterogeneity of the region.

\subsection{Conclusions}

Overall, the fuzzy classification allowed for the assessment of sub-pixel information. As the presence of mixed pixels is particularly problematic when coarse resolution data is used, the ability to assess the heterogeneity within a pixel becomes vital. The FCM method was better able to depict the heterogeneity along field boundaries and in areas of transition than when the standard maximum likelihood classification method was used with Landsat data.

Although the fuzzy maps produced did allow for the analysis of sub-pixel information, inconsistencies in the land cover assignments were problematic. While many areas were correctly classified, there were regions where misclassification errors were abundant (as seen in Figure 16). In addition, a key benefit of fuzzy classification is its ability to use a coarser resolution sensor while still producing similar results to that of a higher resolution sensor. However, while the results from the FCM method were comparable to the results from the high resolution data, it was the MLC map produced from high resolution data that produced the most accurate land cover map. In order to increase the accuracies in 
land cover assignments, further research needs to be conducted. The focus of this research should centre on obtaining the optimal and most representative number of land cover classes, as well as on properly representing the degree of fuzziness for each class.

The goal of this thesis was to accurately depict the heterogeneity of an agriculturally dominated region of eastern Ontario. While the high resolution data resulted in the most accurate class labels, the fuzzy classification provided detailed information regarding the spatial heterogeneity. These results can be expanded to assess the heterogeneity of landscapes in multiple environments across Canada. Further, they can be specifically beneficial in regions where the classification of the landscape has been negatively impacted due to the presence of mixed pixels. 


\subsection{References}

Aronoff, S. 2005. Remote Sensing for GIS Managers (1st ed.). Redlands, CA: ESRI Press.

Augusteijn, M., L. Clemens, and K. Shaw, "Performance evaluation of texture measures for ground cover identification in satellite images by means of a neural network classifier," IEEE Trans. Geosci. Remote Sens., vol. 33, no. 3, pp. 616-626, May 1995.

Bezdek J. and J. Dunn. "Optimal fuzzy partition: A heuristic for estimating the parameters in a mixture of normal distributions," IEEE Trans. Cornput.. vol. C-24, pp. 835-838, 1975.

Bezdek, J. C. Pattern Recognition with Fuzzy Objective Function Algorithms. New York: Plenum, 1981. M. P. Windham. "Cluster validity for the fuzzy c-means clustering algorithm," IEEE Traris. Puttern Anul. Machine Intell., vol. PAMI- 4, no.4, pp. 357-363, 1982.

Bezdek, J., R. Ehrlich, and W. Full. 1984. "FCM: The fuzzy c-means clustering algorithm." Computers \& Geosciences 10(2-3): 191-203.

Berberoglu, S., P.J. Curran, C.D. Lloyd, and P.M. Atkinson, 2007. Texture classification of Mediterranean land cover. International Journal of Applied Earth Observation and Geoinformation 9, 322-334.

Bone, C., S. Dragicevic, and A. Roberts. 2005. "Integrating high resolution remote sensing, GIS and fuzzy set theory for identifying susceptibility areas of forest insect infestations." International Journal of Remote Sensing 26(21): 4809-4828.

Brandtberg, T. 2002. "Individual tree-based species classification in high spatial resolution aerial images of forests using fuzzy sets." Fuzzy Sets and Systems 132(3): 371-387.

Brown, D. 1998. "Mapping historical forest types in Baraga County Michigan , USA as fuzzy sets." Plant Ecology 134: 97-111.

Burrough, P., R. Macmillan, and W. Deursen. 1992. "Fuzzy classification methods for determining land suitability from soil profile observations and topography." Journal of Soil Science 43(2): 193-210.

Burrough, P. and R. McDonnell, "Principles of Geographical Information Systems". 1998. Oxford University Press. 
Burrough, P., P.F. van Gaans, and R MacMillan. 2000. "High-resolution landform classification using fuzzy k-means." Fuzzy Sets and Systems 113(1): 37-52.

Burrough, P., J. P., Wilson, P. van Gaans, and A. Hansen, 2001. "Fuzzy k-means classification of topo-climatic data as an aid to forest mapping in the Greater Yellowstone Area , USA." Landscape Ecology 16: 523-546.

Campbell, J. B., 1996, Introduction to Remote Sensing, 2nd edn (London: Taylor and Francis).

Cannon, R., J.V. Dave, J.C. Bezdek, M.M. Trivedi, 1986. "Segmentation of a Thematic Mapper Image Using the Fuzzy c-Means Clusterng Algorthm." IEEE Transactions on Geoscience and Remote Sensing GE-24(3): 400-408.

Carlotto, M., 2009. "Effect of errors in ground truth on classification accuracy." International Journal of Remote Sensing 30(18): 4831-4849.

Congalton, R. and K. Green, 1999. "Assessing the Accuracy of Remotely Sensed Data: Principles and Practices."CRC Press, Inc. Boca Raton, FL.

Davidson, D. A., S. P. Theocharopoulos, and R. J. Bloksma, 1994. "A land evaluation project in Greece using GIS and based on Boolean and fuzzy set methodologies." International Journal of Geographical Information Science 8(4): 369-384.

DigitalGlobe. (2011). WorldView-2. Retrieved from http://www digitalglobe.com/index.php/88/WorldView-2

Dingle Robertson, L. 2007. "M.Sc. Thesis: Land cover change mapping of Eastern Ontario, 1995 to 2005 using object-based classification." 1-192.

Dingle Robertson, L, and D.J. King, 2011. "Comparison of pixel- and object-based classification in land cover change mapping." International Journal of Remote Sensing 32(6): 1505-1529.

Droj, G., 2007. "The applicability of fuzzy theory in remote sensing image classification." Image (Rochester, N.Y.) LII(1): 89-96.

Eastern Ontario Model Forest (EOMF) (2006) Biodiversity and Your Eastern Ontario Woodlot: Information Report No. 60c. [online] Available at: http://www .eomf .on .ca [Accessed: May 2012].

Eastman, J.R., 2009. “Guide to GIS and Image Processing.” Systems Research (August).

ESRI (2007) ArcGIS Desktop Help. [online] Available at: http://webhelp.esri.com/arcgisdesktop/9.2/ [Accessed: May 2012]. 
Fisher, P, and S Pathirana, 1990. "The evaluation of fuzzy membership of land cover classes in the suburban zone." Remote Sensing of Environment 34(2): 121-132.

Foody, G. M., 1995. "Cross-entropy for the evaluation of the accuracy of a fuzzy land cover classification with fuzzy ground data." ISPRS Journal of Photogrammetry and Remote Sensing: 2-12.

Foody, G., 1996. "Approaches for the production and evaluation of fuzzy land cover classifications from remotely-sensed data." International Journal of Remote Sensing 17(7): 1317-1340.

Foody, G., 1997. "Fully fuzzy supervised classification of land cover from remotely sensed imagery with an artificial neural network." Neural Computing \& Applications 5(4): 238-247.

Foody, G., 2002. "Status of land cover classification accuracy assessment." Remote Sensing of Environmnet, 80, 185-201.

Foody, G., 2008. "Harshness in image classification accuracy assessment." International Journal of Remote Sensing 29(11): 3137-3158.

Franklin, S. E., R. J. Hall, L.M. Moskal, A.J. Maudie, and M.B. Lavigne, (2000). Incorporating texture into classification of forest species composition from airborne multispectral images. International Journal of Remote Sensing, 21,61-79.

Gao, J. 2009. Digital Analysis of Remotely Sensed Imagery (1 st ed.). New York, NY: McGraw-Hill Professional.

Gonçalves, L. Fonte C., E. Julio, and M. Caetano, 2009. "On the information provided by uncertainty measures in the classification of remote sensing images." In IFSAEUSFLAT, p. 1051-1056.

Gopal, J. and Woodcock, C., 1994. "Theory and Methods for Accuracy Assessment of Thematic Maps Using Fuzzy Sets.” Photogrammetric Engineering \& Remote Sensing, 60 (2), 181-188.

Gustafson E. and W. Kessel, "Fuzzy clustering with a fuzzy covariance matrix," in Proc. IEEE CDC, San Diego, CA, 1979, pp. 76 1-766.

Hansson, L., 1977. Landscape ecology and stability of populations. Landscape Plan. 4, 85-93.

Irvin, B., S. Ventura, and B. Slater. 1997. "Fuzzy and isodata classification of landform elements from digital terrain data in Pleasant Valley, Wisconsin." Geoderma 77(24): $137-154$. 
Klir, G.J. and T.A. Folger, 1988. Fuzzy Sets, Uncertainty and Information. Prentice-Hall International, London.

Lee, S., 2006. "Landsat ETM sub-pixel analysis of urban landscape using fuzzy c-means clustering and differentiated impervious surface classes." In ASPRS 2006 Annual Conference, Reno, Nevada.

Lillesand, T., R. Kiefer, and J. Chipman, 2008. Remotes Sensing and Image Interpretation ( $6^{\text {th }}$ ed.). John Wiley and Sons.

Lucas, R., A. Rowlands, A. Brown, S. Keyworth, and P. Bunting, 2007. "Rulo-based classification of multi-temporal satellite imagery for habitat and agricultural land cover mapping." ISPRS Journal of Photogrammetry and Remote Sensing 62(3): 165-185.

Lucieer, A., and M. Kraak, 2004. "Interactive and visual fuzzy classification of remotely sensed imagery for exploration of uncertainty." International Journal of Geographical Information Science 18(5): 491-512.

Maulik, U., and I. Saha, 2010. “Automatic Fuzzy Clustering Using Modified Differential Evolution for Image Classification." IEEE Transactions on Geoscience and Remote Sensing 48(9): 3503-3510.

Melgani, F., B. Al Hashemy, and S. Taha, 2000. "An Explicit Fuzzy Supervised Classification Method for Multispectral Remote Sensing Images." IEEE Transactions on Geoscience and Remote Sensing, 38(1), 287-295.

McMahan, B., K. Weber, and J. Sauder, 2003. "Fuzzy Classification of Heterogeneous Vegetation in a Complex Arid Ecosystem." K. T. Weber [ed.]. Final report: Wildfire effects on rangeland ecosystems and livestock grazing in Idaho.

Melgani, F., B. Al Hashemy, and S. Taha, 2000. "An Explicit Fuzzy Supervised Classification Method for Multispectral Remote Sensing Images." IEEE Transactions on Geoscience and Remote Sensing, 38(1), 287-295.

Maulik, U., and I. Saha. 2010. “Automatic Fuzzy Clustering Using Modified Differential Evolution for Image Classification." IEEE Transactions on Geoscience and Remote Sensing 48(9): 3503-3510.

Myint, S. W., V. Mesev, and N. S. N. Lam, 2006. Texture analysis and classification through a modified lacunarity analysis based on differential box counting method. Geographical Analysis, 38, 371-390.

Noss, R.F., 1983. A regional landscape approach to maintain diversity. Bioscience 33, 700-706. 
Odum, E.P., 1959. Fundamentals of Ecology. W.B. Saunders, Philadelphia, Pennsylvania.

Ontario Ministry of Natural Resources (2012) Ontario's Forest Regions: Great Lakes-St. Lawrence Forest. [online] Available at: http://www.mnr.gov.on.ca/en/Business/Forests/2ColumnSubPage/STDPROD_0912 88.html [Accessed: May 2012].

Pasher, J., D.J. King, S. Mitchell, L. Fahrig, and K. Lindsay, (Submitted) "Selecting sample landscapes for a landscape-scale mensurative experiment"

PCI Geomatics. 2010. Geomatica 10.3 Help. PCI Geomatics Enterprises, Inc.

Robinson, V B., 2003. "A Perspective on the Fundamentals of Fuzzy Sets and their Use in Geographic Information Systems." Transactions in GIS 7(1): 3-30.

Shackelford, A. and C. Davis, 2003. "A Hierarchical Fuzzy Classification Approach for High-Resolution Multispectral Data Over Urban Areas." IEEE Transactions on Geoscience and Remote Sensing, 41(9), 1920-1932.

Sklenicka, P., and T. Lhota, 2002. "Landscape heterogeneity - a quantitative criterion for landscape reconstruction." Landscape and Urban Planning 58: 147-156.

Statistics Canada. 2012. Ottawa - Gatineau (Ontario part), Ontario (Code 505) and Ontario (Code 35) (table). Census Profile. 2011 Census. Statistics Canada Catalogue no. 98-316-XWE. Ottawa. Released May 29, 2012. http://www12.statcan.gc.ca/census-recensement/2011/dppd/prof/index.cfm?Lang $=E$ (accessed June 2012).

Statistics Canada, 2011 Census of Agriculture, Farm and Farm Operator Data, catalogue no. 95-640-XWE.

Stehman, S., 1997. "Selecting and interpreting measures of thematic classification accuracy." Remote Sensing of Environment 62(1): 77-89.

Wang, F., 1990. "Fuzzy Supervised Classification of Remote Sensing Images." IEEE Transactions on Geoscience and Remote Sensing 28(2): 194-201.

Wang, F, and B. Hall, 1996. "Fuzzy representation of geographical boundaries in GIS." International Journal of Geographical Information Science 10(5): 573-590.

Wilkinson, G.G., 2005. "Results and implications of a study of fifteen years of satellite image classification experiments." IEEE Transactions on Geoscience and Remote Sensing 43(3): 433-440. 
Zadeh, L. A., 1965. "Fuzzy Sets.” Information and Control, 8, 338-353.

Zhang, J., and R. Kirby, 1997. "An evaluation of fuzzy approaches to mapping land cover from aerial photographs." ISDRS Journal of Photogrammetry Remote Sensing, 52 , 193-201.

Zhang, J., and G. Foody, 1998. "A fuzzy classification of sub-urban land cover from remotely sensed imagery." International Journal of Remote Sensing 19(14): 27212738 .

Zhang, J., and G. Foody, 2001. "Fully-fuzzy supervised classification of sub-urban land cover from remotely sensed imagery: Statistical and artificial neural network approaches." International Journal of Remote Sensing 22(4): 615-628. 
Appendix I - Training Data
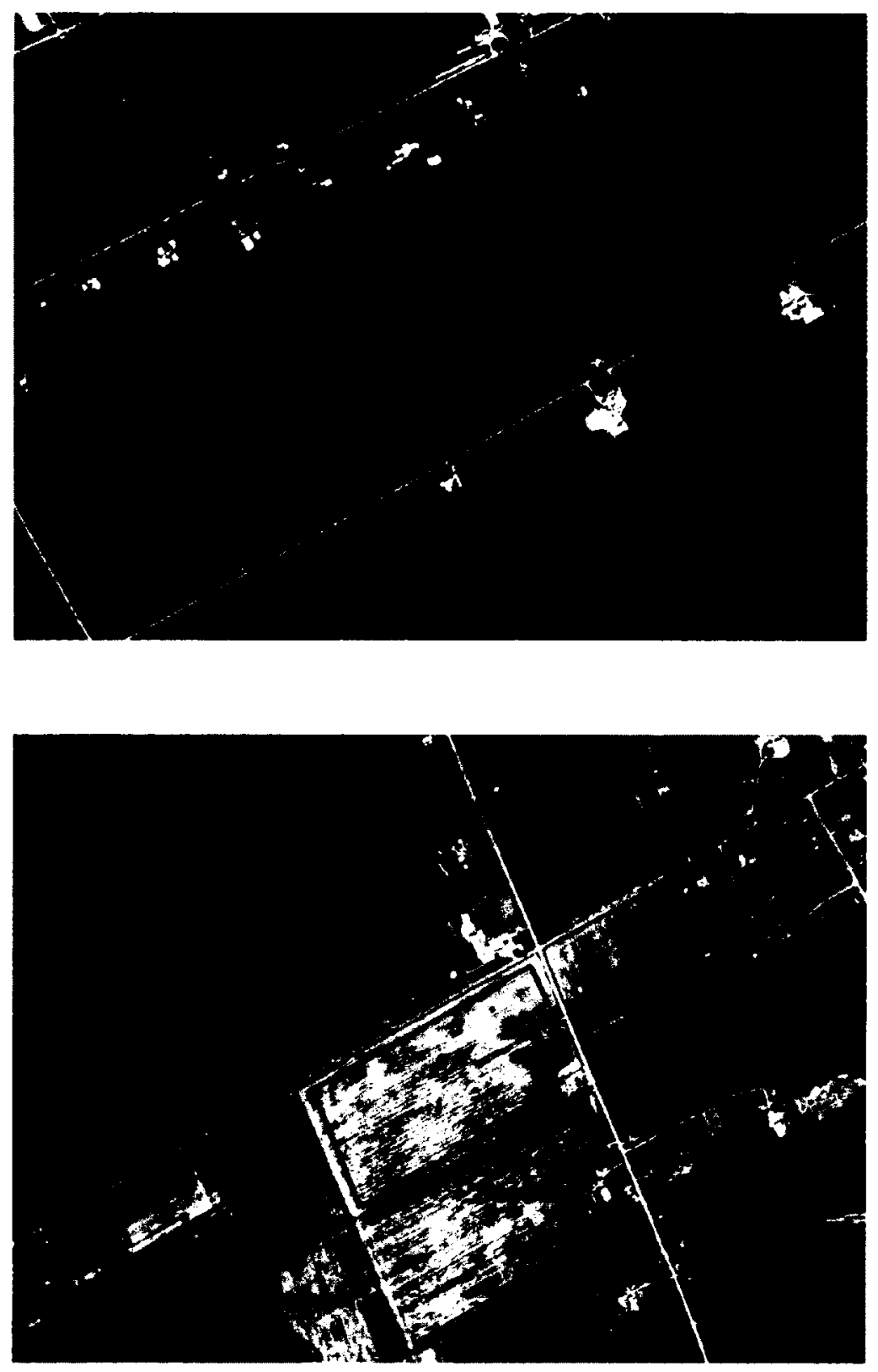

Figure I-A. Examples of training polygons for a select number of classes. 
Table I-A. Transformed divergence for the Landsat data (no texture).

\begin{tabular}{crrrrrrr}
$\begin{array}{c}\text { Average: } \\
\text { Minimum: } \\
\text { Maximum: }\end{array}$ & $\begin{array}{r}1348.51 \\
505.35 \\
1999.03\end{array}$ & & & & & & \\
& Water & Forest & Grass & Corn & Soybeans & Cereal & $\begin{array}{r}\text { Mixed } \\
\text { Vegetable }\end{array}$ \\
& & & & & & & \\
\hline Built-up & 1970.59 & 1815.15 & 1275.15 & 1430.17 & 594.57 & 1887.43 & 505.35 \\
Water & & 1096.90 & 1691.96 & 1672.03 & 1995.95 & 1471.72 & 1999.03 \\
Forest & & & 1130.10 & 990.91 & 1799.87 & 767.60 & 1786.70 \\
Grass & & & & 745.48 & 1279.93 & 804.99 & 1276.29 \\
Corn & & & & & 1320.49 & 732.98 & 1445.39 \\
Soybean & & & & & & 1839.08 & 656.74 \\
Cereal & & & & & & & 1775.72 \\
\hline
\end{tabular}

Table I-B. Transformed divergence for the Landsat data (GLCM mean texture band included).

\begin{tabular}{|c|c|c|c|c|c|c|c|}
\hline $\begin{array}{l}\text { Average: } \\
\text { Minimum: } \\
\text { Maximum: }\end{array}$ & $\begin{array}{r}1503.92 \\
933.01 \\
1999.41 \\
\end{array}$ & & & & & & \\
\hline & Water & Forest & Grass & Corn & Soybeans & Cereal & $\begin{array}{c}\text { Mixed } \\
\text { Vegetable }\end{array}$ \\
\hline Built-up & 1998.35 & 1941.49 & 1461.52 & 1508.97 & 1079.65 & 1903.02 & 988.97 \\
\hline Water & & 1311.56 & 1733.08 & 1716.28 & 1996.84 & 1632.42 & 1999.41 \\
\hline Forest & & & 1451.48 & 1332.46 & 1898.48 & 986.02 & 1844.40 \\
\hline Grass & & & & 1022.09 & 1467.10 & 1003.79 & 1402.63 \\
\hline Corn & & & & & 1401.87 & 956.36 & 1491.86 \\
\hline Soybean & & & & & & 1861.58 & 933.01 \\
\hline Cereal & & & & & & & 1784.99 \\
\hline
\end{tabular}




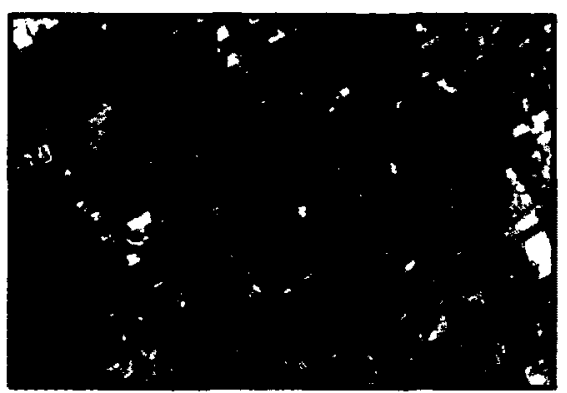

(a) Unclassified Quickbird
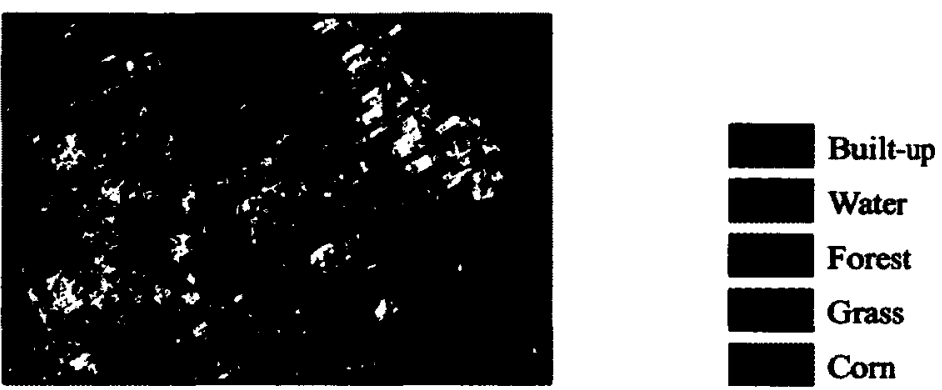

Water

Forest

Grass

Corn

(b) Quickbird MLC
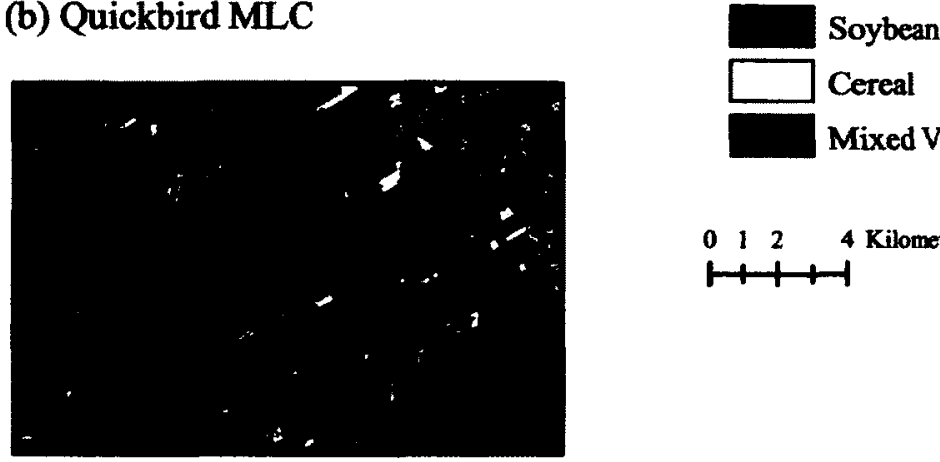

Cereal

Mixed Vegetable

0 124 Kilometers $1+1$

(c) Landsat MLC

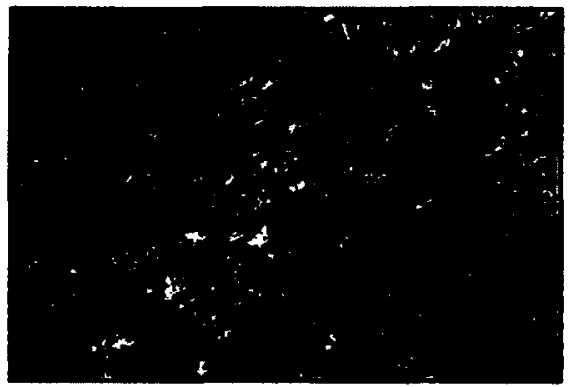

(d) Fuzzyl

Figure II-A. Original unclassified Quickbird image and classified images for Scene 1. 


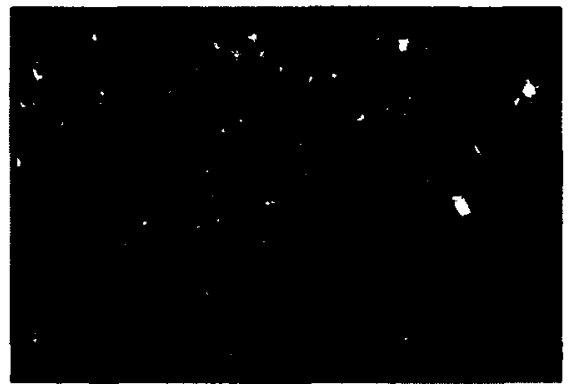

(a) Unclassified Quickbird

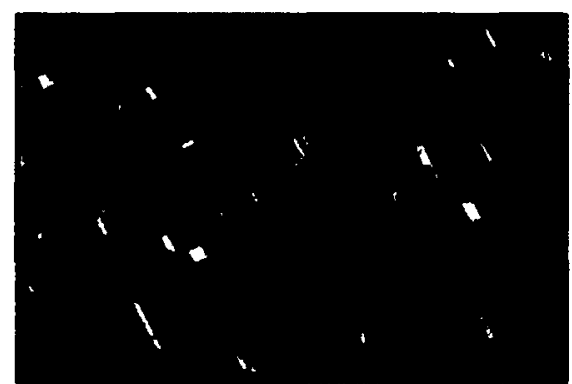

(b) Quickbird MLC

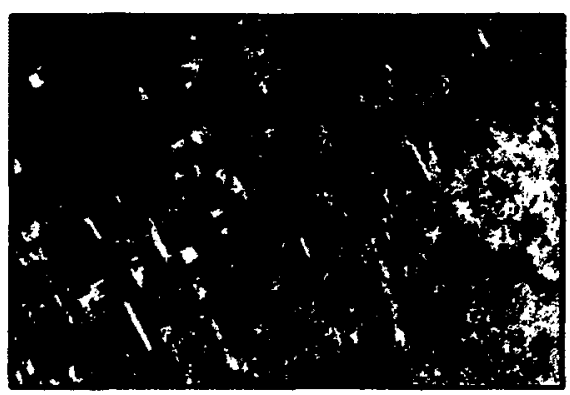

\begin{tabular}{|l|l}
\hline Built-up \\
Water \\
Forest \\
Grass \\
Com \\
\hline Soybean \\
\hline Cereal \\
\hline Mixed Vegetable
\end{tabular}

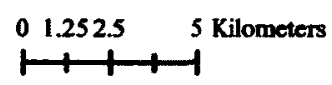

(c) Landsat MLC

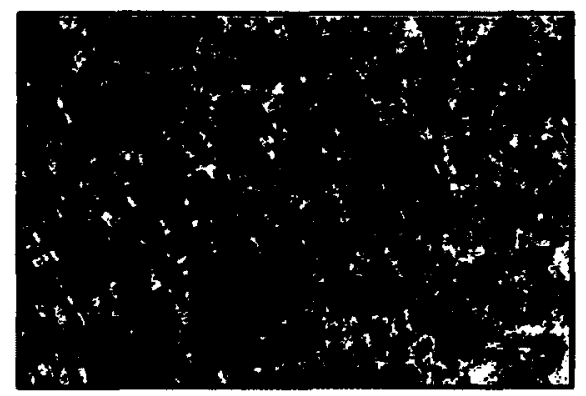

(d) Fuzzy1

Figure II-B. Original unclassified Quickbird image and classified images for Scene 3. 


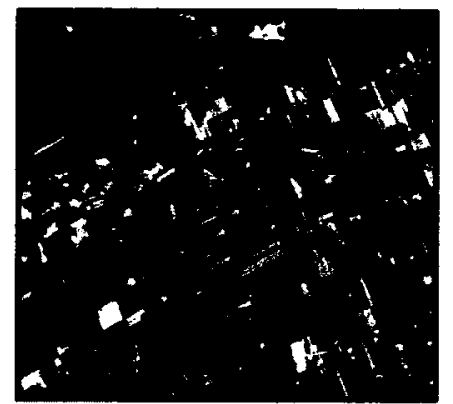

(a) Unclassified Quickbird

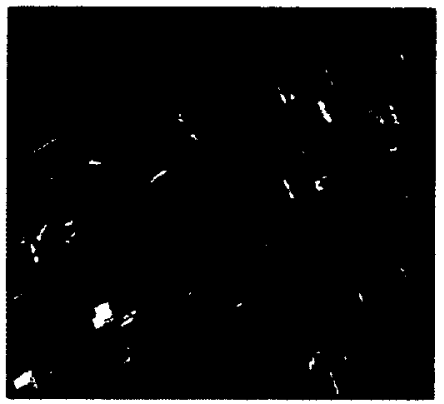

(b) Quickbird MLC

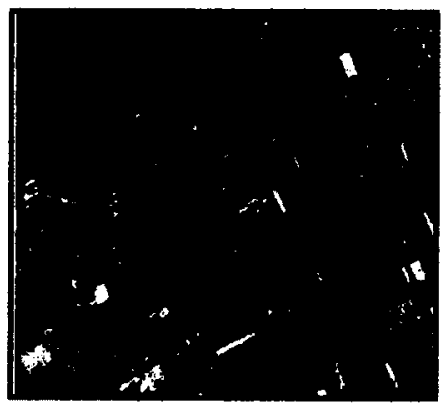

(c) Landsat MLC

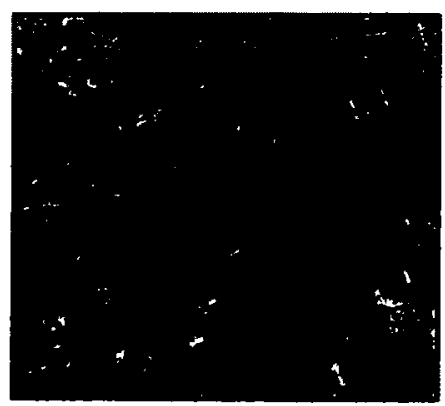

(d) Fuzzyl

Figure II-C. Original unclassified Quickbird image and classified images for Scene 4. 


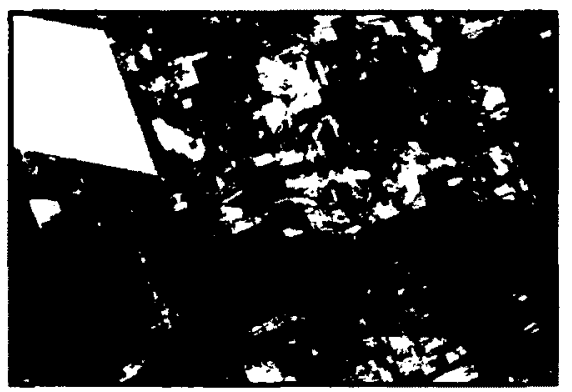

(a) Unclassified Quickbird

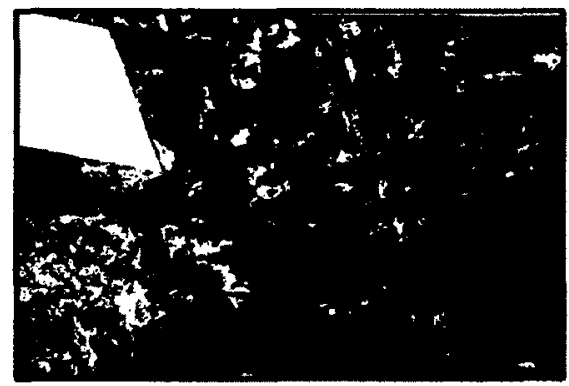

(b) Quickbird MLC
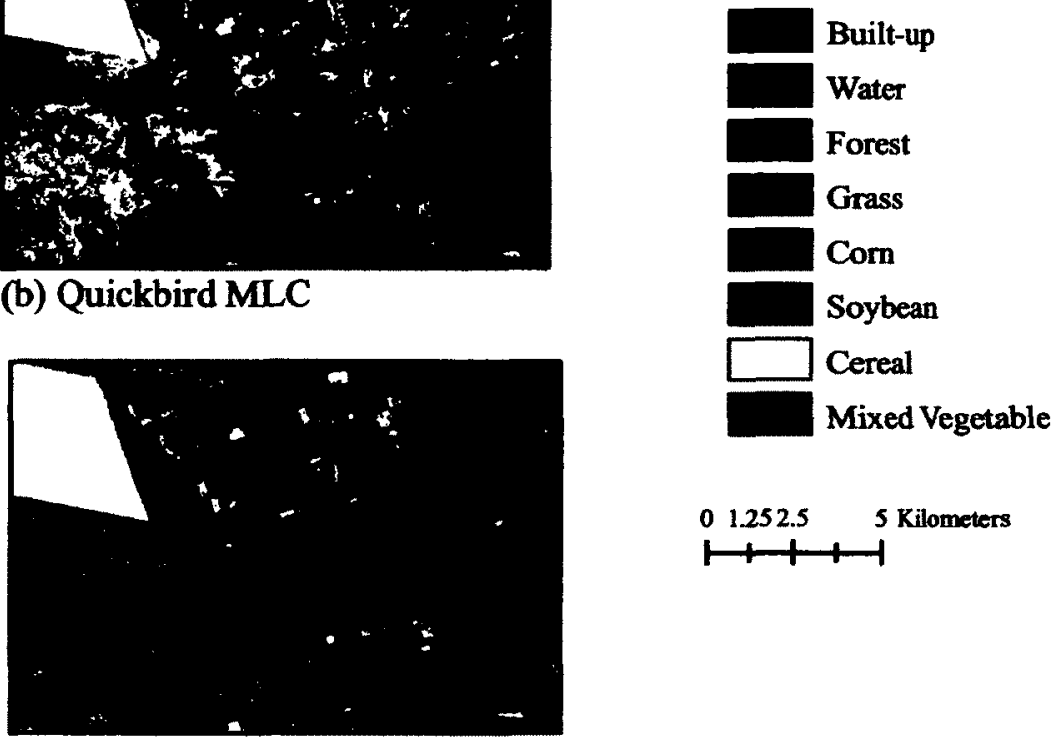

$01.252 .5 \quad 5$ Kilometers

(c) Landsat MLC

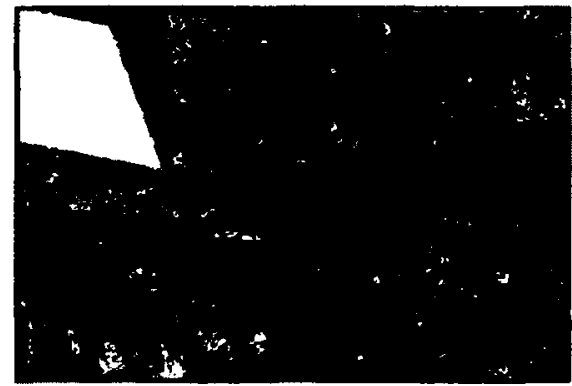

(d) Fuzzy1

Figure II-D. Original unclassified Quickbird image and classified images for Scene 5. 


\section{Appendix III - Accuracy Assessments}

Table III-A. (a) Error matrix and (b) percent commission, omission errors and conditional kappa statistic, per class for Quickbird MLC.

\begin{tabular}{crrrrrrrrr}
\hline Quickbird MLC & Built-up & Water & Forest & Grass & Corn & Soybean & Cereal & $\begin{array}{c}\text { Mixed } \\
\text { Vegetable }\end{array}$ & $\begin{array}{c}\text { Row } \\
\text { sum }\end{array}$ \\
\hline Built-up & 33 & 0 & 4 & 34 & 4 & 4 & 2 & 2 & 83 \\
Water & 0 & 30 & 3 & 9 & 0 & 0 & 1 & 0 & 43 \\
Forest & 1 & 1 & 131 & 20 & 0 & 3 & 1 & 0 & 155 \\
Grass & 30 & 0 & 28 & 1517 & 109 & 101 & 41 & 13 & 1839 \\
Corn & 5 & 0 & 50 & 331 & 2061 & 106 & 65 & 146 & 2764 \\
Soybean & 11 & 0 & 72 & 273 & 72 & 1700 & 41 & 91 & 2260 \\
Cereal & 0 & 0 & 3 & 28 & 6 & 12 & 130 & 2 & 181 \\
Mixed Vegetable & 1 & 0 & 2 & 15 & 0 & 0 & 10 & 10 & 38 \\
\hline Col. sum & 81 & 31 & 293 & 2227 & 2252 & 1926 & 291 & 264 & 7365 \\
\hline
\end{tabular}

(a)

\begin{tabular}{lrrr}
\hline $\begin{array}{c}\text { Quickbird } \\
\text { MLC }\end{array}$ & \multicolumn{1}{c}{$\begin{array}{c}\% \\
\text { Commission }\end{array}$} & $\begin{array}{c}\% \\
\text { Omission }\end{array}$ & $\begin{array}{c}\text { Conditional } \\
\text { Kappa }\end{array}$ \\
\hline Built-up & 60.24 & 59.26 & 0.39 \\
Water & 30.23 & 3.23 & 0.70 \\
Forest & 16.13 & 55.48 & 0.83 \\
Grass & 17.51 & 31.85 & 0.75 \\
Corn & 25.43 & 8.48 & 0.63 \\
Soybean & 24.78 & 11.73 & 0.66 \\
Cereal & 28.18 & 55.33 & 0.71 \\
Mixed Vegetable & 73.68 & 96.21 & 0.24 \\
\hline
\end{tabular}

(b) 
Table III-B. (a) Error matrix and (b) percent commission and omission errors and conditional kappa statistic, per class for Landsat MLC.

\begin{tabular}{crrrrrrrrr}
\hline $\begin{array}{c}\text { Landsat } \\
\text { MLC }\end{array}$ & Built-up & Water & Forest & Grass & Corn & Soybean & Cereal & $\begin{array}{c}\text { Mixed } \\
\text { Vegetable }\end{array}$ & $\begin{array}{c}\text { Row } \\
\text { sum }\end{array}$ \\
\hline Built-up & 12 & 0 & 0 & 23 & 7 & 14 & 4 & 23 & 83 \\
Water & 11 & 17 & 1 & 5 & 2 & 1 & 3 & 3 & 43 \\
Forest & 1 & 0 & 47 & 9 & 49 & 9 & 42 & 0 & 157 \\
Grass & 9 & 0 & 34 & 1095 & 312 & 230 & 124 & 35 & 1839 \\
Corn & 9 & 0 & 57 & 237 & 1688 & 449 & 189 & 135 & 2764 \\
Soybean & 51 & 0 & 2 & 248 & 165 & 1564 & 17 & 213 & 2260 \\
Cereal & 0 & 0 & 1 & 10 & 33 & 16 & 116 & 5 & 181 \\
Mixed Vegetable & 3 & 0 & 0 & 4 & 5 & 7 & 3 & 16 & 38 \\
\hline Col. sum & 96 & 17 & 142 & 1631 & 2261 & 2290 & 498 & 430 & 7365 \\
\hline
\end{tabular}

(a)

\begin{tabular}{lrrr}
\hline $\begin{array}{c}\text { Landsat } \\
\text { MLC }\end{array}$ & $\begin{array}{c}\text { \% } \\
\text { Commission }\end{array}$ & $\begin{array}{c}\text { \% } \\
\text { Omission }\end{array}$ & $\begin{array}{r}\text { Conditional } \\
\text { Kappa }\end{array}$ \\
\hline Built-up & 85.54 & 87.50 & 0.13 \\
Water & 60.47 & 0.00 & 0.39 \\
Forest & 70.06 & 66.90 & 0.29 \\
Grass & 40.46 & 32.86 & 0.48 \\
Corn & 38.93 & 25.34 & 0.44 \\
Soybean & 30.80 & 31.70 & 0.55 \\
Cereal & 35.91 & 76.71 & 0.61 \\
Mixed & & & \\
Vegetable & 57.89 & 96.28 & 0.39 \\
\hline (b)
\end{tabular}

(b) 
Table III-C. (a) Error matrix and (b) percent commission and omission errors and conditional kappa statistic, per class for Fuzzyl.

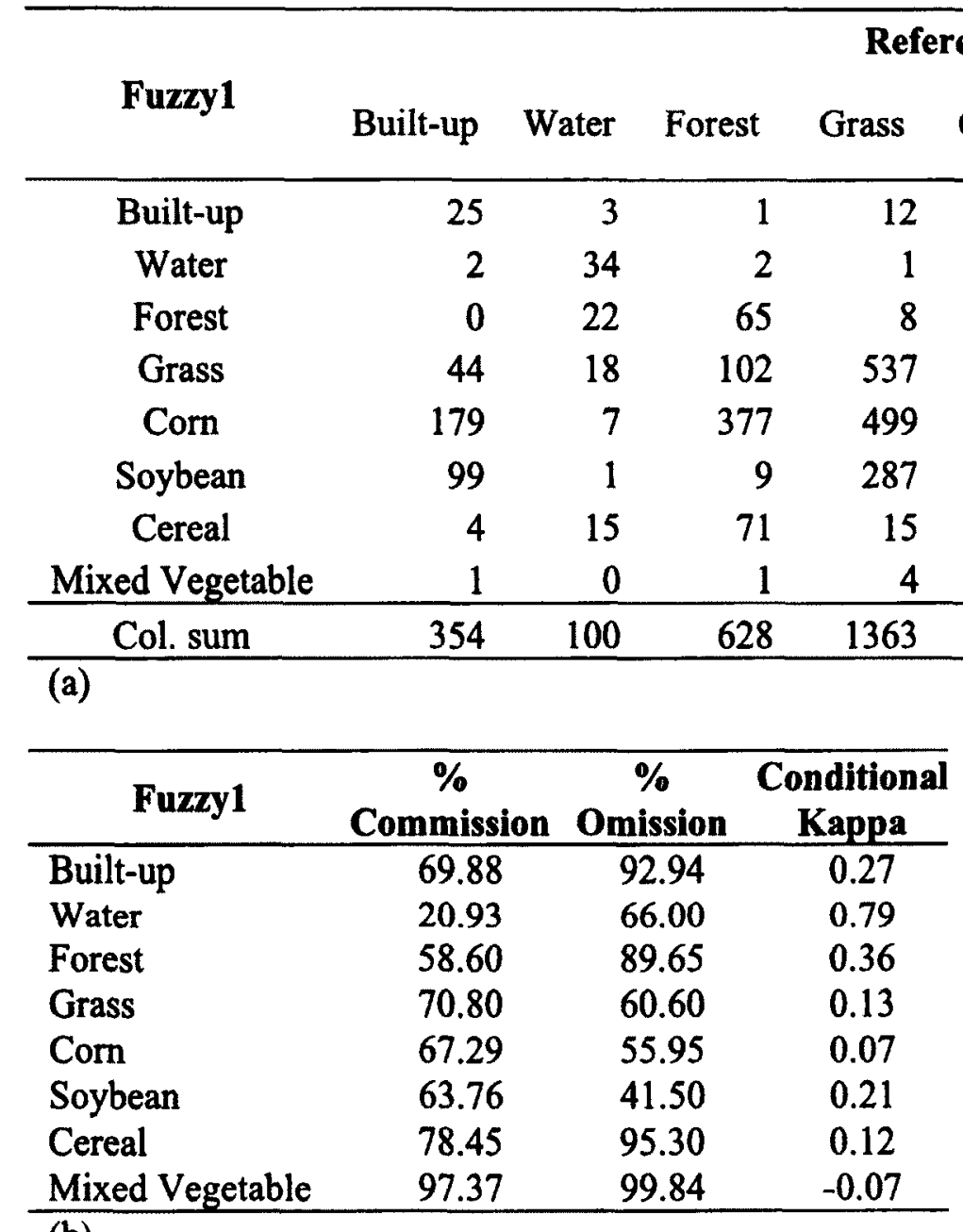

(b) 


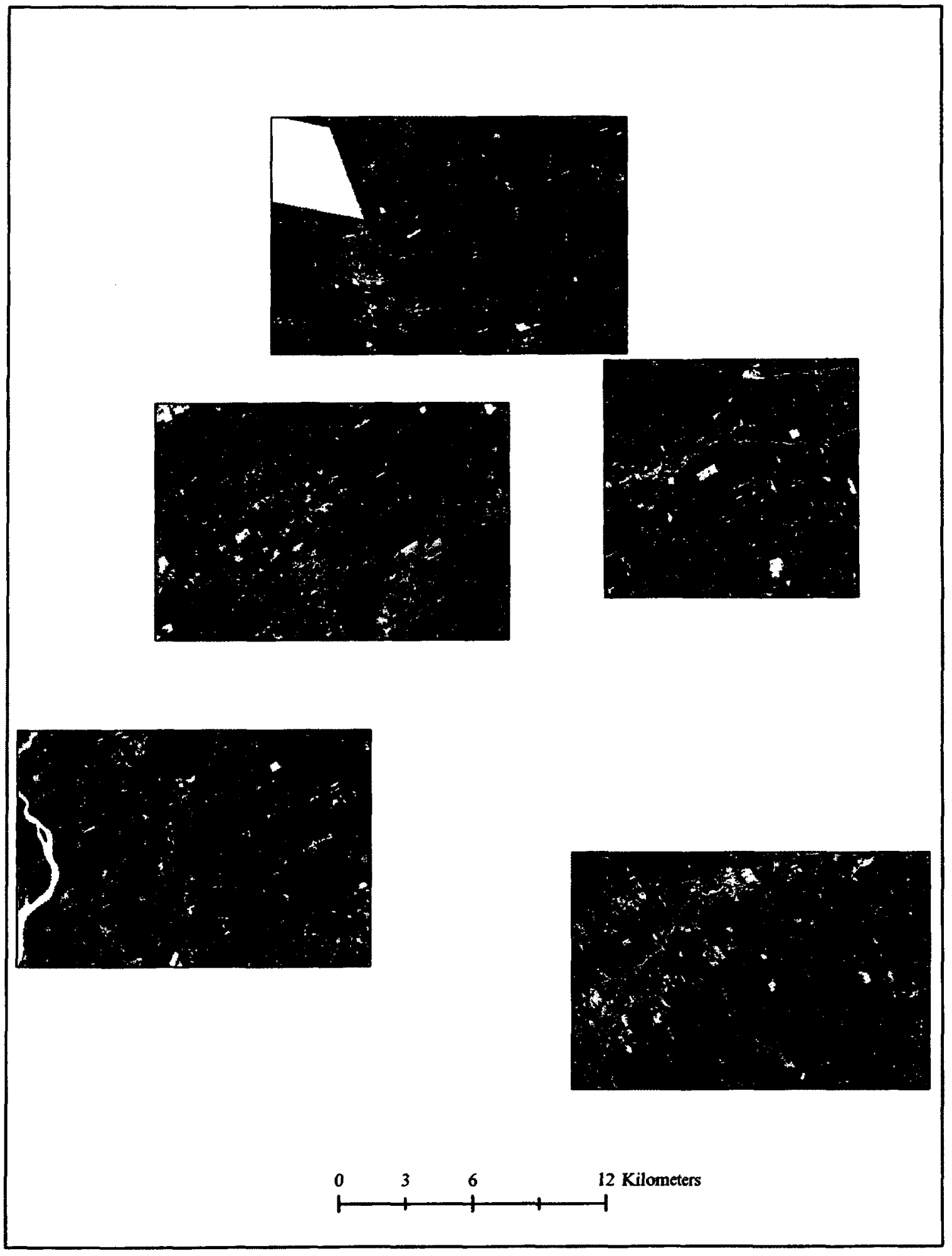

Figure III. Distribution of the normalized entropy for the fuzzy membership values. Low entropy values are indicated in black. 